\title{
DEHYDRATION OF ISOBUTANOL TO ISOBUTENE IN A SLURRY REACTOR
}

\author{
Topical Report
}

\section{Contractor: \\ AIR PRODUCTS AND CHEMICALS, INC. \\ Allentown, PA 18195}

\author{
Bruce E. Latshaw \\ February 1994
}

\section{Prepared for the United States Department of Energy \\ Under Contract No. DE-AC22-91PC90018 \\ Contract Period October 1990 - March 1995}

\section{DISCLAIMER}

\begin{abstract}
This report was prepared as an account of work sponsored by an agency of the United States Government. Neither the United States Government nor any agency thereof, nor any of their employees, makes any warranty, express or implied, or assumes any legal liability or responsibility for the accuracy, completeness, or usefulness of any information, apparatus, product, or process disclosed, or represents that its use would not infringe privately owned rights. Reference herein to any specific commercial product, process, or service by trade name, trademark, manufacturer, or otherwise does not necessarily constitute or imply its endorsement, recommendation, or favoring by the United States Government or any agency thereof. The views and opinions of authors expressed herein do not necessarily state or reflect those of the United States Government or any agency thereof.
\end{abstract}


. 


\section{EXECUTIVE SUMMARY}

The April 1990 Alternative Fuels Proposal to the Department of Energy (RFP \#RP2290PC90018) involved the development of new technology, based on the liquid phase process, for conversion of coal-derived synthesis gas to oxygenated hydrocarbon fuels, fuel additives, and fuel intermediates. The objective of this work was to develop a slurry reactor based process for the dehydration of isobutanol to isobutene. The isobutene can serve as a feedstock for the high octane oxygenated fuel additive methyl tertiary-butyl either (MTBE).

Alumina catalysts were investigated because of their wide use as a dehydration catalyst. Four commercially available alumina catalysts (Catapal B, Versal B, Versal GH, and Al3996R) were evaluated for both activity and selectivity to the branched olefin. All four catalysts demonstrated conversions greater than $80 \%$ at $290^{\circ} \mathrm{C}$, while conversions of near $100 \%$ could be obtained at $330^{\circ} \mathrm{C}$. The reaction favors low pressures and moderate to low space velocities.

A yield of 0.90 mole isobutene per mole reacted isobutanol or better was obtained at conversions of $60-70 \%$ and higher. From 75 to $98 \%$ conversion, the four catalysts all provide isobutene yields ranging from 0.92 to 0.94 with the maximum occurring around $90 \%$ conversion. At low conversions, the concentration of diisobutyl either becomes significant while the concentration of linear butenes is essentially a linear function of isobutanol conversion.

Doping the catalyst with up to $0.8 \mathrm{wt} \%$ potassium showed a modest increase in isobutene selectivity; however, this increase was more than offset by a reduction in activity. Investigations using a mixed alcohols feed (consistent with isobutanol synthesis from syngas) demonstrated a small increase in the $\mathrm{C} 4$ iso-olefin selectivity over that observed for a pure isobutanol feed. 



\section{Table of Contents}

List of Tables $\quad$ ii

List of Figures

Introduction $\quad 1$

Objectives $\quad 2$

Summary and Conclusions $\quad 2$

Patent Situation 3

Safety 3

Regulatory Matters $\quad 3$

Future Programs $\quad 3$

Acknowledgments 4

1. Literature Review 4

2. Thermodynamics of Isobutanol Dehydration to Isobutene 5

3. Experimental 6

4. Results and Discussion 6

4.1 Catalyst Screening $\quad 6$

4.1.1 Temperature 7

4.4.2 Pressure $\quad 8$

4.1.3 Gas Hourly Space Velocity 9

$\begin{array}{ll}\text { 4.1.4 Alcohol Concentration } & 10\end{array}$

4.1.5 Comparison of the Alumina Dehydration Catalysts 11

4.2 Controlling Isobutene Yields $\quad 12$

$\begin{array}{ll}\text { 4.2.1 Catalyst Impurities } & 12\end{array}$

4.2.2 Catalyst Doping for Enhanced Isobutene Selectivity 12

4.2.3 Effect of Feed Composition on the Product Spectrum 14

4.3 Development of Kinetics for the Dehydration of Isobutanol 15

4.3.1 Mass Transfer or Kinetic Limitations 15

4.3.2 Effect of Water on the Dehydration of Isobutanol 16

4.3.3 Development of a Power Law Rate Expression 16

References

Appendices:

I. Literature Survey

II. Thermodynamic Calculations

III. Analytical System

IV. Experimental Data 


\section{List of Tables}

4.1.1 Properties of Alumina Catalysts

4.2.1 Effect of Catalyst Sodium Level on Isobutene Yield

4.2.2 Operating Conditions Necessary to Obtain Identical Conversions for Different Potassium Weight Loadings

4.2.3 Effect of Higher Alcohols on the Product Spectrum

4.2.4 Effect of Methanol on the Product Spectrum

4.3.1 Effect of Impeller Speed on Reaction Rate

4.3.2 Effect of Water on the Reaction Rate 


\section{List of Figures}

3.1 Flow Schematic of $300 \mathrm{cc}$ Autoclave Reactor

4.1.1 Effect of Temperature on Isobutanol Conversion and Isobutene Yield

4.1.2 Yields of Linear Butenes and Diisobutyl Ether as a Function of Reactor Temperature

4.1.3 Effect of Pressure on Isobutanol Conversion and Isobutene Yield at $290^{\circ} \mathrm{C}$

4.1.4 Effect of Pressure on Isobutanol Conversion and Isobutene Yield as a Function of Temperature

4.1.5 Effect of Gas Hourly Space Velocity on Isobutanol Conversion and Isobutene Yield at $290^{\circ} \mathrm{C}$

4.1.6 Effect of Gas Hourly Space Velocity on Isobutanol Conversion and Isobutene Yield at $330^{\circ} \mathrm{C}$

4.1.7 Effect of Feed Isobutanol Concentration on Isobutanol Conversion and Isobutene Yield

4.1.8 Effect of Isobutanol Conversion on Product Distribution for Catapal B and Versal B

4.1.9 Effect of Isobutanol Conversion on Product Distribution for Versal GH and Engelhard Al-3996R

4.1.10 Yield of Isobutene based on Moles Isobutanol Feed as a Function of Reactor Temperature

4.2.1 Effect of Gas Hourly Space Velocity on Isobutanol Conversion and Isobutene Yield for Potassium Doped Catapal B

4.2.2 Effect of Gas Hourly Space Velocity on Isobutanol Conversion and Isobutene Yield for Potassium Doped Versal B

4.2.3 Effect of Potassium Dopant Weight on Isobutene Yield

4.3.1 Calculated Rate vs. Measured Rate for Power Law Rate Expression 


\section{Introduction}

Since 1982, Air Products and Chemicals, Inc., with support from the U. S. Department of Energy, has been developing reaction technology based on the conversion of coal-derived synthesis gas in a liquid-phase process. The liquid-phase reactor operates by bubbling the synthesis gas up through an inert mineral oil containing a powdered catalyst. This mineral oil provides excellent temperature control allowing for isothermal operation. The scope of this work has involved several major objectives. The first objective was to develop a liquid-phase process to produce methanol (LPMeOH) This process was designed as a once through reactor for incorporation into coal gasification combined cycle (CGCC) plants where it would be used to produce methanol from the synthesis gas during off-peak hours. Stored methanol could then be used for power production during peak hours allowing the size of the gasification unit to be reduced.

A second objective was to extend the methanol technology to produce dimethyl ether (LPDME) by dehydration of the methanol in a single reactor. The synthesis of DME leads to higher syngas conversion per pass than methanol equilibrium. DME synthesis has importance as a chemical building block and as a potential oxygenated additive to the transportation fuel market.

The current objective is stated under sub task 3.1 in the April 1990 Alternate Fuels Proposal to the Department of Energy (RFP \# DE-RP22-90PC90018). It involves developing new technology, based on the liquid-phase process, for conversion of coal-derived synthesis gas to oxygenated hydrocarbon fuels, fuel additives, and fuel intermediates. These oxygenates consist of higher alcohols and ethers which possess high octane numbers and can be used as additives to current fuel mixtures.

One such ether currently being used in transportation fuel is methyl tertiary-butyl ether (MTBE). Recent research in the Process Systems Group has focused on the synthesis of MTBE from syngas using liquid phase technology. This work has progressed in two separate stages. The first consists of developing the process for producing isobutanol directly from synthesis gas. This work has focused on defining a catalyst system and operating conditions which yield high selectivities of branched higher alcohols, namely isobutanol. Equilibrium concentration of methanol, which can serve as a feed stock for MTBE production, is also produced in this process.

The second stage consists of establishing the use of a liquid phase reactor for dehydration of the isobutanol to isobutene. This entails the development of a catalyst system and reaction conditions which provide high conversion of the alcohol and high selectivity for the branched olefin. Production of MTBE from isobutene and methanol is well known technology.

Because of increasing environmental concerns throughout the world, the demand for MTBE as an oxygenated fuel additive has increased dramatically over the past few years. Currently, the major source of isobutene is the $\mathrm{C} 4$ fraction from steam cracking or catalytic cracking. ${ }^{1}$ A fraction of the isobutene supply is obtained from the dehydration of tertiary-butyl alcohol (TBA). TBA is a major byproduct in the manufacture of propylene oxide from propylene and tertiary

hydroperoxide. ${ }^{2}$ Due to limited capacities of these sources, the increasing demand for .MTBE is predicted to cause a short-fall in the near future. Technology that is currently being implemented to supplement the capacity of isobutene consists of a two stage process whereby normal butane is isomerized into isobutane which is then dehydrogenated to produce isobutene. This technology establishes the benchmark for the liquid phase process. If proven economically viable, the liquid phase technology will provide the ability to produce isobutene from coal and natural gas thereby expanding the sources of this important chemical. 
This report describes the initial results of the exploratory investigations in the use of a liquid phase reactor for the conversion of isobutanol to isobutene. Also included is a survey of the prior knowledge associated with the dehydration of higher alcohols.

\section{Qbjectives}

The overall objective of this research program was to develop a slurry reactor based process for the dehydration of isobutanol to isobutene. The specific objectives were:

(1.) To screen catalysts for dehydration of isobutanol.

(2.) To define operating conditions which provide high conversion of isobutanol to isobutene.

(3.) To minimize isomerization of the branched structure upon dehydration.

\section{Summary and Conclusions}

Experiments were performed in a $300 \mathrm{cc}$ autoclave reactor to evaluate the use of a liquid phase reactor process for the dehydration of isobutanol. The primary product of the dehydration is isobutene which can serve as a feed stock for methyl tertiary-butyl ether (MTBE) production. Alumina catalysts were chosen for the investigation because of their wide use as a dehydration catalyst. Four commercially available alumina catalysts were evaluated for both activity and selectivity to the branched olefin.

All four catalysts demonstrated high conversions ( $>80 \%$ ) at temperatures of $290^{\circ} \mathrm{C}$ and a pressure of $150 \mathrm{psig}$. Conversions of near $100 \%$ could be obtained at $330^{\circ} \mathrm{C}$. Increased pressure had a detrimental effect on the isobutanol conversion. The reactor feed consisted of 5 mol\% isobutanol in nitrogen. As the GHSV was increased from 1200 to $6000 \mathrm{~s} / \mathrm{kg}$-hr (60 to 300 $\mathrm{sl} / \mathrm{kg}$-hr based on isobutanol), the isobutanol conversion decreased from 17.7 to $35.9 \%$ for the alumina catalysts.

A yield of 0.90 mole isobutene per mole reacted isobutanol or better was obtained at conversions of $60-70 \%$ and higher for all four catalysts. From 75 to $98 \%$ conversion, the four catalysts all provide an isobutene yield ranging from 0.92 to 0.94 with the maximum occurring at about $90 \%$ conversion. At conversions lower than $90 \%$, the concentration of diisobutyl ether increases significantly with decreasing conversion. The concentration of linear butenes is essentially a linear function of conversion up to $98 \%$ where it begins to rise rapidly. Formation of the isobutene occurs through a concerted (E2) mechanism involving an adsorbed alcohol molecule. Diisobutyl ether is formed by reaction of a surface alkoxide with an adsorbed alcohol. The mechanism of linear butene formation is uncertain. They may be formed by re-adsorption of the isobutene and secondary isomerization, primary isomerization during the dehydration step, or from decomposition of the ether.

Doping of the catalyst with up to $0.8 \mathrm{wt} . \%$ potassium showed a modest increase in isobutene selectivity. The increase was proportional to the potassium loading up to $0.5 \mathrm{wt}$.\%. A weight loading greater than $0.5 \%$ did not provide any further increase in selectivity. This increase in isobutene selectivity, however, was more than offset by a reduction in activity resulting in substantially lower yields. Investigations using a mixed alcohols feed (consistent with that produced in isobutanol synthesis from syngas) demonstrated a small increase in the selectivity of the C4 iso-olefin over that observed for a pure isobutanol feed. 
The dehydration reaction was modeled using a simple power law expression. The effects of water and isobutene were separated through experiments using a mixture of isobutanol and water. The rate of isobutanol dehydration is essentially first order in alcohol and is a strong inverse function of the concentration of water present in the reactor. The power law expression provided a good correlation to the experimental data.

\section{Patent Situation}

The following idea proposal was submitted:

"A Novel Isobutanol Dehydration Catalyst Derived From Hydrotalcite-Type Anionic Clay", I-C2818, 29 April 1992.

The idea proposal was dropped from the committee because experiments in a packed bed reactor showed poor performance for both isobutanol conversion and isobutene selectivity.

\section{Safety}

The primary hazards associated with this experimental study were the flammability of isobutene and isobutanol. The source of isobutanol was the liquid injection pump. The volume of the pump was small enough to maintain the concentration below flammability limits even in the event of a hood failure. Gloves, safety glasses, and lab coat were worn during filling of the pump to guard against contact.

Isobutene originated from dehydration of the isobutanol and from isobutene standards used for calibration of the GC. The standards were fitted with restrictor valves to minimize flow. The experimental apparatus was contained in a ventilated enclosure equipped with a flammable monitor which was interfaced to the reactor system allowing for automatic shutdown.

\section{Requlatory Matters}

1,3 butadiene is an OSHA regulated suspect carcinogen. This chemical is present in minute quantities in the product stream. Enclosure of the apparatus in the ventilation system and venting of reaction products to the atmosphere prevented accumulation.

\section{Future Programs}

Further investigations of the process developed in this report will focus on high isobutanol feed concentrations approaching pure isobutanol. This technology is scheduled for a demonstration run at the AFDU at LaPorte in late summer 1993. Another area of future consideration is development of a catalyst which inhibits isomerization of the branched carbon structure while maintaining high activity for the dehydration reaction. 


\section{Acknowledgments}

The research described herein was supported in part under contracts from the United States Department of Energy. The author would like to thank Foster Kartsotis for assistance in operating the autoclave system and Tom Dahl for assistance in maintaining the reactor system. In addition, Tom Hsiung and Bernie Toseland provided valuable guidance during this project.

\section{Literature Review}

A literature review was conducted in the initial stage of this project. The initial literature search was performed on "dehydration of isobutanol". Chem Abstracts was searched from 1967 to present. Limited information prompted an expanded search on the dehydration of alcohols, specifically those with similar structure, i.e. 2-methyl-1-alkanols. This information was summarized in a memo dated 24 March 1992 and is included in Appendix I. Several patents concerned with dehydration of tertiary butanol were obtained after distribution of the memo and will be discussed briefly due to their importance in the development of a new process for the dehydration of isobutanol.

Prior art for the dehydration of tertiary butanol involved conventional batch methods wherein the water formed during the reaction had a detrimental effect on the reaction rate. This process used ion exchange resins dispersed in an alcohol-water mixture which initially contained up to 20-30 wt.\% water. Process temperatures were $70-100^{\circ} \mathrm{C}$ at pressures around atmospheric producing isobutene as an overhead gas. ${ }^{3}$

An Atlantic Richfield patent disclosed a continuous dehydration process in which water formed in the reaction was removed by azeotrope formation with benzene. ${ }^{3}$ A cation exchange resin, in particular, the sulfonic acid type was used with the amount of benzene ranging from 2 to 20 times the weight of catalyst. Temperatures of 70 to $90^{\circ} \mathrm{C}$ were used with the isobutene and benzenewater azeotrope removed overhead. The benzene-water azeotrope was condensed and allowed to separate into two phases, a hydrocarbon and an aqueous phase. The hydrocarbon was recycled maintaining the concentration of benzene approximately constant in the reactor. Reaction rates 10 times higher than those of the batch methods were obtained. The authors claimed that the isobutene purity was much higher compared to product spectrums from sulfuric acid and high temperature vapor phase catalytic dehydrations. Temperatures greater than $100^{\circ} \mathrm{C}$ were avoided to prevent dimerization of the isobutene.

A Cities Service patent expanded on this technology by placement of the alcohol feed at the three phase separator. 4 With this configuration, a wet tertiary butanol feed was dried significantly before entering the dehydrator. The feed alcohol dissolved in the hydrocarbon phase causing most of the feed water to enter the aqueous phase. The hydrocarbon phase was then pumped back to the reactor providing the dry alcohol feed as well as the azeotrope forming hydrocarbon. This process provided an inexpensive means to dry a typical feed stream which may contain up to $60 \mathrm{wt} . \%$ water. Analysis of the mixed xylene solution (azeotrope forming hydrocarbon) showed $40 \%$ of the xylenes underwent butylation. This alkylation is undesirable because it changes the character of the azeotrope forming mixture and also consumes alcohol.

Another patent issued to Cities Service described the use of a liquid catalyst, para-toluenesulfonic acid, dissolved in a mixed xylene solvent. 5 This catalyst overcomes the problem of catalyst attrition affiliated with the particulate ion exchange resins. Temperatures up to $200^{\circ} \mathrm{C}$ may be used providing higher reaction rates. Above $200^{\circ} \mathrm{C}$, significant dimerization of isobutene 
occurred. Butylation of the mixed xylene solvent was still a problem. Paraxylene, which is more expensive than mixed xylenes, did not undergo butylation.

A Nippon Oil patent disclosed a process for dehydration of tertiary butanol whereby water present in the reactor from both the feed and as a reaction product was withdrawn from the bottom of the reactor. 6 This process used a cation exchange resin catalyst dispersed in an alcohol-water mixture. The liquid mixture contained 10-60 wt.\% alcohol. Reaction temperatures ranged from $90-180^{\circ} \mathrm{C}$ with elevated pressures to maintain the alcohol-water mixture as a liquid. The feed was introduced to the reactor as a gas at a level $1 / 2$ to $9 / 10$ below the top of the liquid mixture. Overhead from the reactor contained isobutene and unreacted alcohol. A bottoms stream was withdrawn to remove the water. This bottoms stream must be distilled to recover unreacted alcohol significantly increasing the cost of the process.

A German patent issued to BASF discussed a process for the dehydration of alcohols where the catalyst was dispersed in a high-boiling mineral oil. ${ }^{7}$ The authors claim that both soluble and insoluble acid catalysts could be used; however, data are shown for only one catalyst, dodecylbenzosulfonic acid. Suggested reactors for this process include bubble cap columns, bubble towers, and packed columns. In this process, liquid or gaseous alcohol is fed into the bottom of the reactor. The reactor is operated at temperatures above the boiling point of the feed. The product stream is withdrawn overhead containing olefin, water, and unreacted alcohol. Benefits of this process include use of soluble catalysts as well as good temperature control.

While the BASF patent discloses a process which parallels the one described in this report, it fails to address a critical issue with regard to the dehydration of branched alcohols, namely rearrangement of the branched structure. Only limited data was presented for tertiary butanol, cyclohexanol, and 1-butanol. The dehydration of 1-butanol resulted in a yield of only $86 \% 1$ butene with the remainder consisting of the 2-butenes. Thus, the issues to be addressed include determination of a catalyst and process conditions which provide high yields of the branched olefin as well as scaling up the process for commercialization.

\section{Thermodynamics of Isobutanol Dehydration to Isobutene}

Thermodynamic calculations were performed on the dehydration reactions for isobutanol and tertbutanol to isobutene and water (Appendix II). At equilibrium, isobutanol has a higher conversion than tert-butanol at all the reaction conditions calculated. The difference becomes more pronounced at lower temperatures where only about $50 \%$ of the tert-butanol is converted. Isobutanol is essentially completely converted at temperatures from 100 to $300^{\circ} \mathrm{C}$ and pressures from 1 to 52 atm.

An endothermic heat of reaction of $6.4 \mathrm{kcal} / \mathrm{gmol}$ was calculated for the dehydration of isobutanol. Using this value, adiabatic temperature drops were calculated to determine the plausibility of performing this reaction in an adiabatically operated packed bed reactor (Appendix II). The temperature drop is quite large $\left(130\right.$ to $\left.170^{\circ} \mathrm{C}\right)$ and presents the possibility of formation of a liquid phase at higher conversions. This large temperature drop makes an adiabatically operated packed bed reactor unfavorable, thus providing the incentive to investigate the use of a liquid phase reactor for the dehydration of isobutanol. Advantages of a liquid phase reactor over a packed bed with interstage heating are simplicity of design and operation and isothermal temperature control. 


\section{Experimental}

The experiments were conducted in a mechanically stirred $300 \mathrm{cc}$ autoclave reactor (Autoclave Engineers). The reactor unit was operated in a continuous once-through mode. Specific details of the unit are given in the hazards review. ${ }^{8}$ A simplified schematic of the equipment is shown in Figure 3.1.

The slurrying liquid was Drakeol 10, a white mineral oil composed of C16-C38 straight-chain, branched, and naphthenic saturated hydrocarbons. About $30 \mathrm{~g}$ of calcined catalyst was mixed with the oil representing a $20 \mathrm{wt} . \%$ catalyst loading. The catalysts were calcined at $500^{\circ} \mathrm{C}$ under a nitrogen atmosphere. Isobutanol was injected into a preheater/vaporizer unit by an Isco high pressure syringe pump. Nitrogen was used as a carrier gas for the vaporized alcohol. Contamination of the vaporizer unit with catalyst from previous experiments prompted removal of the unit and direct injection of the alcohol into the reactor. The alcohol was preheated before entrance into the reactor. A radial flow turbine impeller with a stirring speed of $1200 \mathrm{rpm}$ was used to ensure mass transfer effects were negligible. This was based on LPMEOH and LPDME studies. Exit gases from the reactor passed through a gas-liquid separator where entrained oil was refluxed back to the reactor. The flow rate of the exit stream was measured by a wet test meter. Pressure in the reactor was controlled by a back pressure regulator on the exit line.

The product gas stream was analyzed by on-line gas chromatography. Two Hewlett-Packard 5890 GCs were used. The one contained two Thermal Conductivity Detectors (TCDs), one for detection of $\mathrm{N}_{2}$ and the other for $\mathrm{H}_{2}$. The second GC contained two Flame Ionization Detectors (FIDs), one for detection of the unreacted isobutanol and the second for isobutene and the butene isomers. The analytical system is described in more detail in Appendix III.

\section{Results and Discussion}

\subsection{Catalyst Screening}

A large number of possible dehydration catalysts obtained from the literature were screened using a packed bed reactor (Fran Waller, CSTC). Those giving the best performance were aluminabased. Synthesis studies of dimethyl ether from syngas also focused on alumina-based dehydration catalysts. ${ }^{9}$ Thus, four commercially available alumina catalysts were chosen for screening studies in the $300 \mathrm{cc}$ autoclave to test their use in a bubble column reactor. The catalysts used were Conoco gamma-alumina (Catapal B), LaRoche gamma-alumina (Versal GH), Engelhard gamma-alumina (Al-3996R), and LaRoche eta-alumina (Versal B). Physical property data are listed in Table 4.1.1. The stability of Drakeol 10 oil in the presence of an alumina catalyst was tested at $350^{\circ} \mathrm{C}$ with no degradation of the oil observed by GC analysis. Previous experience with Drakeol 10 and an alumina was at temperatures of $250-280^{\circ} \mathrm{C}$.

Experiments were performed using a $5 \mathrm{~mol} \%$ isobutanol in nitrogen feed with direct injection of the isobutanol into the reactor, thus bypassing the vaporizer. Initial experiments had shown that contamination of the vaporizer from previous usage was causing dehydrogenation of the 
isobutanol. High concentrations of isobutanol could not be used due to condensation of the product water and unconverted alcohol in the exit stream providing inaccurate GC analysis.

\subsubsection{Temperature}

The performance of the four catalysts as a function of temperature was investigated for a feed of $5 \mathrm{~mol} \%$ isobutanol in N2, a pressure of $150 \mathrm{psig}$, and a GHSV of $2500 \mathrm{sl} / \mathrm{kg}-\mathrm{hr}$ (Figures 4.1 .1 and 4.1.2). The conversions at $330^{\circ} \mathrm{C}$ are the same among the catalysts ranging from 98.6 to $99.7 \%$ isobutanol conversion. At $290^{\circ} \mathrm{C}$ the variability in the catalyst activities is more apparent. The activity for Versal B at $290^{\circ} \mathrm{C}$ was that of Versal B doped with $0.2 \mathrm{wt} . \%$ potassium. The activity of Versal B was similar to that of Versal B doped with $0.2 \mathrm{wt} . \%$ potassium at several other operating conditions and is expected to be so at this condition. Catalyst Al-3996R has a higher activity at $290^{\circ} \mathrm{C}$ than the other three catalysts. As the temperature is decreased below $330^{\circ} \mathrm{C}$, all four catalyst demonstrate a decrease in activity, Al-3996R having the smallest followed by Catapal B, Versal GH, and finally Versal B. Below $290^{\circ} \mathrm{C}$, the activity decreases rapidly with temperature indicating that $280-290^{\circ} \mathrm{C}$ is the low temperature limit where conversions of $80 \%$ or better can still be obtained. This is an important result with regard to implementation of this technology into the DOE's Alternative Fuels Development Unit (AFDU) at LaPorte, Texas. The current temperature limitation of the AFDU is about $300^{\circ} \mathrm{C}$. Because the reaction is endothermic and heat is required to drive the reaction, the highest temperature obtainable during a run may actually be lower than $300^{\circ} \mathrm{C}$ which would result in low yields of isobutene

The yield of isobutene, based on converted isobutanol, possesses a maximum at $290^{\circ} \mathrm{C}$ for all four catalysts. While data at lower temperatures than $290^{\circ} \mathrm{C}$ is not available for Versal $\mathrm{GH}$ and $\mathrm{Al}-3996 \mathrm{R}$, it is believed that they exhibit a true maximum in isobutene yield around $290^{\circ} \mathrm{C}$. Further evidence of this will be discussed in a later section. Below $290^{\circ} \mathrm{C}$, Catapal B and Versal $\mathrm{B}$ demonstrate a sharp decrease in isobutene yield with decreasing temperature, while above $290^{\circ}$ $\mathrm{C}$, all four catalysts show a more gradual decline in yield. Figure 4.1.2 illustrates the yields of linear butenes and diisobutyl ether as a function of temperature for the four catalysts. For temperatures below $290^{\circ} \mathrm{C}$, the yield of ether increases substantially leading to the sharp decrease in the yield of isobutene. At a temperature of $250^{\circ} \mathrm{C}$, diisobutyl ether can represent $20-30 \mathrm{wt} . \%$ of the organics. As the temperature is raised, the yield of ether drops toward zero. However, the concentration of linear butenes increases almost linearly with temperature causing the yield of isobutene to decrease at higher temperatures. Therefore, the optimum yield of isobutene appears to be a function of competing mechanisms.

It is believed that the dehydration of isobutanol occurs via an E2 reaction mechanism which involves a single transition state. The mechanism involves the abstraction of the $\beta$-hydrogen of the alcohol by a surface oxide ion with simultaneous cleavage of the alcohol hydroxyl group forming water and a surface oxide ion. ${ }^{9}$ An E1 mechanism involves cleavage of the hydroxyl ion to form a carbonium ion in the first step. In the second step the carbonium ion losses a proton to the base to form the alkene. In kinetic isotope studies, Knozinger and Scheglila ${ }^{10}$ found the 
largest isotope effect occurred for $\beta$-carbon deuteration of isobutanol while having only a small effect on tertiary butanol, thus establishing the E2 mechanism for isobutanol.

According to Pines and $\mathrm{Haag}^{9}$ as well as Knozinger and Scheglila ${ }^{10}$, pure $\beta$-elimination occurs to form the primary dehydration product, the olefin. This olefin product may then re-adsorb onto strong acid sites where it may undergo isomerization. This would seem consistent with regard to the increase in the concentration of linear butenes with conversion. As the conversion increases, the concentration of isobutene on the surface and in the pores increases presenting a greater probability for re-adsorption. However, if re-adsorption were occurring it is expected that there would also be evidence of oligomerization. Oligomerization would occur because the readsorbed isobutene molecules are highly active when undergoing isomerization. According to GC analysis, there was no evidence in any of the dehydration experiments of dimers or trimers of isobutene.

It is also possible that formation of the linear butenes is a direct temperature effect and not necessarily dependent on the concentration of isobutene. One possibility is that the catalyst sites responsible for isomerization have a higher activation energy than the majority of active sites on the catalyst surface. At higher temperatures, a greater proportion of these isomerization sites would be active causing the isobutene selectivity to decrease. Knozinger ${ }^{11}$ suggests that instead of re-adsorption of the isobutene, it is possible that at higher temperatures $\left(\mathrm{T}>300^{\circ} \mathrm{C}\right) \gamma-\mathrm{H}$ elimination may occur with subsequent migration of the hydrogen or methyl group leading to the linear isomers.

Arai et al. 12 through studies on ethanol dehydration, postulated that ether was formed by reaction of two nearby surface ethoxides. The presence of surface ethoxides was verified through IR studies. Knozinger and Kohne ${ }^{13}$ proposed that diethyl ether was formed by reaction of an adsorbed alcohol molecule with a surface ethoxide. They found similar behavior for straightchained alcohols up to n-hexanol. As the chain length was increased, the temperature range in which ether was the only product decreased. No ether was detected by Knozinger and Kohne as a dehydration product for the branched butanols. They also state that the ether formed undergoes decomposition above a certain temperature to olefin and alcohol or to olefin and water. The temperature of decomposition is dependent on the molecular weight of the ether. de Boer et al. ${ }^{14}$ found no evidence of ethylene production from dietheyl ether at low alcohol conversions and suggests both reactions occur simultaneously under dehydration conditions. According to Knozinger and Kohne, ${ }^{13}$ at higher temperatures the free energy for olefin formation decreases more rapidly than that of ether causing the shift toward direct olefin formation. Thus, as the temperature is increased, the dehydration mechanism shifts from reaction of a surface alkoxide to a concerted mechanism involving an adsorbed alcohol.

\subsubsection{Pressure}

The effect pressure has on the reaction is illustrated in Figures 4.1.3 and 4.1.4. Experiments were performed using $5 \mathrm{~mol} \%$ isobutanol in $\mathrm{N}_{2}$ and a GHSV of $2500 \mathrm{sl} / \mathrm{kg}-\mathrm{hr}$. An increase in pressure from 150 to 500 psig resulted in a decrease of 21.0 and $13.7 \%$ in the isobutanol conversion for 
Catapal B and A1-3996R at $290^{\circ} \mathrm{C}$. Pressure data is not available for Versal B and Versal GH at $290^{\circ} \mathrm{C}$. Isobutene yield also decreased with an increase in reactor pressure. The isobutene yield with Al-3996R decreased $0.8 \%$ and that of Catapal B by $1.6 \%$. This is due to an increase in the concentration of diisobutyl ether at the lower conversions.

As the temperature was increased, the effect pressure had on the conversion became less

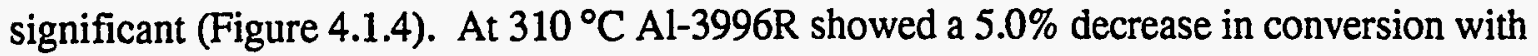
increased pressure, while at $330^{\circ} \mathrm{C}$ isobutanol conversion with Catapal B dropped only $0.2 \%$. Thus as the temperature is raised to $330^{\circ} \mathrm{C}$, the reactor pressure becomes insignificant with regard to conversion. The functionality of isobutene yield is more complex. At $250^{\circ} \mathrm{C}$ the yield, based on converted isobutanol, decreased $11.2 \%$ with increased pressure due to an increased ether concentration. This trend is also seen at $290^{\circ} \mathrm{C}$ for both Catapal B and Al-3996R, but to the extent of only 1.4 and $0.6 \%$, respectively. At 310 and $330^{\circ} \mathrm{C}$, the isobutene yield increased with increased pressure which is opposite to the trend at lower temperatures. At these high temperatures, the concentration of ether is insignificant; however, the concentration of linear butenes has proportionally increased causing an affect on isobutene yield. Interestingly, the isobutene yield for catalyst Al-3996R is approximately the same at $290^{\circ} \mathrm{C}, 150 \mathrm{psig}$ and $310^{\circ} \mathrm{C}$, 500 psig where the conversion is the same. The product compositions were identical except for a trace quantity of diisobutyl ether at $310^{\circ} \mathrm{C}, 500 \mathrm{psig}$. This indicates that temperature is not the only factor influencing the reaction mechanism.

The dehydration reaction favors low pressure, which is especially evident at $290^{\circ} \mathrm{C}$. This is an important factor because the second major product of the dehydration reaction is water.

Operating at low pressures reduces the temperature constraints necessary to maintain the feed and products in the gas phase. Condensation of water in the reactor unit could lead to catalyst deactivation through re-hydration of the catalyst surface. High pressure also causes a slight increase in the formation of diisobutyl ether.

\subsubsection{Gas Hourly Space Velocity}

Evaluation of the effect GHSV has on this reaction is more difficult because a feed of only 5 mole percent was being tested. Thus the actual space velocity of isobutanol is much lower than that stated in the figures and tables. The current configuration of the reactor system limits the concentration of isobutanol in the feed due to condensation problems. On a commercial unit the feed would consist of either $100 \%$ isobutanol or a mixture of isobutanol and higher carbon number alcohols. Using this feed it is possible to run at low space velocities while still obtaining reasonable productivity. While limited in scope, the experimental results do provide some important information. The experimental conditions were 290 and $330^{\circ} \mathrm{C}, 150 \mathrm{psig}$, and $5 \mathrm{~mol} \%$ isobutanol in $\mathrm{N}_{2}$.

The GHSV has a significant effect on the isobutanol conversion at $290^{\circ} \mathrm{C}$ as is shown in Figure 4.1.5. As the GHSV was increased from 1200 to $6000 \mathrm{sl} / \mathrm{kg}-\mathrm{hr}$ ( 60 to $300 \mathrm{sl} / \mathrm{kg}-\mathrm{hr}$ based on isobutanol), the isobutanol conversion decreased $17.7 \%$ for Al-3996R and 35.9\% for Versal GH. 
The percentage decrease for Catapal B and Versal B was predicted to be 25 and $36 \%$, respectively, based on the data at 2500 and $6000 \mathrm{sl} / \mathrm{kg}-\mathrm{hr}$. This trend is not unexpected since the increase in GHSV represents up to a five-fold decrease in the mean residence time of the alcohol in the reactor. Al-3996R demonstrated the best activity over the range of space velocities with the separation in performance increasing with increasing GHSV. Isobutene yield demonstrated the same trends as seen with temperature and pressure. At conversions less than $90 \%$ the yield decreased as a result of increased ether formation. This was evident for all of the catalysts. Versal GH had the sharpest decline in isobutene yield due to having the largest drop in conversion. Al-3996R was the only catalyst having conversion data above $90 \%$ under these conditions. At a conversion greater than $90 \%$ the isobutene yield declined as a result of an increase in the concentration of linear butenes.

At $330^{\circ} \mathrm{C}$, the effect of varying GHSV is less significant (Figure 4.1.6). Al-3996R showed only a $0.6 \%$ decline in conversion while Versal $\mathrm{GH}$ had a $3.5 \%$ decline. Interestingly, all of the catalysts showed a similar slope in the decline in conversion between 2500 and $6000 \mathrm{sl} / \mathrm{kg}$-hr except Al$3996 \mathrm{R}$ which showed almost no change in activity. The isobutene yield followed the trend that had been demonstrated in Figure 4.1.5. As the isobutanol conversion decreased from near $100 \%$ toward $90 \%$, the yield of isobutene increased due to a decrease in the concentration of linear butenes. At this temperature and these high conversions, diisobutyl ether was nonexistent. Catalyst Al-3996R showed a discrepancy in this trend. It presents a maximum in isobutene yield at a GHSV of $2500 \mathrm{sl} / \mathrm{kg}$-hr even though the conversion is above $99 \%$ for all three space velocities. The reason for this is unknown, but thought to be a problem with the GC analysis.

Comparison of Figures 4.1.3 and 4.1.5 indicates that there may be a correlation between the effects pressure and GHSV have on catalyst activity and isobutene yield. An increase in GHSV from 2500 to $6000 \mathrm{sl} / \mathrm{kg}-\mathrm{hr}$ at $290^{\circ} \mathrm{C}$ produced the same decrease in isobutanol conversion for both Al-3996R and Catapal B as did an increase in pressure from 150 to 500 psig. The surprising point is that both variable changes produced almost identical yields of isobutene, ether, and linear butenes given that only the conversion was identical. An increase in reactor pressure has the effect of increasing the partial pressures of isobutanol, isobutene, diisobutyl ether, and water. This would be expected to have an influence on the chemical kinetics and possibly favor the formation of one product over another in simultaneous reactions. Increasing the GHSV causes a decrease in the mean residence time providing less contact time between the alcohol and the catalyst. Therefore, it is not expected that a change in these two variables producing the same degree of alcohol conversion should produce the exact same yield of several products. This result is similar to that mentioned previously where the same yield of products was obtained for two separate runs at different temperatures and pressures but providing the same alcohol conversion.

\subsubsection{Alcohol Concentration}

The effect alcohol concentration has on the product distribution was investigated with Catapal $B$ and Versal B at conditions of $330^{\circ} \mathrm{C}, 150 \mathrm{psig}$, and a GHSV of $2500 \mathrm{sl} / \mathrm{kg}$-hr (Figure 4.1.7). At alcohol concentrations of $5 \mathrm{~mol} \%$, both catalysts showed conversions of almost $100 \%$. At 10 mol\% isobutanol, the difference in catalyst activity becomes more apparent. The decrease in 
conversion for Versal B was $3.8 \%$ for a $5 \%$ increase in alcohol concentration while that for Catapal B was only $2.1 \%$. Catapal B demonstrated the same activity at $15 \%$ alcohol feed as did Versal $B$ at $10 \%$. These results indicate that a significantly lower space velocity will have to be used to obtain high conversions ( $>90 \%$ ) when the concentration of isobutanol is raised to near $100 \%$. Isobutene yields demonstrate the same trend as was established earlier. As the alcohol conversion decreases from 100 to $90 \%$, the isobutene yield increases toward a maximum.

\subsubsection{Comparison of the Alumina Dehydration Catalysts}

In summary, several catalysts were investigated for use in a slurry reactor for the intramolecular dehydration of isobutanol to isobutene. The goal is to achieve high conversion of the alcohol while maintaining a high selectivity to the branched olefin for use as a feed stock for MTBE production. High overall productivity is essential to be economically competitive with the two stage process involving isomerization of $n$-butane.

In evaluating the catalysts performance, both activity and selectivity are critical to the viability of the process. Analysis of the experimental data in the process variable section had shown that a relationship existed between the isobutanol conversion and isobutene selectivity. Figures 4.1.8 and 4.1.9 illustrate this relationship for the four catalysts. The data are for a range of temperatures, pressures, GHSV, and isobutanol feed concentrations to show that the trend is process variable independent. The selectivity of isobutene, linear butenes, and diisobutyl ether are a function of isobutanol conversion and variations in the process variables producing the same conversion also produce the same product distribution. This conclusion is true for conversions greater than $30-40 \%$. Below this the yield of isobutene and diisobutyl ether are more dependent on the process variables. This appears to be due to the much higher concentrations of ether at these conversions. Limited data available at these low conversions makes it difficult to offer a conclusion on this phenomena.

All of the catalysts demonstrate an isobutene yield (based on the isobutanol converted) of 0.90 or better at conversions of $60-70 \%$ and higher. From 75 to $98 \%$ conversion, the four catalysts all provide yields ranging from 0.92 to 0.94 with the maximum occurring at about $90 \%$ conversion. Therefore, all four catalysts are capable of obtaining high yields of isobutene. The key difference is that different operating conditions are required by the different catalyst to obtain these high yields. A better measure of the performance is illustrated in Figure 4.1.10 where the yield of isobutene, based on isobutanol feed, is plotted. This data accounts for both the conversion and the product selectivities. Catalyst Al-3996R demonstrates the best performance followed by Catapal $\mathrm{B}$ in the range of operating temperatures at LaPorte, namely $290-310^{\circ} \mathrm{C}$. At $330^{\circ} \mathrm{C}$ there is no difference between the catalysts.

These results show that Al-3996R is a viable catalyst for slurry-phase dehydration of isobutanol and is recommended for a trial at the AFDU. Further testing of the catalyst before the trial should include high concentrations of isobutanol and long-term life tests. The data points for Versal B at 44 and $48 \%$ conversion represent replicates of the same operating conditions at the start and end of the test series. This variation may indicate that a significant change in catalyst performance 
occurs over time. No data is available on catalyst performance for longer than eight hours of continuous alcohol feed. The alcohol feed was stopped overnight while a small purge of nitrogen was maintained.

\subsection{Controlling Isobutene Yields}

The primary product in the dehydration of isobutanol is isobutene. Production of diisobutyl ether and linear butenes represents a yield loss based on the production of MTBE. Therefore, it is of interest to investigate ways to alter the catalyst selectivity to decrease the production of these other compounds. Since running the reaction at conditions which produce high conversion of alcohol also reduces the production of ether to zero, the study has focused on decreasing the isomerization of the isobutene to linear butenes.

\subsubsection{Catalust Impurities}

In the literature many authors have shown that the activity of aluminas depends on their method of preparation. $14,15,16$ According to the findings of Pines and Haag ${ }^{16}$, aluminas containing no alkali contain a substantial number of strong acid sites; whereas, aluminas prepared from alkali aluminates contain a large number of weak acid sites. If this variation in acid site strength is the result of incorporated alkali in the alumina structure, then a high alkali content should lead to a higher isobutene selectivity. It is believed that isomerization of the branched structure occurs on these strong acid sites. The levels of sodium in the catalysts are listed in Table 4.2.1 as weight percent $\mathrm{Na}_{2} \mathrm{O}$. Isobutene yields (based on converted alcohol) are also listed in Table 4.2.1 for two different space velocities at conversions of $95 \%$ and better. While the highest sodium content alumina (Versal B) has the highest yield at both space velocities, the yields of the other three catalysts do not agree with the order of their sodium levels. Therefore, the results do not indicate any functionality of the isobutene selectivity on the sodium level for sodium levels covering two orders of magnitude.

In addition, variations in the catalyst activity do not coincide with the levels of sodium. This sodium is present in the alumina as an impurity. Other impurities include silicon, iron, carbon, and sulfur. Because the level of sodium in these catalysts represents a good correlation to the total level of impurities, this means that the activities are not related to the purity level of the catalyst. It is believed that the variation in the catalyst activity is due to differences in the catalyst surface areas and pore volumes after calcination. This is being investigated through characterization of the physical properties of the catalysts both before and after calcination.

\subsubsection{Catalyst Doping for Enhanced Isobutene Selectivity}

The literature indicates that the surface of alumina contains acidic and basic sites. These acid sites consist of both Lewis and Bronsted type of varying strength. It is believed that rearrangement of the branched alkene occurs by re-adsorption of the newly formed molecule onto a strong acid site 
as opposed to rearrangement via a carbonium ion during the primary reaction. According to the literature, it is possible to alter the distribution of acid site strengths by doping the alumina with an alkali metal. ${ }^{17}$ In this manner, the number of strong acid sites is decreased and consequently a higher selectivity to the branched alkene produced. Attempts were made to alter the selectivity distribution of the butene isomers by doping two aluminas (Catapal B and Versal B) with potassium obtained from potassium hydroxide. The weight loading of potassium ranged from 0.2 to $0.8 \mathrm{wt} . \%$. The catalyst doping was carried out using the spray method after which the catalyst samples were calcined at $500^{\circ} \mathrm{C}$.

The results from experiments performed at $330^{\circ} \mathrm{C} ; 150 \mathrm{psig}$, and $5 \mathrm{~mol} \%$ isobutanol are presented in Figure 4.2.1 for Catapal.B and Figure 4.2.2 for Versal B at GHSVs of 2500 and $6000 \mathrm{sl} / \mathrm{kg}-\mathrm{hr}$. For Catapal B there is a dramatic decline in catalyst activity with increased potassium loading. At $2500 \mathrm{sl} / \mathrm{kg}$-hr the isobutanol conversion decreased $6.0,14.4$, and $31.8 \%$ as the potassium weight percent was increased to $0.2,0.5$ and $0.8 \%$. For a GHSV of $6000 \mathrm{si} / \mathrm{kg}-\mathrm{hr}$ the isobutanol conversion dropped $13.8,30.7$, and $53.2 \%$ for the same potassium loadings. This large decline in activity with the increase in space velocity was seen before with the four aluminas. Again when the operating conditions are varied so as to cause a decrease in isobutanol conversion, the gap in performance between catalysts increased. Isobutene yields follow the same trend established for the four aluminas. When the conversion was greater than $90 \%$, a decline in conversion toward $90 \%$ resulted in an increase in isobutene yield while a decrease in conversion below $90 \%$. caused a significant drop in the yield.

Versal B demonstrated only a 0.6 and $2.5 \%$ decline in conversion on going to a $0.2 \mathrm{wt} . \%$ potassium loading at 2500 and $6000 \mathrm{sl} / \mathrm{kg}-\mathrm{hr}$, respectively. This was a much smaller change than was observed for the Catapal B series. This difference may be the result of an inaccurate measure of the weight loading for Versal B since the pore volume had to be estimated. Since the conversions for Versal B are all relatively the same, the isobutene yields can be compared directly. At both space velocities, the $0.2 \mathrm{wt} . \% \mathrm{~K}$ doped catalyst demonstrated a sizable increase in yield over that of the base alumina. This suggests that an increase in the weight loading of potassium causes a decrease in skeletal rearrangement of the branched-structure. However, the decline in activity offsets this increase somewhat providing only about a $1 \%$ improvement in overall yield based on total isobutanol feed.

A direct comparison of the isobutene yields for the doped Catapal B series is impossible using Figure 4.2.1 because of the large variation in activity. To properly compare the catalysts in terms of yield performance, the isobutene yield was plotted as a function of conversion for experiments conducted at $330^{\circ} \mathrm{C}$.(Figure 4.2.3). While the curves do not all overlap, a comparison can be made at $90 \%$ conversion by extrapolating the Catapal B curve slightly following the established curvature. From this it is evident that doping the alumina with potassium does provide an increase in the isobutene yield as was seen with the Versal B. An increase in yield can be obtained with an increase in potassium loading up to about $0.5 \mathrm{wt} . \%$. Potassium weight loadings higher than this do not provide any benefit and in fact are detrimental with regard to conversion. The problem is that the increase in isobutene yield is more than offset by the decline in catalyst activity. As an example of this, Table 4.2.2 lists the range of operating conditions that must be 
used to obtain the same conversion among the doped catalysts in order to take advantage of the increased yield. Obviously using a doped alumina decreases the economic viability of the process.

\subsubsection{Effect of Feed Composition on the Product Spectrum}

Commercial application of the liquid phase technology for the production of isobutene will consist of two stages: 1. production of isobutanol from coal or natural gas derived synthesis gas, and 2. dehydration of the isobutanol to isobutene. The product isobutene can then be used for the production of methyl tertiary-butyl ether. Tertiary ethers of higher carbon number also have high octane numbers and can be used in transportation fuels. Current isobutanol synthesis work has demonstrated a high selectivity for 2-methyl-1-alcohols as well as isobutanol. An alcohol feed consisting of the approximate higher alcohol composition from isobutanol synthesis was used for two dehydration experiments. The composition of the alcohol mixture is listed in Table 4.2.3. The two experiments were performed at $330^{\circ} \mathrm{C}, 150 \mathrm{psig}$, and GHSV of 2500 and $1050 \mathrm{sl} / \mathrm{kg}-\mathrm{hr}$. A $0.8 \mathrm{wt} . \% \mathrm{~K}$ doped Catapal B catalyst was used. The feed consisted of about $5 \mathrm{~mol} \%$ mixed alcohol in nitrogen.

Table 4.2.3 lists the molar selectivities of the individual branched alcohols in the feed along with those of the corresponding olefin products. These selectivities represent the ratio of branched to total alcohol for the feed and branched to total alkenes in the product stream. Also listed is the selectivity of the grouped 2-methyl-1-alkenes compared to that of the branched alcohols in the feed. All of the branched alcohols exhibited isomerization, but the degree of isomerization increased with increasing carbon number. The selectivity of isobutene to the total butenes is higher than expected based on experiments using a pure isobutanol feed. The selectivity of isobutanol to $\mathrm{C} 4$ alcohols in the feed was $89.2 \%$. That of isobutene to $\mathrm{C} 4$ alkenes was $87.0 \%$ for the high space velocity experiment. For a pure isobutanol feed, the selectivity for isobutene at approximately the same conversion was about $96.2 \%$. Accordingly, if the isobutanol underwent the same degree of isomerization in the mixed alcohol feed as when used by itself, the selectivity of isobutene should be $85.8 \%$. This difference in isomerization selectivity indicates that the presence of the higher carbon number alcohols hinders the isomerization of the isobutanol. This result is consistent with those of Fran Waller (CSTC) who performed dehydration experiments in a packed bed reactor. Fran observed a difference of about $2 \%$ compared to the difference of $1.2 \%$ listed here. This difference is believed to be outside experimental error.

The second experiment showed this isomerization effect more clearly. This experiment was performed at a GHSV of $1050 \mathrm{sl} / \mathrm{kg}$-hr providing a longer residence time for the alcohol feed. The selectivity of isobutene to total butenes $(87.5 \%$ ) was slightly higher than that for the high space velocity experiment. At this higher conversion, the selectivity for a pure isobutanol feed was $96.0 \%$. The expected isobutene isomerization selectivity for the mixed feed was $85.6 \%$. Therefore, this experiment shows an even larger difference between the observed and expected selectivities.

In the second experiment, significantly lower selectivities for the $\mathrm{C} 5$ and $\mathrm{C} 6$ branched olefins were observed. The decrease of the $\mathrm{C} 5$ and $\mathrm{C} 6$ branched olefin selectivities with the increased alcohol 
conversion is consistent with the trend observed in the pure isobutanol experiments. The $\mathrm{C4}$ selectivity does not follow this trend but remains approximately constant with an increase in conversion. The reason for this is not clear.

Feeley et al. ${ }^{18}$ tested the use of a gamma alumina catalyst for the direct synthesis of methyl tertiary-butyl ether from a mixed feed of isobutanol and methanol. While this effort failed, he found that at $250^{\circ} \mathrm{C}$ the only butene formed from dehydration of the isobutanol was isobutene. This suggested the possibility that methanol may also hinder isomerization of isobutanol. In the synthesis of isobutanol, an equilibrium concentration of methanol is also formed making it feasible to feed a mixture of isobutanol and methanol directly to the dehydration reactor. A dehydration experiment was performed using a liquid feed consisting of a $2: 1$ molar ratio of isobutanol:methanol. Conditions for the experiment were $330^{\circ} \mathrm{C}, 33 \mathrm{psig}, 6 \mathrm{~mol} \%$ alcohol in nitrogen, and GHSV of $1600 \mathrm{sl} / \mathrm{kg}$-hr using a $0.5 \mathrm{wt} . \% \mathrm{~K}$ doped Catapal B catalyst. A higher temperature was used because the conversion at $250^{\circ} \mathrm{C}$ is too low to make the process economical. Table 4.2 .4 shows that the same degree of isobutanol conversion is obtained for both feeds; however, the isobutene yield for the pure feed is significantly higher. The mixed feed produced methylisobutyl ether resulting in the yield loss. The yield ratio of isobutene to linear butenes is $\mathbf{1 9 . 2 7}$ for the pure isobutanol feed and 20.00 for the mixed feed. This indicates that there may be a slight decrease in the isomerization of the branched structure with the methanol co-feed, but the loss in yield makes this an undesirable process.

An interesting result from the methanol/isobutanol experiment is that significant amounts of dimethyl and methylisobutyl ether were formed (about 10 and $7 \mathrm{wt} . \%$ of the organic products) while only a trace amount of diisobutyl ether was formed (about $0.2 \mathrm{wt} . \%$ ). When the higher alcohols mixture was used, no compounds with higher molecular weights than diisobutyl ether were detected on the GC indicating that either higher carbon number ethers are unstable or the mechanism for their formation is unstable at this temperature. These results are consistent with the findings of Knozinger and Kohne ${ }^{13}$ in which ethers of lower carbon number were stable up to higher temperatures over alumina.

\subsection{Development of Kinetics for the Dehvdration of Isobutanol}

\subsubsection{Mass Transfer or Kinetic Limitations}

In determining a kinetic expression for the dehydration reaction it is important to separate mass transfer and kinetic effects. To accomplish this, a series of experiments were performed in which the impeller speed was varied to determine the rate at which the reaction becomes mass transfer limited. The experiments were performed at aggressive conditions of $310^{\circ} \mathrm{C}, 500 \mathrm{psig}$, and GHSV of $11500 \mathrm{sl} / \mathrm{kg}$-hr using catalyst Al-3996R gamma alumina. These conditions were used to obtain reaction rates significantly higher than those previously obtained. The feed consisted of $5 \mathrm{~mol} \%$ isobutanol in nitrogen. The results of these runs are listed in Table 4.3.1. The reaction rate is the same for impeller speeds of 1200 and 2000 RPM. As the speed was lowered below 1200 , the reaction rate decreased indicating mass transfer effects became important. All previous catalyst runs were carried out at an impeller speed of 1200 RPM and reaction rates were lower 
than those obtained in this set of experiments. Therefore, mass transfer effects can be neglected in analysis of the data.

\subsubsection{Effect of Water on the Dehydration of Isobutanol}

During the dehydration of isobutanol, one mole of alcohol reacts to form one mole of olefin and one mole of water. Therefore, water and isobutene are perfectly correlated. To develop a kinetic expression for this reaction, it is critical to separate the effects of water and isobutene. This was done by using two different feed compositions ( 3 moles isobutanol: 1 mole water, 3 moles isobutanol: 2 moles water) to measure the effect water has on the reaction. Table 4.3.2 summarizes the performance of Al-3996R gamma alumina as a function of the feed composition for two different temperatures, 290 and $310^{\circ} \mathrm{C}$. The liquid feed rates were adjusted to give a reactor inlet composition of approximately $5 \mathrm{~mol} \%$ isobutanol for all experiments. An increase in the concentration of water in the feed caused a decrease in isobutanol conversion. The reaction rate is a strong inverse function of the concentration of water present in the reactor. This is consistent with the findings discussed in the literature review section where water was found to inhibit dehydration.

\subsubsection{Development of a Power Law Rate Expression}

The conversion of isobutanol and the selectivity of isobutene obtained in these experiments is high. This might lead one to believe that development of a mechanistic expression for the dehydration of isobutanol is straight forward. However this is not the case. Figures 4.1.8, 4.1.9, and 4.2.3 show the functionality between the isobutanol conversion and the isobutene yield (based on converted isobutanol). As was discussed earlier, the yield of isobutene decreases as the conversion increases toward $100 \%$. At conversions greater than $98 \%$, there is a rapid decline in the isobutene yield. Several possibilities exist for the mechanism of linear butene formation as has been discussed earlier in this text, none of which have been verified. These possibilities include re-adsorption of the isobutene and subsequent isomerization, isomerization of the branched structure during the primary dehydration step, decomposition of the ether, or even a combination of these.

The uncertainties in the mechanism of the reaction make it difficult to derive a mechanistic rate expression. However, this does not mean that a meaningful correlation of the data cannot be obtained. An empirical power law rate expression was used to correlate the experimental data. The parameters for this expression were determined using the fugacities of the products in the reactor exit stream. The concentrations of the butenes were lumped together to get a rate which predicted the formation of butenes and not necessarily just isobutene. Since the yield of isobutene is at least $90 \%$ and greater for most of the experiments, this rate expression basically predicts the formation of isobutene. Small traces of propene, butane, and isobutane were detected in most of the runs. These concentrations were never more than a fraction of a weight percent and so were neglected in developing the rate expression. 
A regression was performed on the data neglecting the concentration of ether since it represents only a small percentage of the product stream for most of the runs. The expression for the rate is shown below.

$$
-\mathrm{r}_{\mathrm{iBuOH}}=\mathrm{kf}_{\mathrm{a}} \mathrm{f}^{0.81} \mathrm{f}_{\mathrm{o}} 0.56 / \mathrm{f}_{\mathrm{w}}{ }^{2.32}
$$

activation energy $=44247 \mathrm{cal} / \mathrm{gmol}$

correlation coefficient $=0.93$

$\mathrm{fa}, \mathrm{fo}$, and fw are the isobutanol, butene, and water fugacities

The fit to the data is illustrated in Figure 4.3.1. The correlation between the rate expression and the experimental data is quite good.

Since the concentration of diisobutyl ether increases to about $10 \mathrm{wt} . \%$ of the products as the conversion decreases from 100 to $50 \%$, a second regression was performed to test the significance of the ether. Here the ether in the product stream was taken to be unreacted alcohol thereby accounting for all of the products. The results for this regression are listed below.

\author{
ether assumed unreacted alcohol $\quad-\mathrm{r}_{\mathrm{iBuOH}}=\mathrm{kf}_{\mathrm{a}} 0.79 \mathrm{f}_{\mathrm{o}} 0.57 / \mathrm{f}_{\mathrm{w}} 2.35$ \\ activation energy $=44660 \mathrm{cal} / \mathrm{gmol}$ \\ correlation coefficient $=0.92$ \\ where $\mathrm{fa}$, fo, and fw are the isobutanol, butene, and water fugacities
}

An identical correlation is obtained when the ether is assumed to be unreacted alcohol. While this rate expression does not provide a mechanistic explanation for the dehydration reaction, it does provide a starting point for developing a mechanistic expression. Further work is needed to understand the significance of the ether formation and the isomerization of isobutene before a truly accurate rate expression for the formation of isobutene can be developed.

\title{
References
}

1. Anthony, R. G., and Thomas, P.E., Hydrocarbon Proc., Nov. 95 (1984)

2. Abraham, O. C., and Prescott, G. F., Hydrocarbon Proc., Feb., 51 (1992).

3. Rosenthal, R., U.S. Patent 3,510,538 (1970).

4. Levine, R., U.S. Patent 4,155,945 (1979).

5. Levine, R., and Olechowski, J.R., U.S. Patent 4,165,343 (1979).

6. Imaizum, M., Mitsuo, Y., Sakata, K., and Hirano, N., U.S. Patent 4,208,540 (19). 
7. Dockner, T., and Krug, H., DE Patent 3317165 A1 (1984).

8. Dahl, T. A., "Periodic Hazards Review for Autoclave Reactor System No. 1300 cc Unit", APCI Memorandum, 22 November 1991.

9. Pines, H., and Haag, W. O., J. Am. Chem. Soc., 83 , 2847, (1961).

10. Knozinger, H., and Scheglila, A., J. Catal., 17, 252 (1970).

11. Knozinger, H., "The Dehydration of Alcohols" in "The Chemistry of the Hydroxyl Group," S. Patai, ed., Interscience-Publishers, 1971.

12. Arai, H., Take, J., Saito, Y., and Yoneda, Y., J. Catal., 2,146 (1967).

13. Knozinger, H., and Kohne, R., J. Catal., 5 , 264 (1966).

14. de Boer, J. H., Fahim, R. B., Linsen, B. G., Visseren, W. J., and de Vleesschauwer, W. F., J. Catal., I, 163 (1967).

15. Pines, H., and Pillai, C. N., J. Am. Chem. Soc. $\underline{83}, 3270$ (1961).

16. Pines, H., and Haag, W. O., J. Am. Chem: Soc., 82, 2471 (1960).

17. Latshaw, B. APCI memo, "Literature Report and Related Information-Dehydration of Isobutanol to Isobutylene." 24 March 1992.

18. Feeley, O.C., M.A. Johansson, R.G. Herman, and K. Klier. Preprints, Div. Fuel Chem., ACS, $\underline{37}$ (4), 1817 (1992). 
Figure 3.1

FLOW SCHEMATIC OF 300CC AUTOCLAVE REACTOR

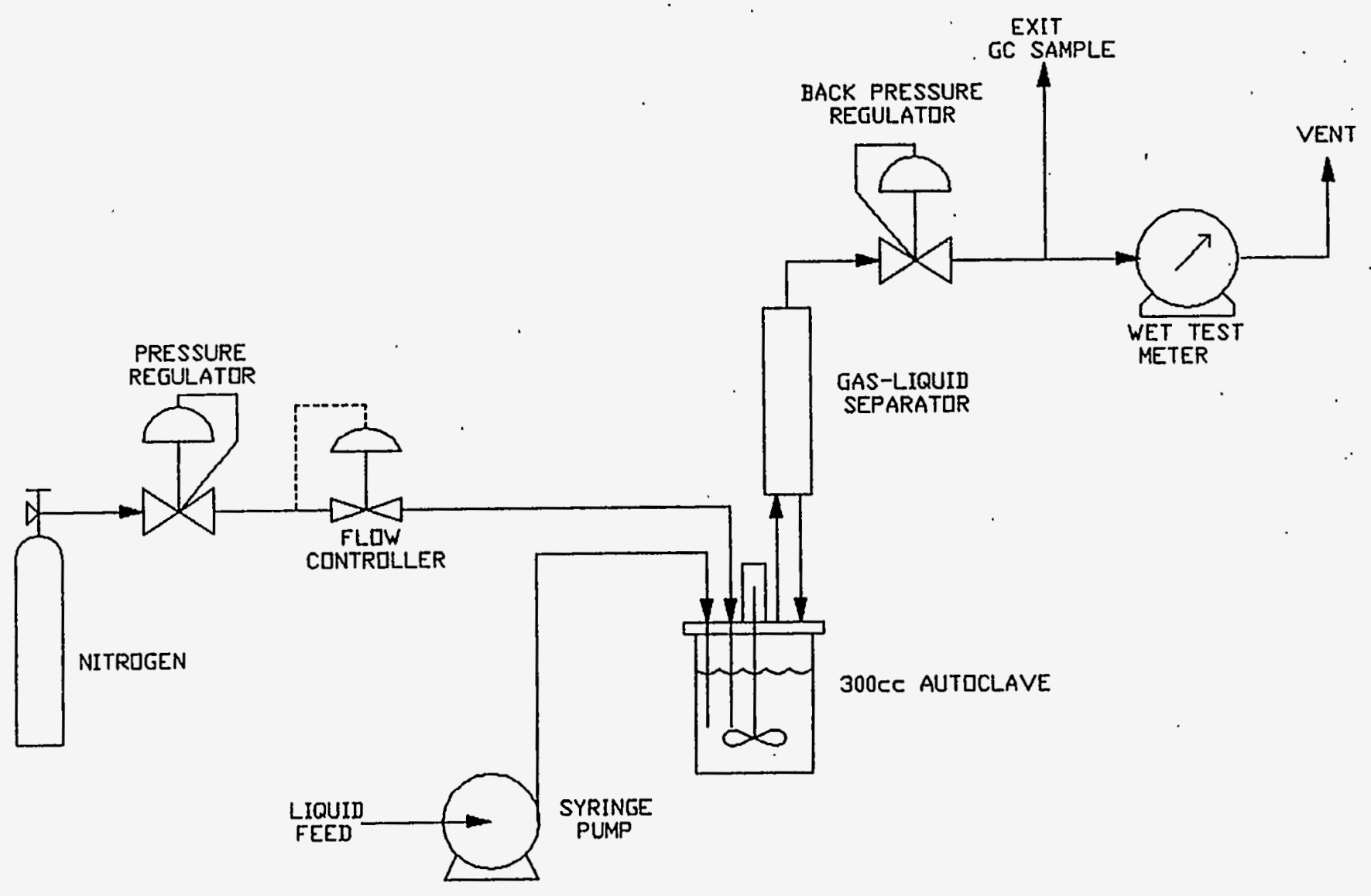




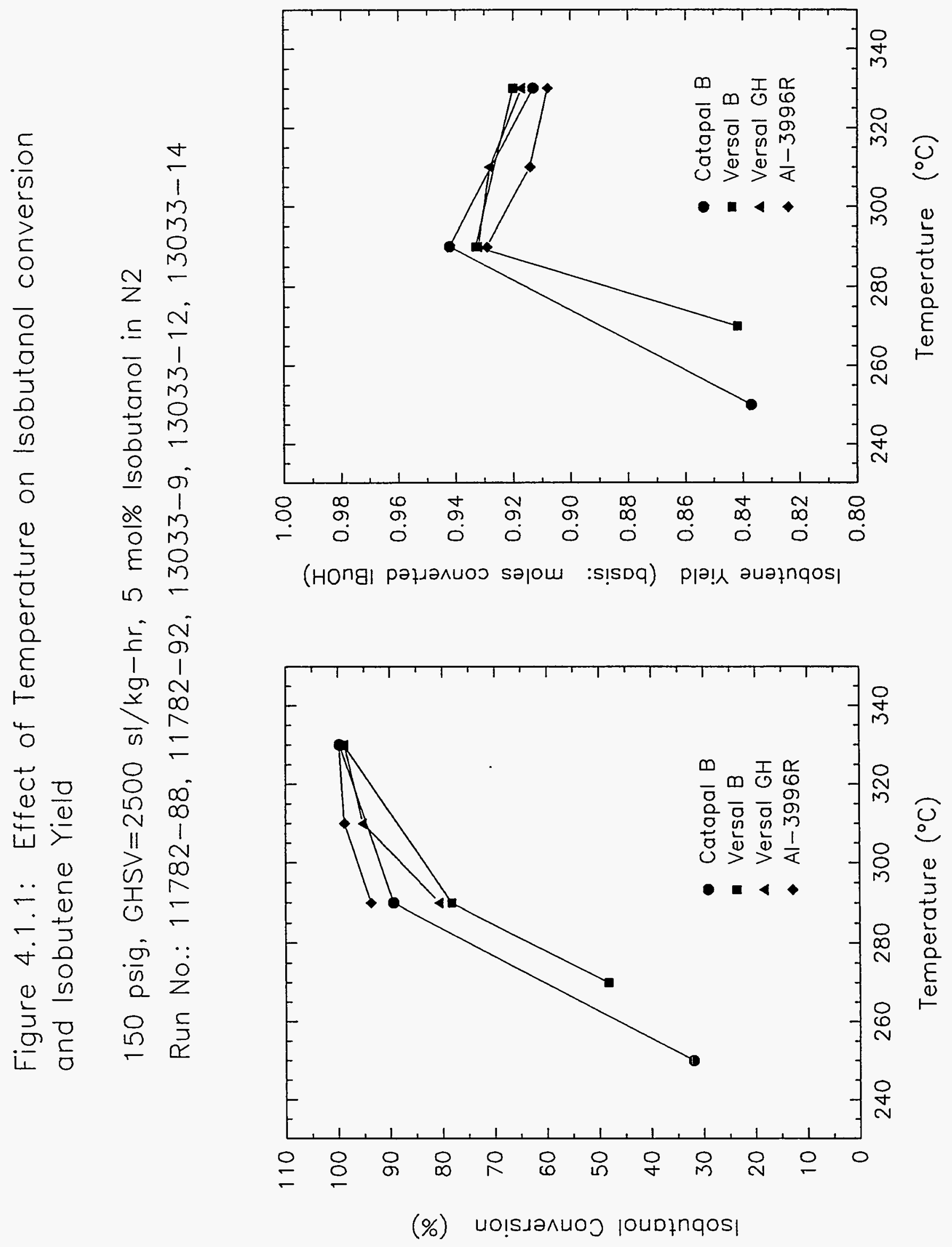


Figure 4.1.2: Yields of Linear Butenes and Dlisobutyl Ether as a Function of Reactor Temperature

150 psig, GHSV $=2500 \mathrm{sl} / \mathrm{kg}-\mathrm{hr}, 5 \mathrm{~mol} \%$ Isobutanol in N2

Run No.: 11782-88, 11782-92, 13033-9, 13033-12, 13033-14

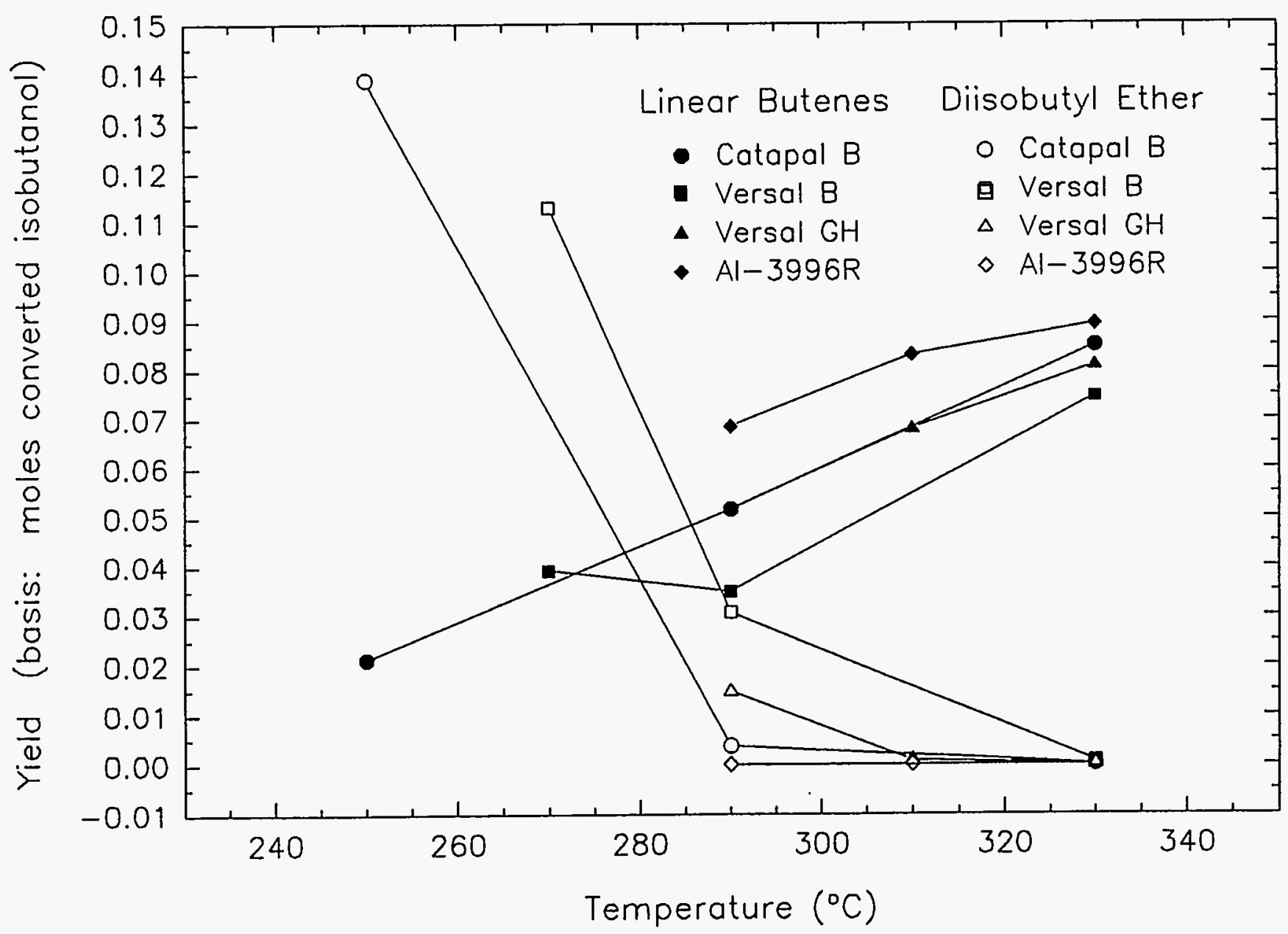


Figure 4.1.3: Effect of Pressure on Isobutanol conversion and Isobutene Yield at $290^{\circ} \mathrm{C}$

$290{ }^{\circ} \mathrm{C}, \mathrm{GHSV}=2500 \mathrm{sl} / \mathrm{kg}-\mathrm{hr}, 5$ mol\% Isobutanol in N2

Run No.: 11782-88, 13033-9, 13033-12, 13033-14
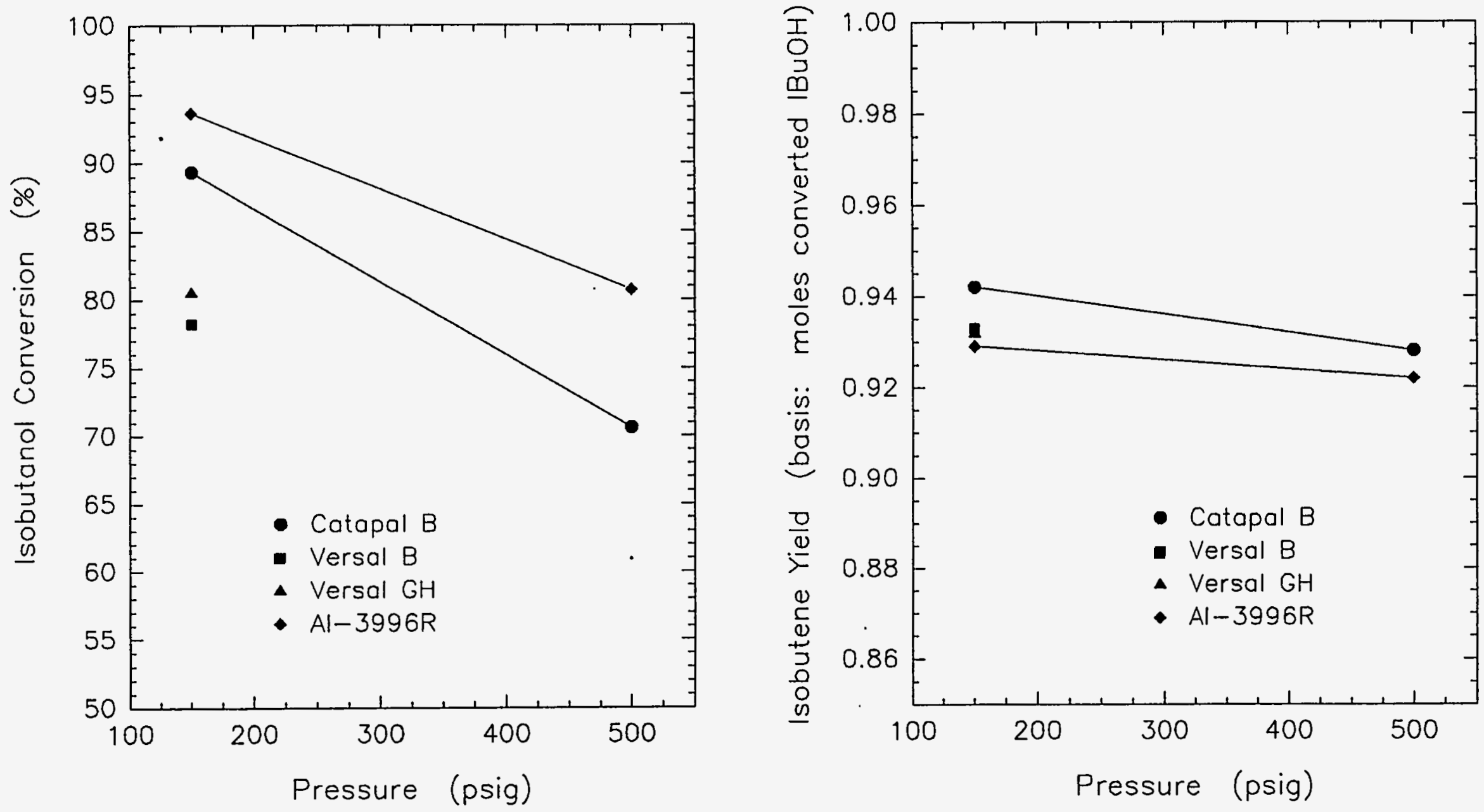
Figure 4.1.4: Effect of Pressure on Isobutanol conversion and Isobutene Yield as a Function of Temperature

$\mathrm{GHSV}=2500 \mathrm{sl} / \mathrm{kg}-\mathrm{hr}, 5 \mathrm{~mol} \%$ Isobutanol in N2

Run No.: 11782-78, 11782-88, 13033-14
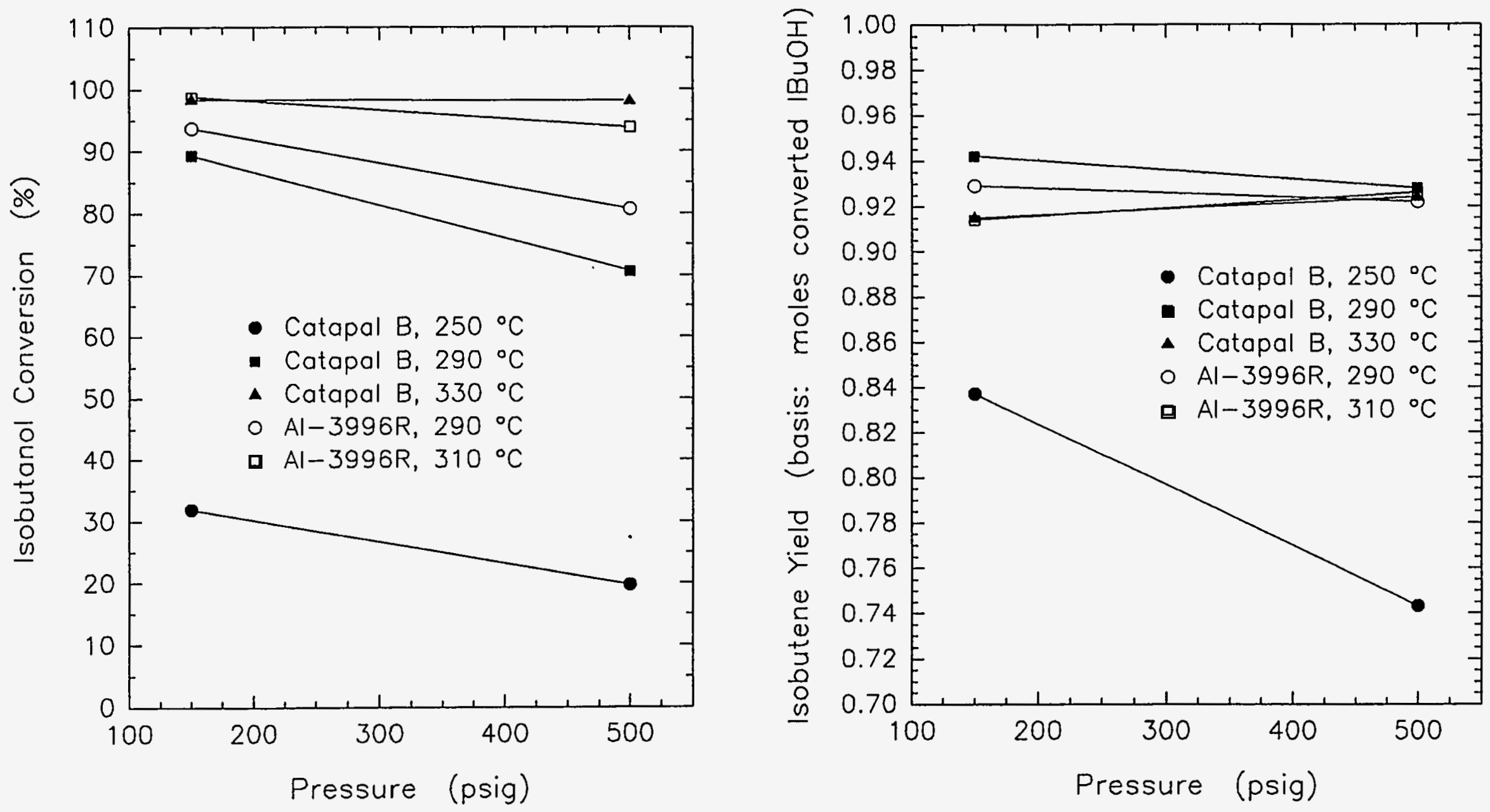


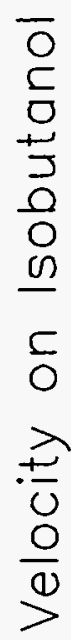

O) O

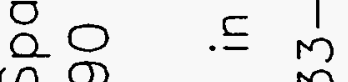

U $\bar{O}$

齐茂 咞

오 일

n $=\frac{\text { n }}{0} \mathrm{~m}$

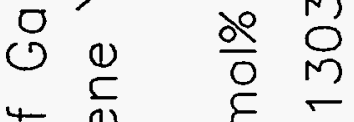

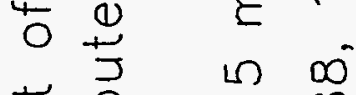

$+0)$

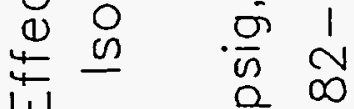

$\begin{array}{rrr}\text { 山. } & 0 & \infty \\ 0 & 0 & 0 \\ 0 & 0 & -\end{array}$

मी

$\because \frac{c}{\circ}$ o $\frac{0}{z}$

๖⿺ 丶

or 0

¿ 0

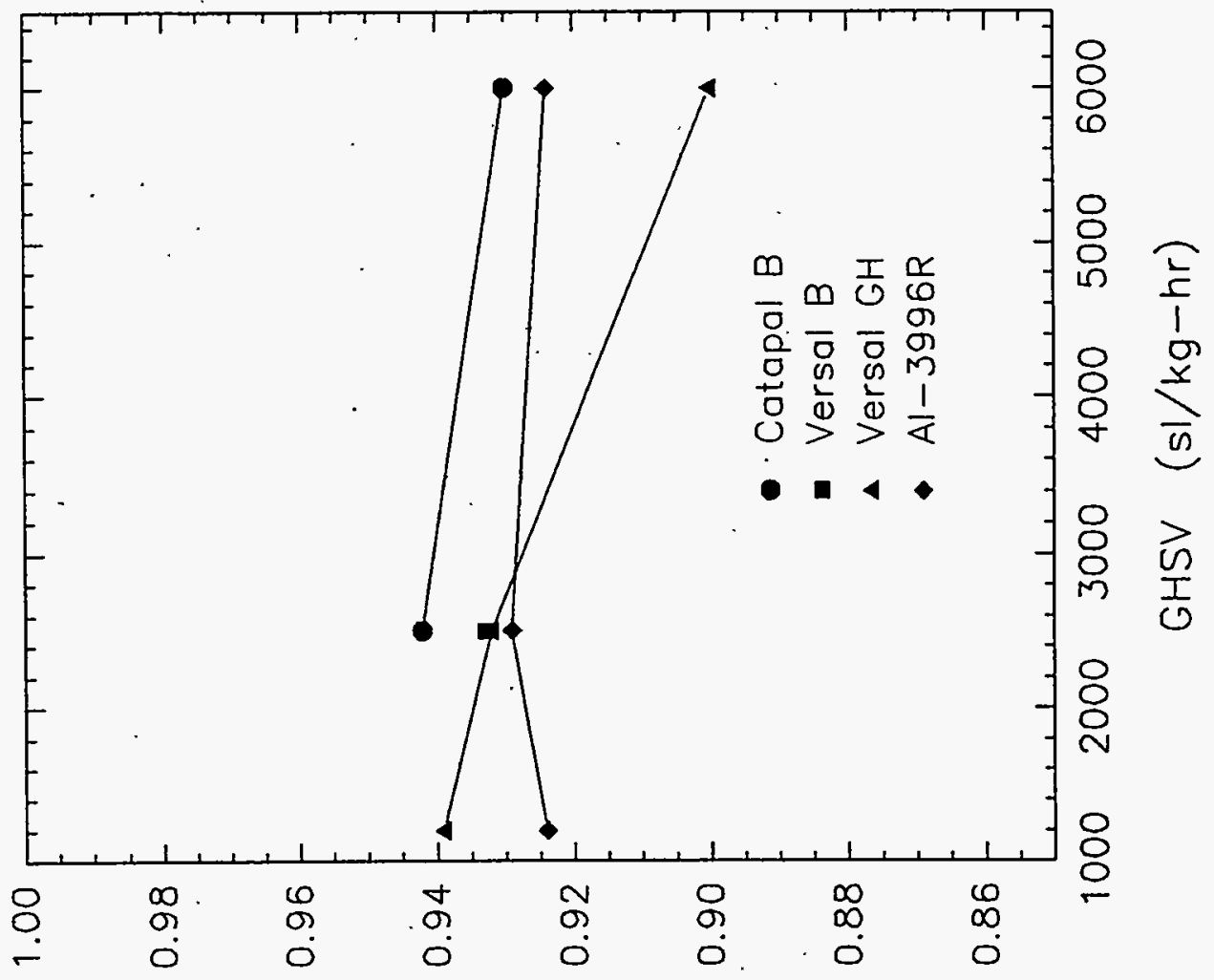

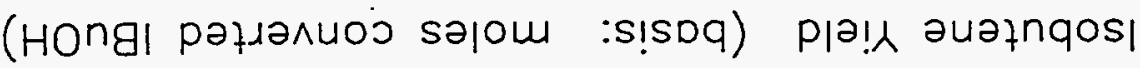

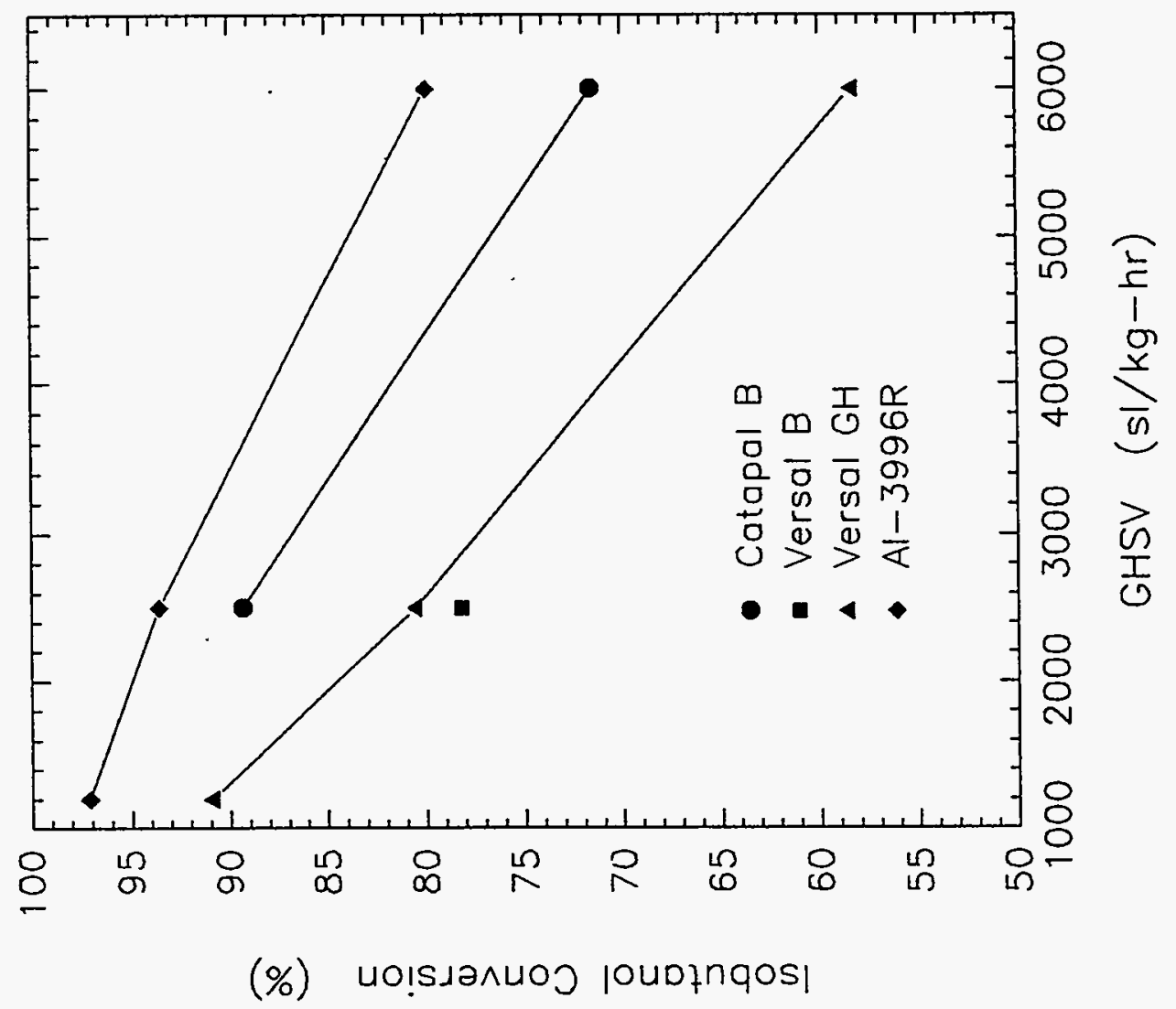


0
0
0
0
0
0
0
0
0
0
0
0

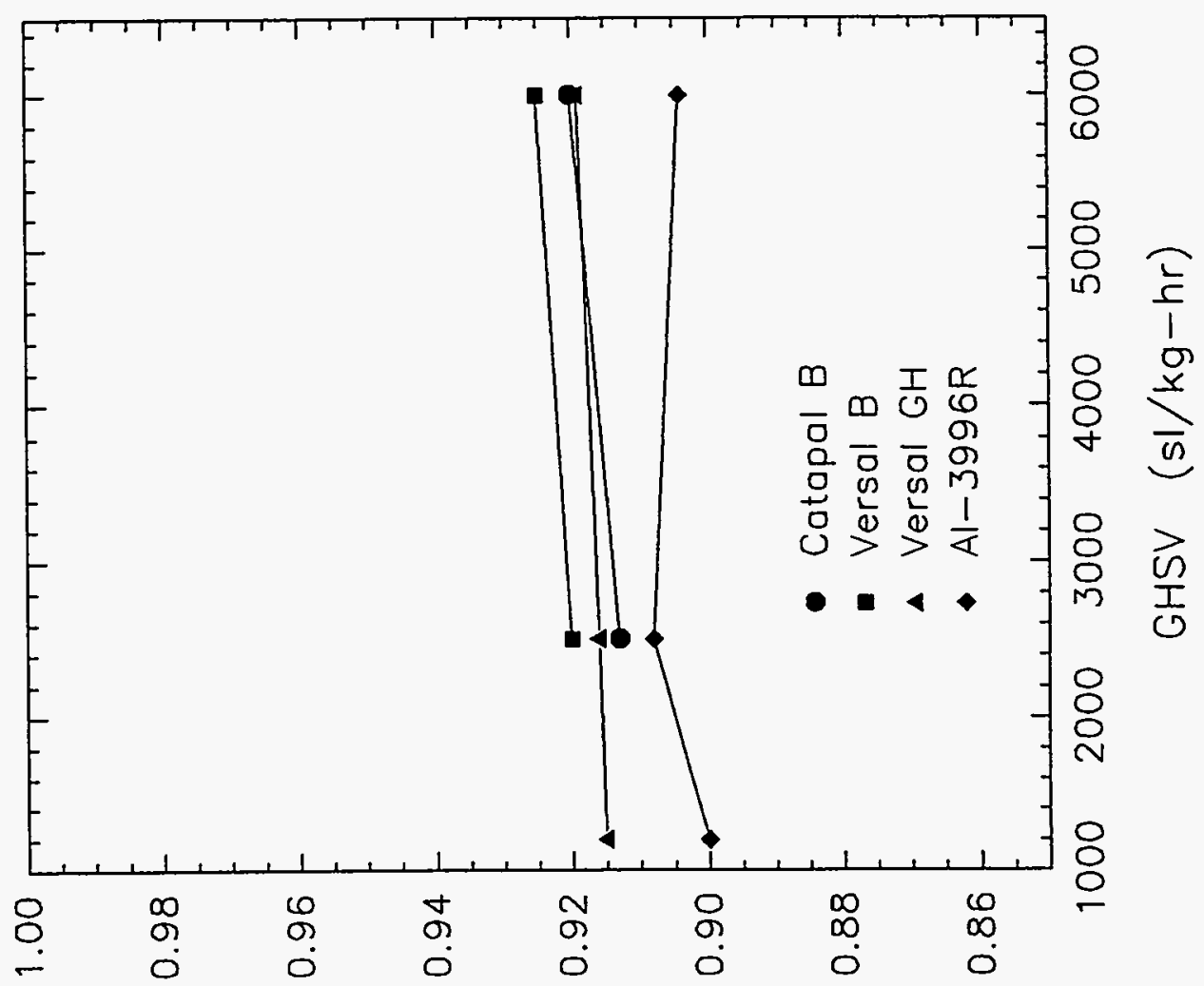

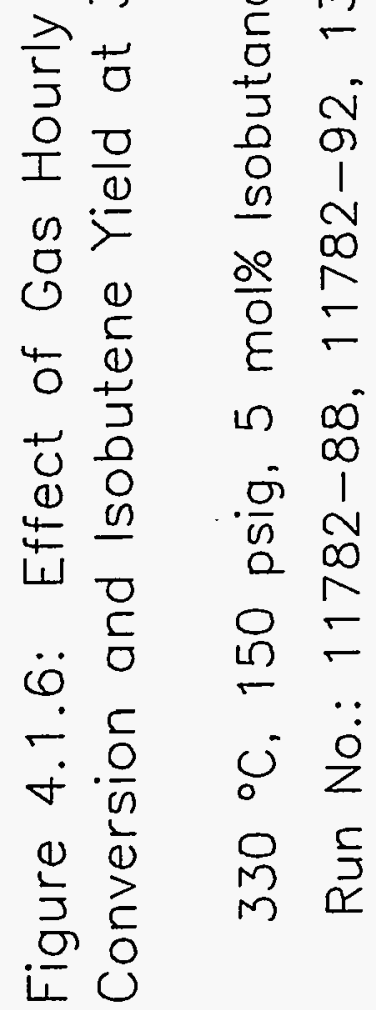

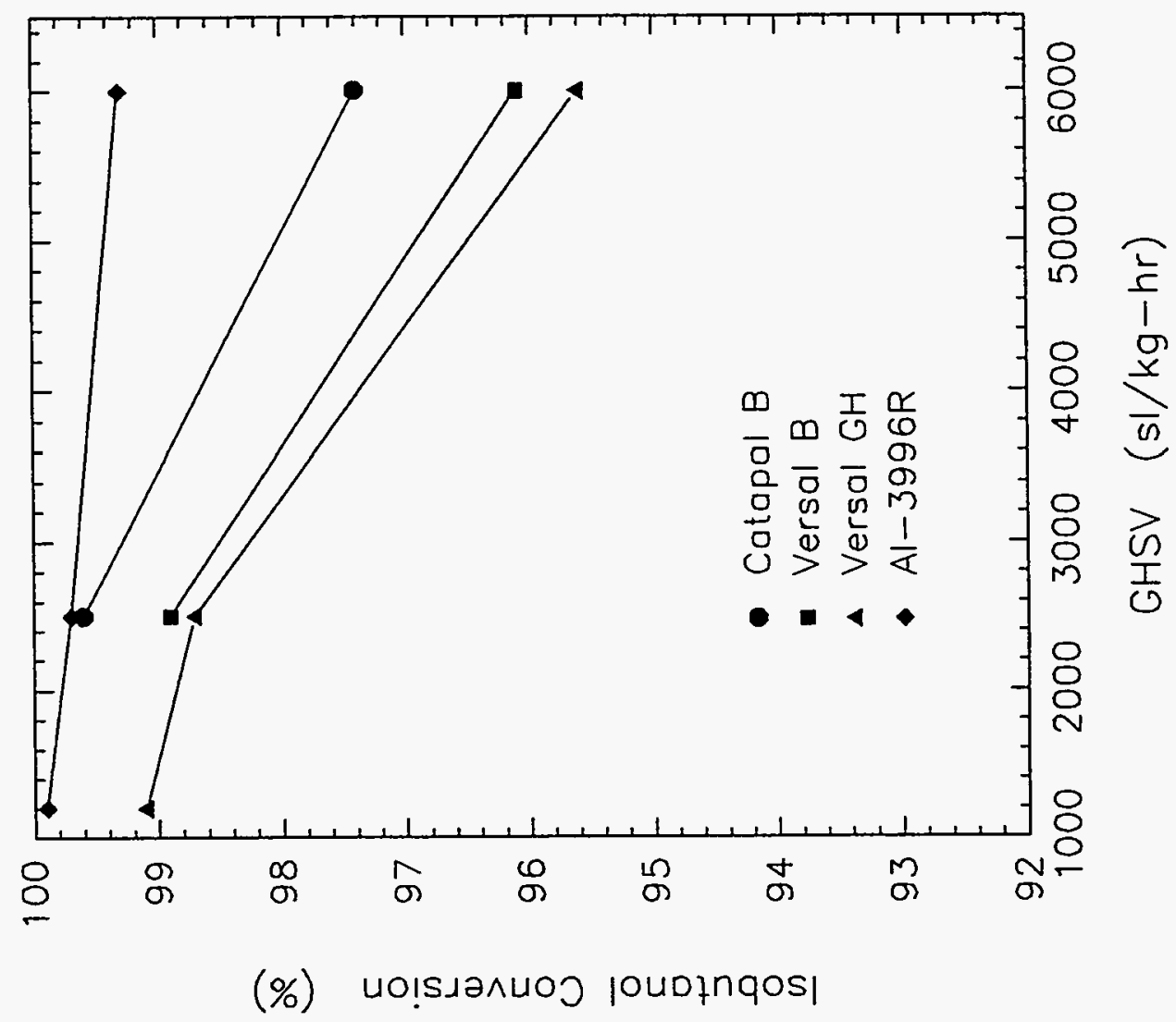


Figure 4.1.7: Effect of Feed Isobutanol Concentration on Isobutanol Conversion and Isobutene Yield

$330{ }^{\circ} \mathrm{C}, 150 \mathrm{psig}, \mathrm{GHSV}=2500 \mathrm{sl} / \mathrm{kg}-\mathrm{hr}$, feed: Isobutanol in N2 Run No.: 11782-88, 11782-92
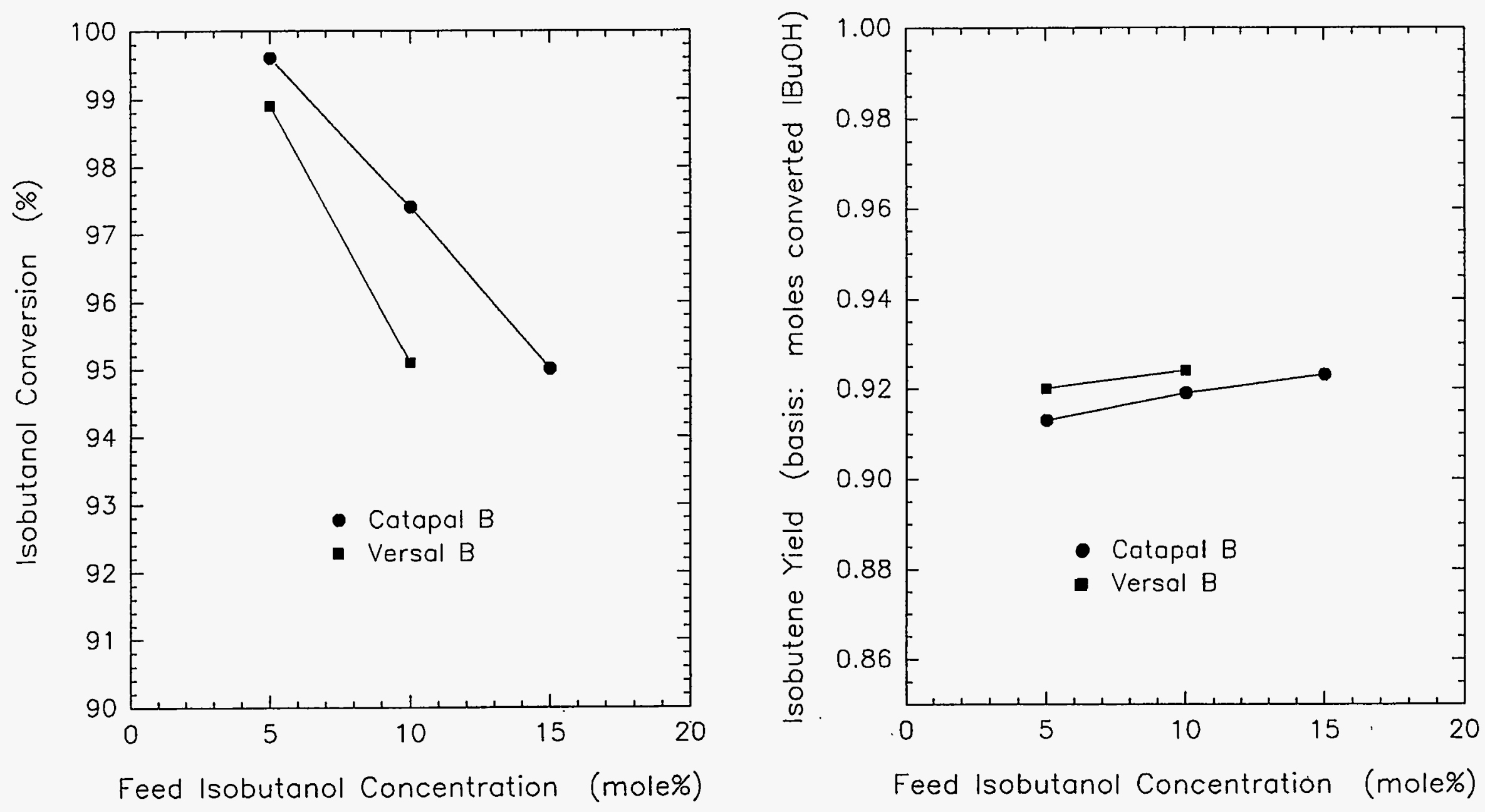
Figure 4.1.8: Effect of Isobutanol Conversion on Product Distribution

Catapal B

Run No.: $11782-88$

$250,290,330^{\circ} \mathrm{C}$

150,500750 psig

GHSV $=2500,6000 \mathrm{sl} / \mathrm{kg}-\mathrm{hr}$

$5,10,15 \mathrm{~mol} \% \mathrm{IBuOH}$ in N2

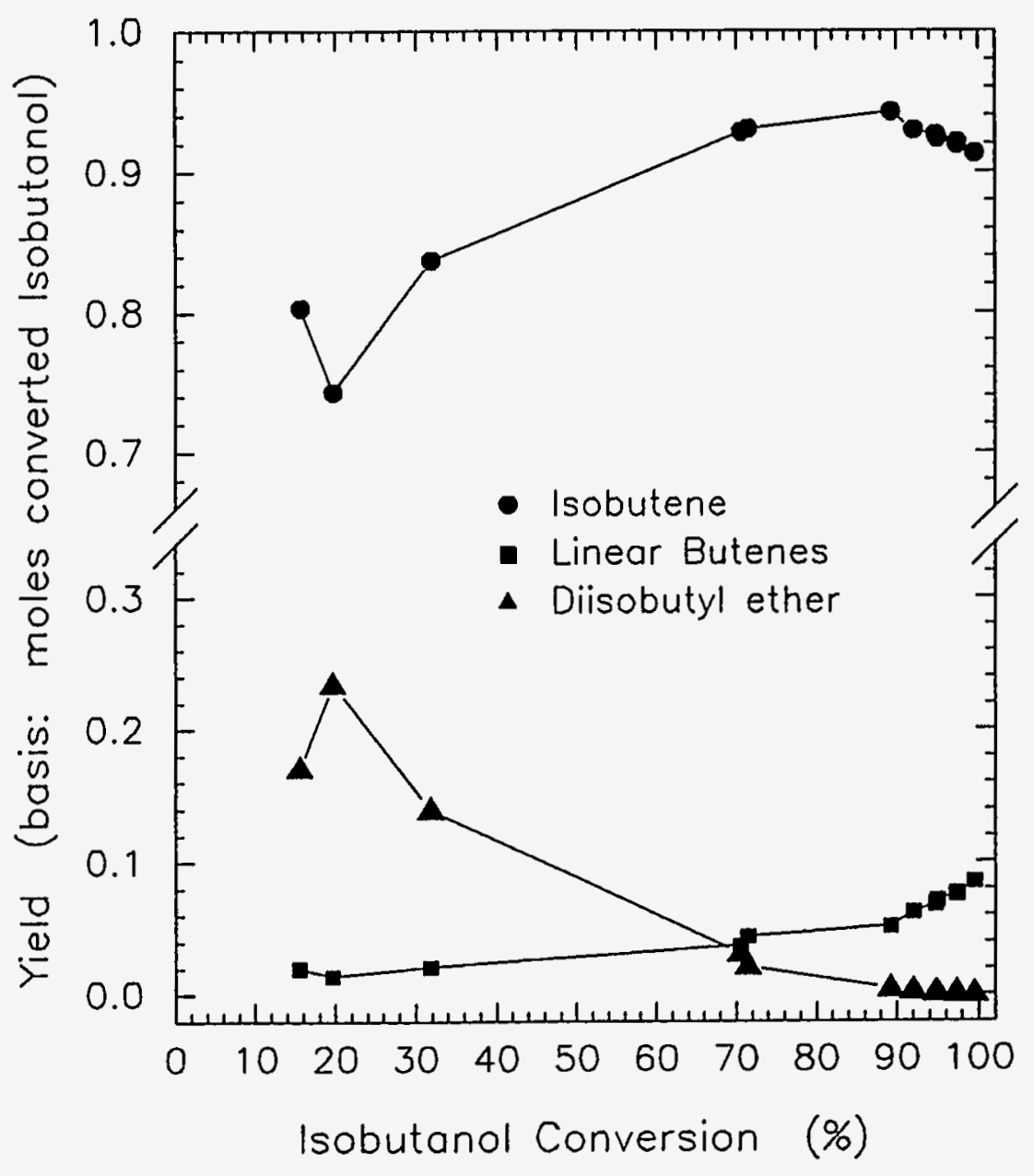

Versal $B$

Run No.: $11782-92$

$270,330^{\circ} \mathrm{C}$

99,150 psig

GHSV $=2500,6000 \mathrm{~s} / \mathrm{kg}-\mathrm{hr}$

5,10, mol\% IBuOH in N2

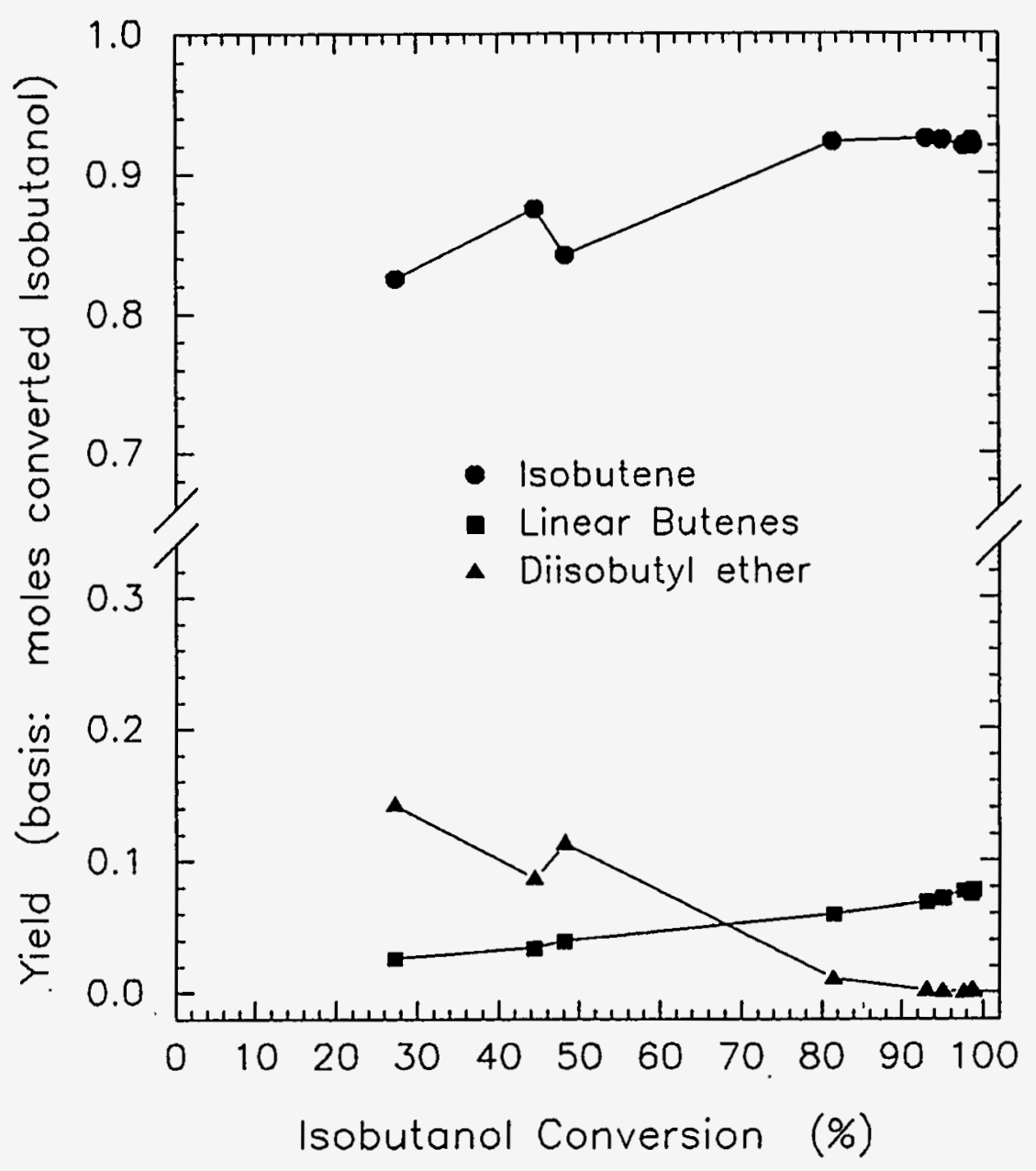


Figure 4.1.9: Effect of Isobutanol Conversion on Product Distribution

\section{Versal GH}

Run No.: $13033-12$

$290,310,330^{\circ} \mathrm{C}$

150 psig

$\mathrm{GHSV}=1200,2500,6000 \mathrm{sl} / \mathrm{kg}-\mathrm{hr}$

$5 \mathrm{~mol} \% \mathrm{IBuOH}$ in $\mathrm{N} 2$

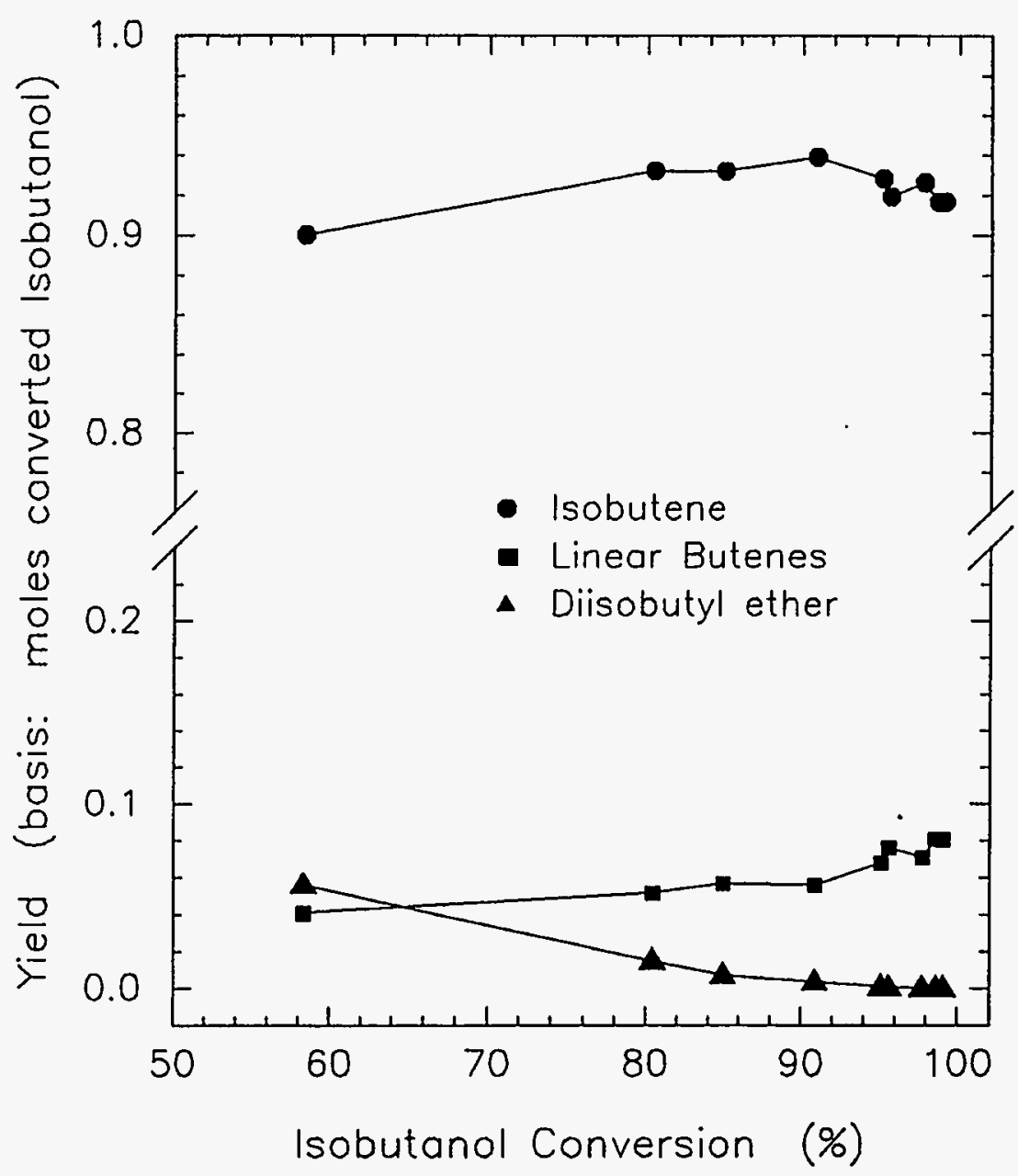

Engelhard Al-3996R

Run No.: 13033-14 $290,310,330{ }^{\circ} \mathrm{C}$

150,500 psig

$\mathrm{GHSV}=1200,2500,6000 \mathrm{sl} / \mathrm{kg}-\mathrm{hr}$

$5 \mathrm{~mol} \% \mathrm{IBuOH}$ in N2

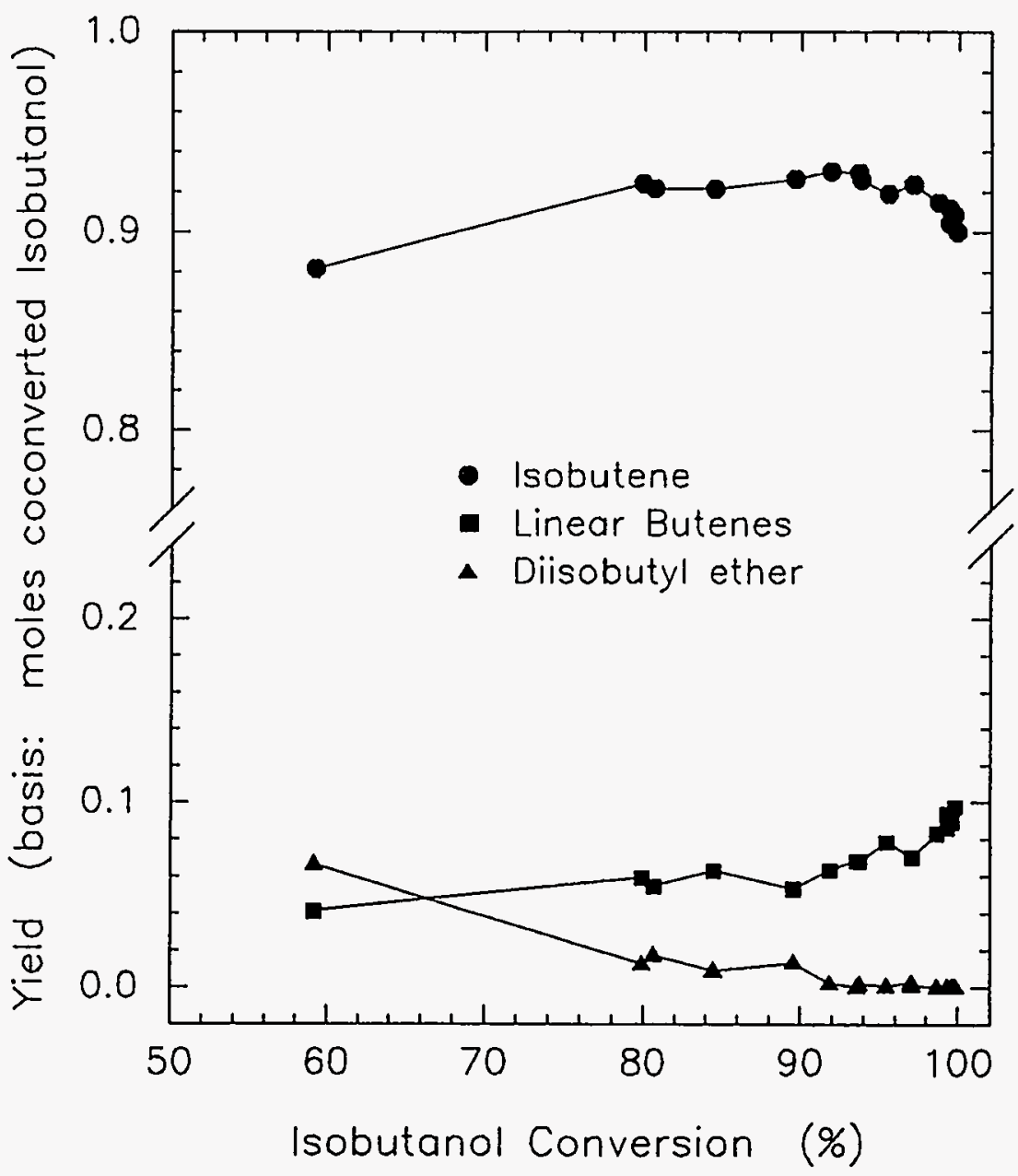


Figure 4.1.10: Yield of Isobutene Based on Moles of Isobutanol Feed as a Function of Reactor Temperature

$150 \mathrm{psig}, \mathrm{GHSV}=2500 \mathrm{sl} / \mathrm{kg}-\mathrm{hr}, 5 \mathrm{~mol} \%$ Isobutanol in N2

Run No.: 11782-88, 11782-92, 13033-9, 13033-12, 13033-14

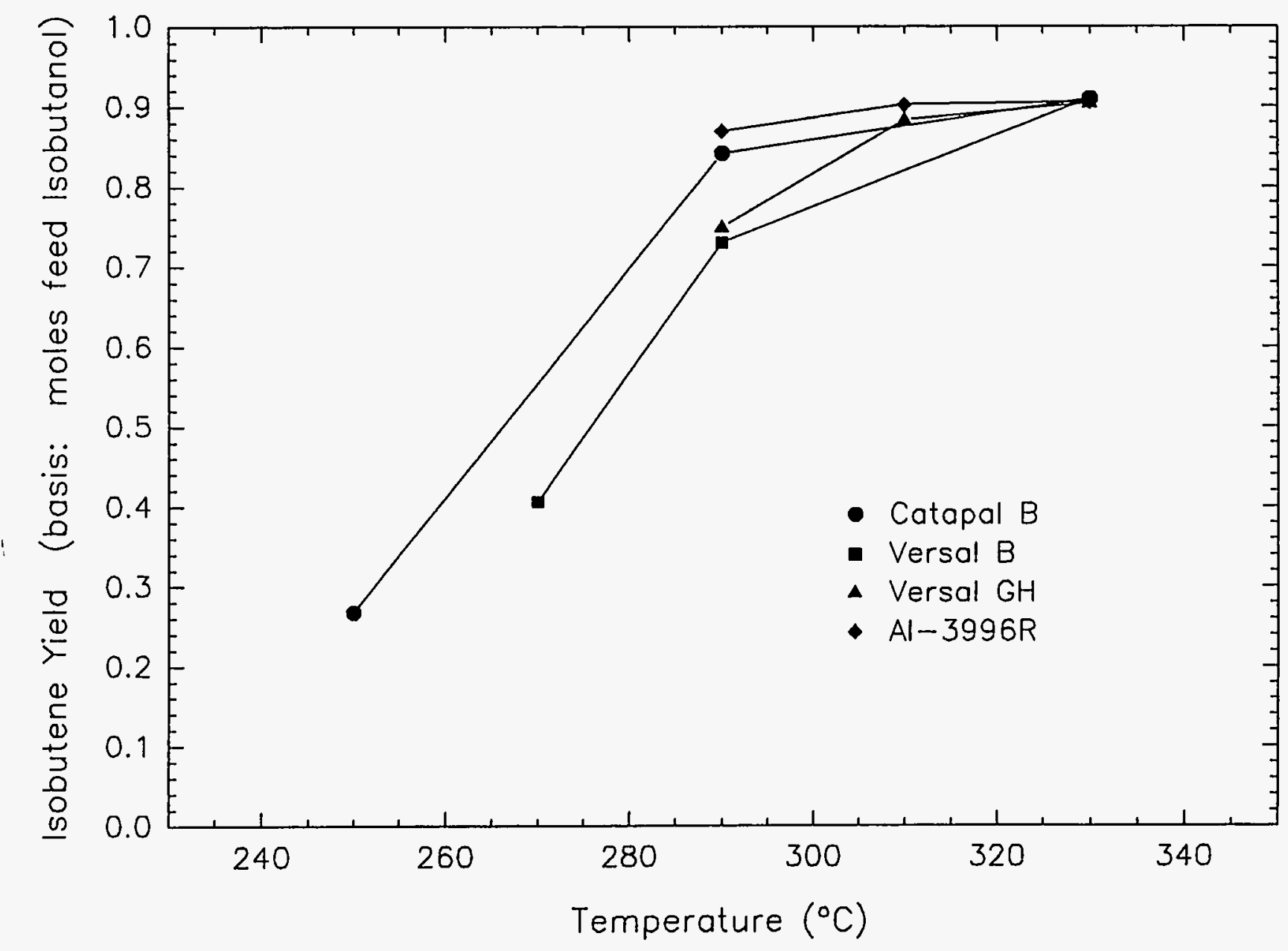


Figure 4.2.1: Effect of Gas Hourly Space Velocity on Isobutanol Conversion and Isobutene Yield for Potassium Doped Catapal B

$330^{\circ} \mathrm{C}, 150$ psig, 5 mol\% Isobutanol in N2

Run No.: $11782-88,11782-92,13033-12,13033-14$
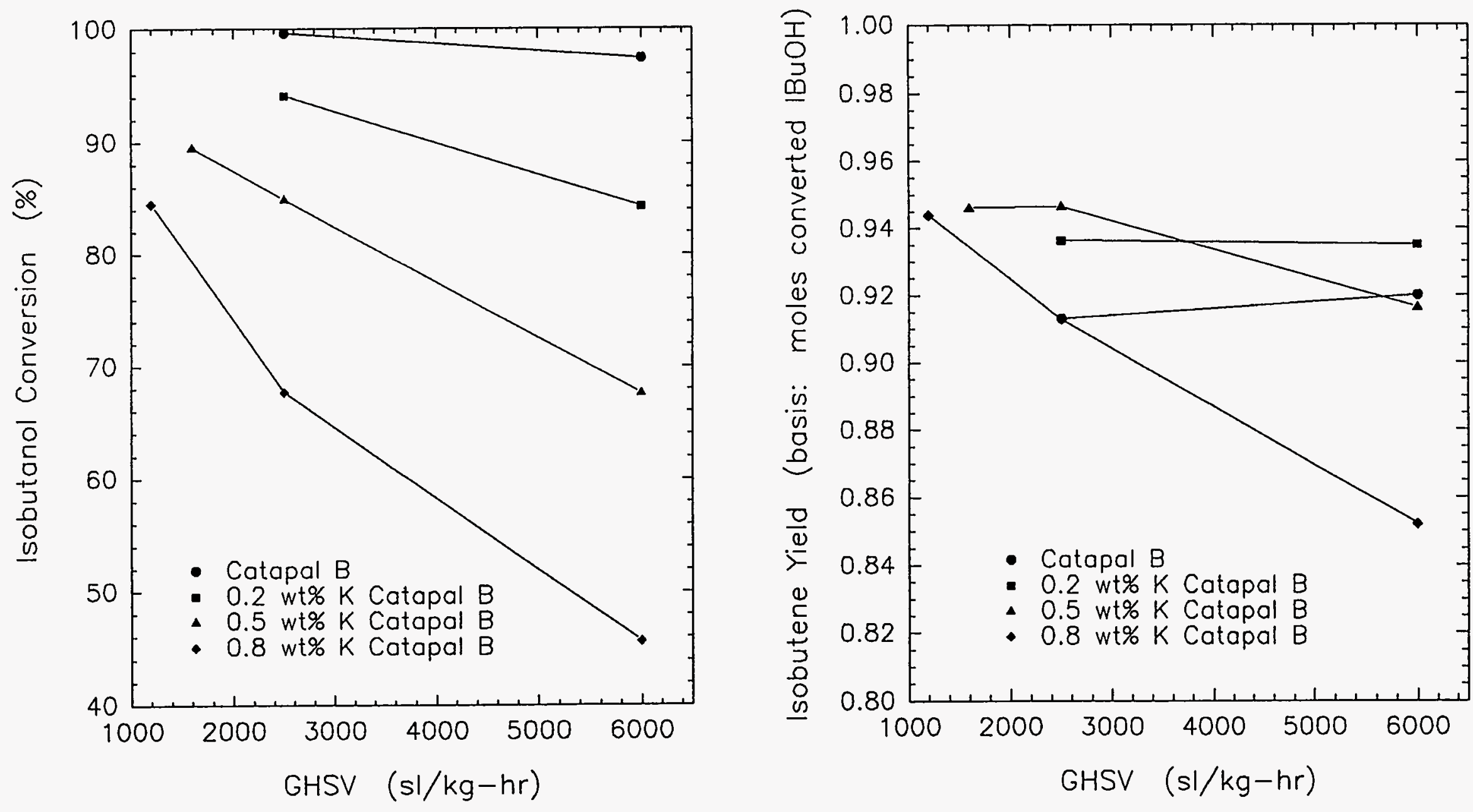
O

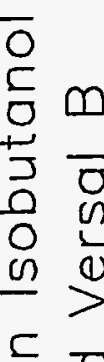

$5 \mathrm{O}$

$>\mathrm{O}$

ㅇํㅁㄷㅡ

응 $\varepsilon \quad \overline{0}$

$>\frac{5}{2} \stackrel{\frac{5}{2}}{\frac{0}{3}}$

(1) N 0

은 으

जि $0 \mathrm{~m}$

츤

으 $\square$ ก

I $\frac{0}{0} \quad$ o

थ $\doteq$ क

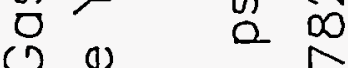

证这

苍苛

\&

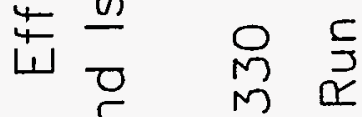

$\ddot{\gamma} 0$

i

$\dot{\nabla} \cdot \frac{\sigma}{n}$

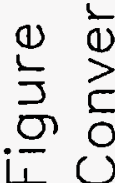

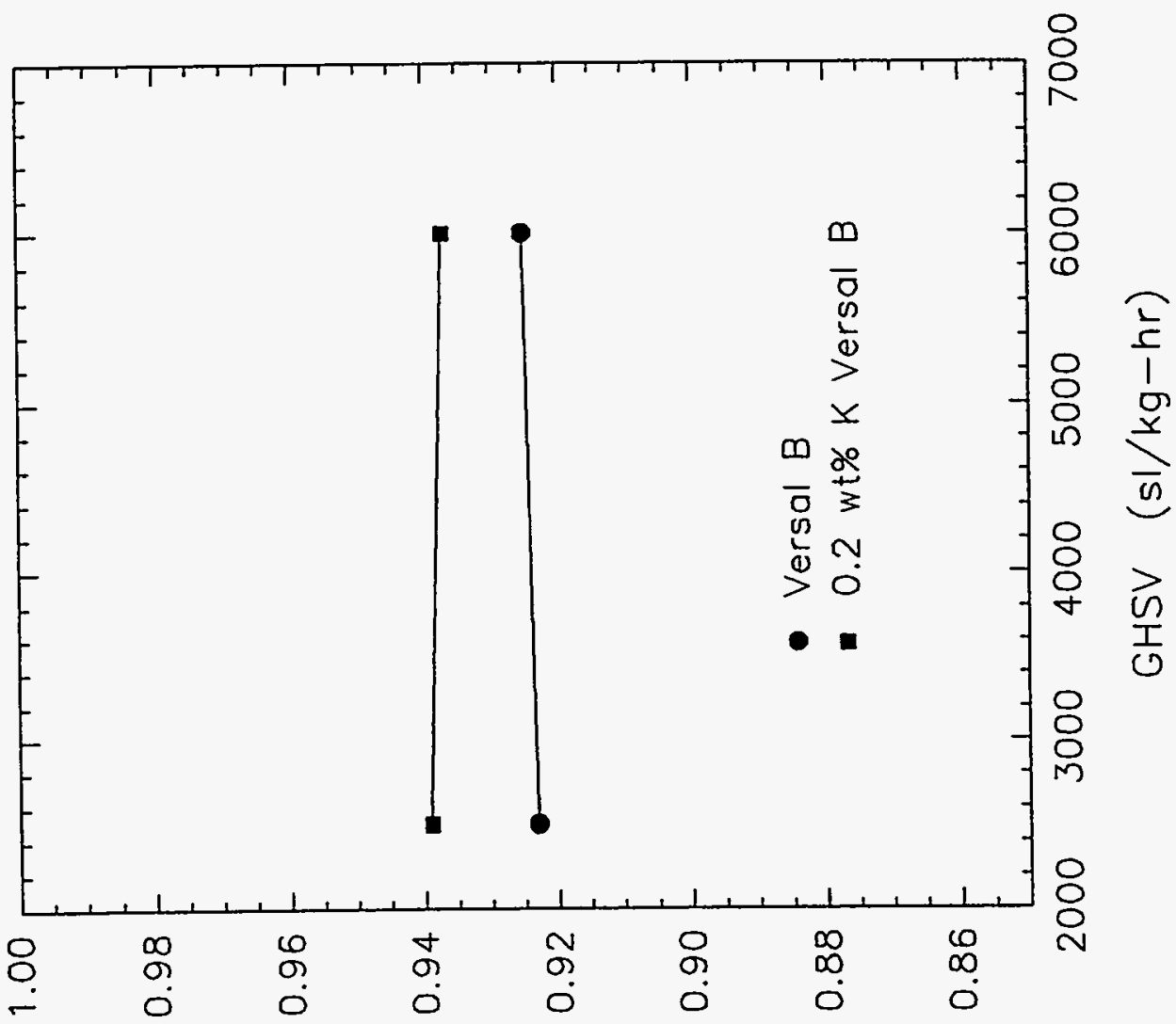

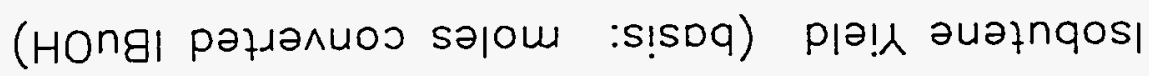

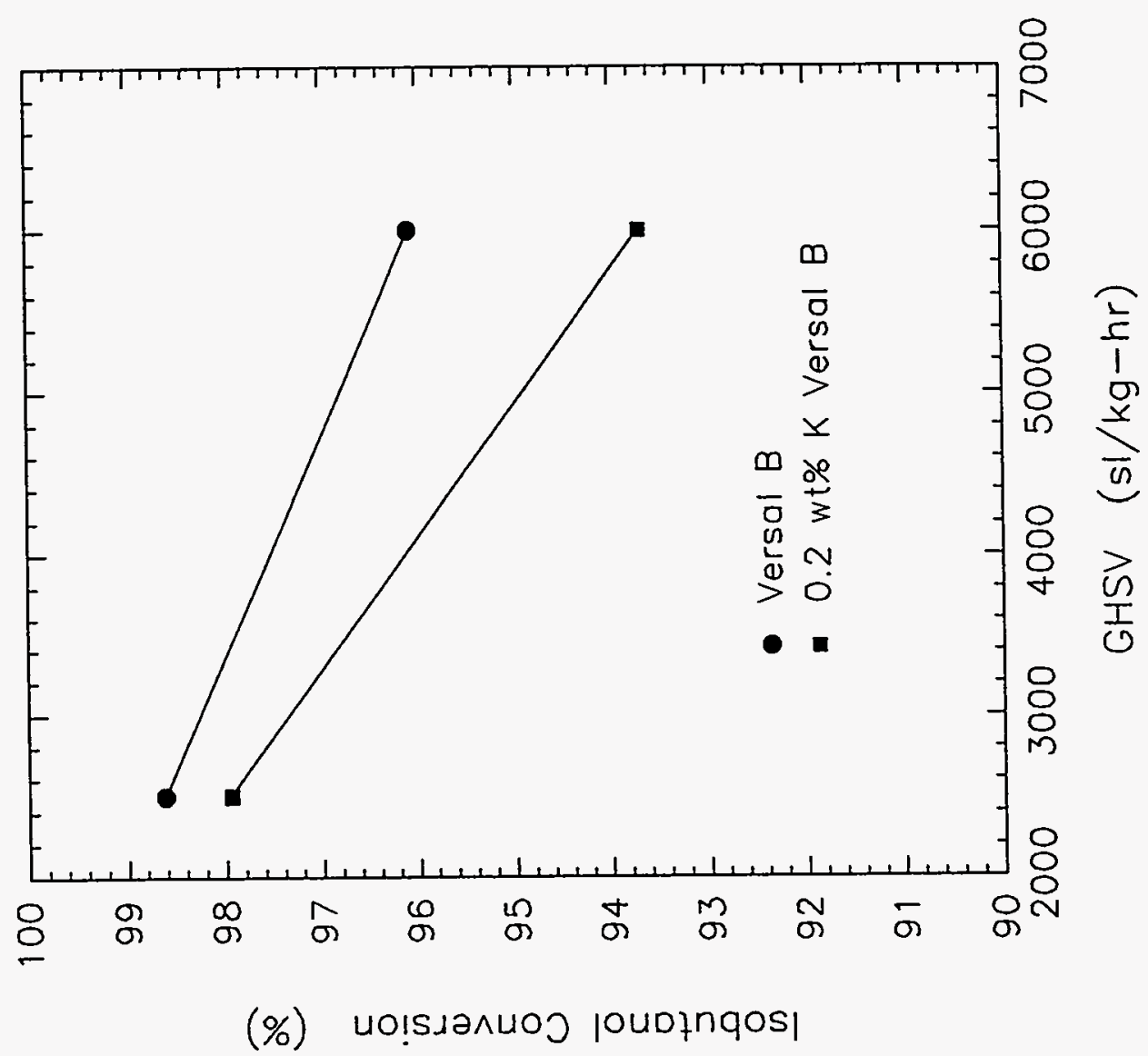


Isobutene Yield (basis: moles converted Isobutanol)

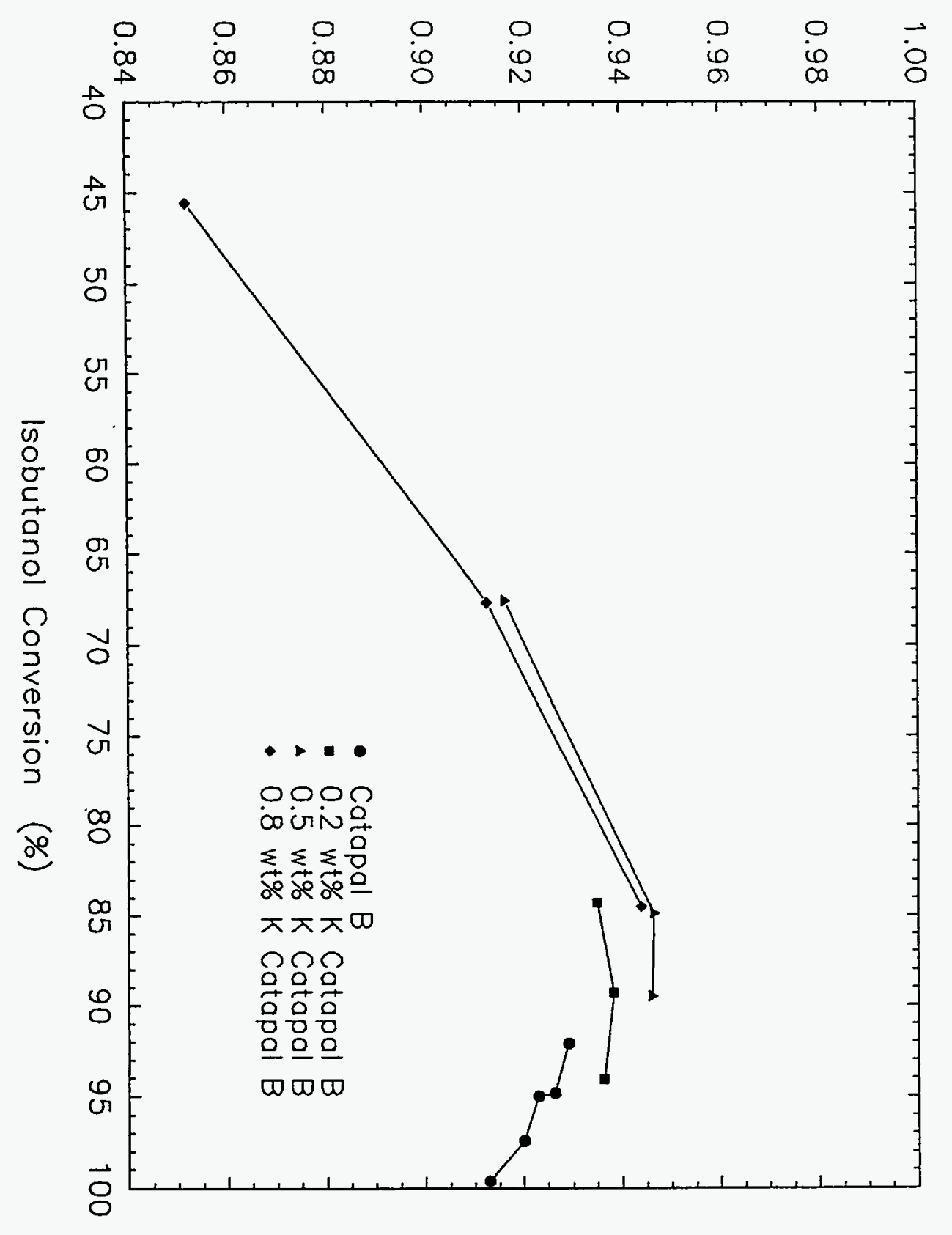

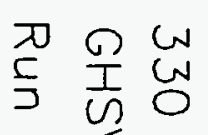

$\frac{\pi}{\frac{1}{0}}$

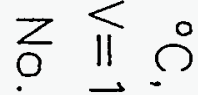

$\therefore \vec{\sim} \rightarrow$

$\begin{array}{lll}\mathrm{V} & \vec{O} & \overrightarrow{0} \\ \overrightarrow{0} & \stackrel{0}{0} & \stackrel{0}{0}\end{array}$

$\stackrel{\infty}{N} \overrightarrow{0} 0$

$\stackrel{\infty}{N} \overrightarrow{0} \mathrm{O} \quad$

$\infty 0.0$

$\infty$ N v

$\rightarrow$ ug n

$\vec{\nabla} \bigcirc$

No $\frac{\infty}{1} \quad \frac{5}{3}$

$\begin{array}{llll}1 & 0 & 0 & 0 \\ 0 & 0 & 0\end{array}$

$\infty$ O 0 u

$\vec{\sim} \stackrel{0}{0} \stackrel{0}{2}$

ํㅜㅅ 3

$N \frac{1}{2} \frac{0}{20} \quad \sum_{0}$

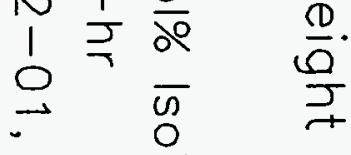

$\rightarrow \quad$ O 0

$\overrightarrow{0}$ 至

w $\frac{0}{3}$

w

$\rightarrow \quad$ Ј

$Z_{N} \frac{\vec{D}}{\vec{D}}$

$\frac{\widehat{D}}{2}$ 


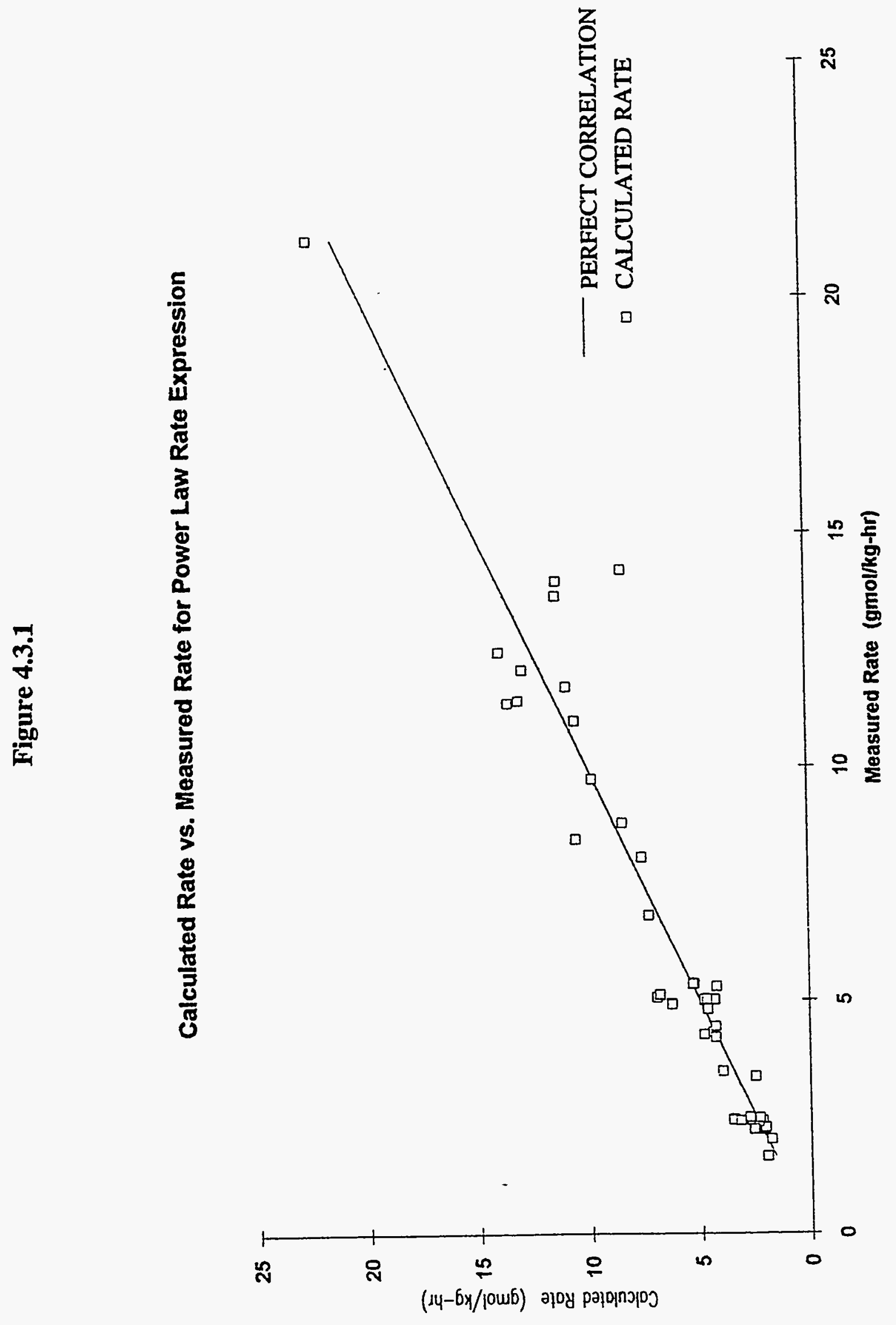


TABLE 4.1.1: Properties of Alumina Catalysts

Determined by supplier

\begin{tabular}{|c|c|c|c|c|c|c|}
\hline Catalyst & Supplier & Alumina Phase & $\begin{array}{c}\text { Surface Area } \\
\left(\mathrm{m}^{2} / \mathrm{g}\right)\end{array}$ & $\begin{array}{c}\text { Pore Volume } \\
(\mathrm{cc} / \mathrm{g})\end{array}$ & Loss on Ignition & $\begin{array}{c}\text { Sodium Level } \\
(\text { wt.\% Na2O) }\end{array}$ \\
\hline Catapal B & Conoco & gamma & 250 & 0.45 & 25.8 & 0.004 \\
\hline Versal GH & LaRoche & gamma & $150-290$ & ---- & $1-3$ & 0.08 \\
\hline Al-3996R & Engelhard & gamma & 180 & 0.64 & --- & 0.05 \\
\hline Versal B & LaRoche & eta & 400 & --- & 35 & 0.1 \\
\hline
\end{tabular}


TABLE 4.2.1: Effect of Catalyst Sodium Level on Isobutene Yield

Conditions: $330^{\circ} \mathrm{C}, 150 \mathrm{psig}, 5 \mathrm{~mol} \%$ isobutanol in nitrogen, GHSV of $2500 \mathrm{sl} / \mathrm{kg}-\mathrm{hr}$

\begin{tabular}{|c|c|c|c|c|c|c|}
\hline & & & & \multicolumn{3}{|c|}{ Yield (basis: moles converted Isobutanol) } \\
\hline Run \# & Catalyst & (wt.\% Na2O) & $\mathrm{i}-\mathrm{BuOH}$ Conv (\%) & Isobutene & Linear Butenes & Diisobutyl Ether \\
\hline $11782-88$ & Catapal B & 0.004 & 99.6 & 0.913 & 0.085 & 0.00 \\
\hline $13033-12$ & Versal GH & 0.05 & 98.7 & 0.917 & 0.081 & 0.00 \\
\hline $13033-14$ & Al-3996R & 0.08 & 99.7 & 0.908 & 0.089 & 0.00 \\
\hline $11782-92$ & Versal B & 0.1 & 98.9 & 0.920 & 0.078 & 0.00 \\
\hline
\end{tabular}

Conditions: $330{ }^{\circ} \mathrm{C}, 150 \mathrm{psig}, 5 \mathrm{~mol} \%$ isobutanol in nitrogen, GHSV of $6000 \mathrm{sl} / \mathrm{kg}-\mathrm{hr}$

\begin{tabular}{|c|c|c|c|c|c|c|}
\hline & & & \multicolumn{3}{|c|}{ Yield (basis: moles converted Isobutanol) } \\
\hline Run \# & Catalyst & $\left(\mathrm{wt} . \% \mathrm{Na}_{2} \mathrm{O}\right)$ & $\mathrm{i}-\mathrm{BuOH}$ Conv (\%) & Isobutene & Linear Butenes & Diisobutyl Ether \\
\hline $11782-88$ & Catapal B & 0.004 & 97.4 & 0.924 & 0.076 & 0.00 \\
\hline $13033-12$ & Versal GH & 0.08 & 95.6 & 0.919 & 0.083 & 0.00 \\
\hline $13033-14$ & Al-3996R & 0.05 & 99.3 & 0.904 & 0.094 & 0.00 \\
\hline $11782-92$ & Versal B & 0.1 & 96.1 & 0.925 & 0.071 & 0.00 \\
\hline
\end{tabular}


TABLE 4.2.2: Operating conditions Necessary to Obtain Identical Conversions for Different Potassium Weight Loadings

Conditions: $5 \mathrm{Mol} \%$ Isobutanol in Nitrogen

\begin{tabular}{|c|c|c|c|c|c|c|c|c|}
\hline Run \# & Catalyst & $\begin{array}{c}\text { Temperature } \\
\left({ }^{\circ} \mathrm{C}\right)\end{array}$ & $\begin{array}{c}\text { Pressure } \\
(\mathrm{psig})\end{array}$ & $\begin{array}{c}\text { GHSV } \\
(\mathrm{sl} / \mathrm{kg}-\mathrm{hr})\end{array}$ & $\begin{array}{c}\text { \% i-BuOH } \\
\text { Conversion }\end{array}$ & Isobutene & $\begin{array}{c}\text { Linear } \\
\text { Butenes }\end{array}$ & $\begin{array}{c}\text { Diisobutyl } \\
\text { Ether }\end{array}$ \\
\hline $11782-88$ & Catapal B & 290 & 150 & 2500 & 89.3 & 0.942 & 0.052 & 0.004 \\
\hline $11782-98$ & $\begin{array}{c}\text { Catapal B } \\
0.2 \text { wt.\% K }\end{array}$ & 330 & 500 & 2500 & 89.3 & 0.938 & 0.053 & 0.005 \\
\hline $11782-01$ & $\begin{array}{c}\text { Catapal B } \\
0.5 \text { wt.\% K }\end{array}$ & 330 & 150 & 1600 & 89.5 & 0.946 & 0.045 & 0.004 \\
\hline $11782-98$ & $\begin{array}{c}\text { Catapal B } \\
0.2 \text { wt.\% K }\end{array}$ & 330 & 150 & 6000 & 84.3 & 0.935 & 0.052 & 0.008 \\
\hline $11782-01$ & $\begin{array}{c}\text { Catapal B } \\
0.5 \text { wt.\% K }\end{array}$ & 330 & 150 & 2500 & 84.9 & 0.946 & 0.041 & 0.009 \\
\hline $13033-1$ & $\begin{array}{c}\text { Catapal B } \\
0.8 \text { wt.\% K }\end{array}$ & 330 & 150 & 1200 & 84.5 & 0.944 & 0.039 & 0.011 \\
\hline
\end{tabular}


TABLE 4.2.3: Effect of Higher Alcohols on the Product Spectrum

\section{Conditions: $330^{\circ} \mathrm{C}, 150 \mathrm{psig}, 5 \mathrm{~mol} \%$ alcohol in nitrogen, GHSV of $2500 \mathrm{~s} / \mathrm{kg}-\mathrm{hr}$}

Run \# 13033-1

Alcohol Conversion (\%): 74.9

\begin{tabular}{ll} 
Alcohol Feed & Mole\% \\
\hline isobutanol & 58.17 \\
1-butanol & 7.04 \\
2-methyl-1-butanol & 14.88 \\
1-pentanol & 3.65 \\
2-methyl-1-pentanol & 11.75 \\
1-hexanol & 4.50
\end{tabular}

Feed Molar Selectivity (mole\%)

2-methyl-1-C3 alcohol/ C4 alcohol: 89.2

2-methyl-1-C4 alcohol/ C5 alcohol: 80.3

2-methyl-1-C5 alcohol/ C6 alcohol: 72.3

2-methyl-1-alcohol/ total feed: $\quad 84.8$

Product Molar Selectivity (mole\%)

2-methyl-1-C3 alkene/C4 alkene: $\quad 87.0$

2-methyl-1-C4 alkene/C5 alkene: $\quad 70.0$

2-methyl-1-C5 alkene/C6 alkene: $\quad 49.3$

2-methyl-1-alkene/total alkene:

76.9

Conditions: $330{ }^{\circ} \mathrm{C}, 150 \mathrm{psig}, 5 \mathrm{~mol} \%$ alcohol in nitrogen, GHSV of $1050 \mathrm{~s} / \mathrm{kg}$-hr

Run \# 13033-1

Alcohol Conversion (\%): 84.5

\begin{tabular}{ll} 
Alcohol Feed & Mole\% \\
\cline { 2 - 2 } isobutanol & 58.17 \\
1-butanol & 7.04 \\
2-methyl-1-butanol & 14.88 \\
1-pentanol & 3.65 \\
2-methyl-1-pentanol & 11.75 \\
1-hexanol & 4.50
\end{tabular}

Feed Molar Selectivity (mole\%)

2-methyl-1-C3 alcohol/ C4 alcohol: 89.2

2-methyl-1-C4 alcohol/ C5 alcohol: 80.3

2-methyl-1-C5 alcohol/ C6 alcohol: 72.3

2-methyl-1-alcohol/ total feed: $\quad 84.8$
Product Molar Selectivity (mole\%)

2-methyl-1-C3 alkene/C4 alkene:

2-methyl-1-C4 alkene/C5 alkene:

2-methyl-1-C5 alkene/C6 alkene:

2-methyl-1-alkene/total alkene: 
TABLE 4.2.4: Effect of Methanol on the Product Spectrum

Conditions: $330{ }^{\circ} \mathrm{C}, 33 \mathrm{psig}$, GHSV of $1600 \mathrm{~s} / \mathrm{kg}-\mathrm{hr}$

\begin{tabular}{|c|c|c|c|c|c|c|c|}
\hline & & & \multicolumn{3}{|c|}{ Yield (basis: moles converted lsobutanol) } \\
\hline Run \# & Feed & $\begin{array}{c}\text { i-BuOH in N2 } \\
(\text { mole\%) }\end{array}$ & $\begin{array}{c}\text { i-BuOH Conv } \\
(\%)\end{array}$ & Isobutene & Linear Butene & Diisobutyl Ether & $\begin{array}{c}\text { Methyl isobutyl } \\
\text { Ether }\end{array}$ \\
\hline $13033-7$ & pure isobutanol & 5.1 & 92.2 & 0.944 & 0.049 & 0.002 & -- \\
\hline $13033-7$ & $\begin{array}{c}2 \text { moles isobutanol/ } \\
1 \text { mole methanol }\end{array}$ & 4.2 & 92.1 & 0.900 & 0.045 & 0.001 & 0.049 \\
\hline
\end{tabular}


TABLE 4.3.1: Effect of Impeller Speed on Reaction Rate

Conditions: $310{ }^{\circ} \mathrm{C}, 500 \mathrm{psig}, 5 \mathrm{Mol} \%$ Isobutanol in Nitrogen, GHSV $11500 \mathrm{sl} / \mathrm{kg}-\mathrm{hr}$

\begin{tabular}{|c|c|c|c|c|c|c|}
\hline \multicolumn{4}{|c|}{} & \multicolumn{2}{c|}{ Yield (basis: moles converted Isobutanol) } \\
\hline Run \# & $\begin{array}{c}\text { Stirrer Speed } \\
(\mathrm{RPM})\end{array}$ & $\begin{array}{c}\text { Isobutanol Conv } \\
(\%)\end{array}$ & $\begin{array}{c}\text { Isobutene Rate } \\
(\mathrm{gmole} / \mathrm{kg}-\mathrm{hr})\end{array}$ & Isobutene & Linear Butenes & Diisobutyl Ether \\
\hline $13033-14$ & 300 & 58.6 & 17.4 & 0.884 & 0.050 & 0.058 \\
\hline $13033-14$ & 600 & 67.2 & 18.5 & 0.906 & 0.052 & 0.034 \\
\hline $13033-14$ & 800 & 70.6 & 19.9 & 0.907 & 0.055 & 0.028 \\
\hline $13,033-14$ & 1200 & 74.3 & 20.8 & 0.913 & 0.058 & 0.022 \\
\hline $13033-14$ & 2000 & 73.3 & 20.6 & 0.909 & 0.057 & 0.024 \\
\hline
\end{tabular}


TABLE 4.3.2: Effect of Water on the Reaction Rate

Conditions: $290{ }^{\circ} \mathrm{C}, 150 \mathrm{psig}, 5 \mathrm{~mol} \%$ isobutanol in nitrogen, GHSV of $6000 \mathrm{~s} / \mathrm{kg}-\mathrm{hr}$

\begin{tabular}{|c|c|c|c|c|c|c|}
\hline & & & & \multicolumn{2}{|c|}{ Yield (basis: moles converted Isobutanol) } \\
\hline Run \# & Feed & $\begin{array}{c}\mathrm{i}-\mathrm{BuOH} \text { Conv } \\
(\%)\end{array}$ & $\begin{array}{c}\text { Isobutene Rate } \\
(\mathrm{gmole} / \mathrm{kg}-\mathrm{hr})\end{array}$ & Isobutene & Linear Butenes & Diisobutyl Ether \\
\hline $13033-14$ & pure isobutanol & 79.9 & 11.3 & 0.924 & 0.059 & 0.012 \\
\hline $13033-20$ & $\begin{array}{c}3 \text { moles isobutanol/ } \\
\text { 1 mole water }\end{array}$ & 72.1 & 9.4 & 0.924 & 0.055 & 0.016 \\
\hline $13033-20$ & $\begin{array}{c}3 \text { moles isobutanol/ } \\
\text { 2 moles water }\end{array}$ & 55.1 & 7.6 & 0.902 & 0.047 & 0.044 \\
\hline
\end{tabular}

Conditions: $310^{\circ} \mathrm{C}, 150 \mathrm{psig}, 5 \mathrm{~mol} \%$ isobutanol in nitrogen, GHSV of $6000 \mathrm{~s} / \mathrm{kg}-\mathrm{hr}$

\begin{tabular}{|c|c|c|c|c|c|c|}
\hline Run \# & Feed & $\begin{array}{c}\mathrm{i}-\mathrm{BuOH} \text { Conv } \\
(\%)\end{array}$ & $\begin{array}{c}\text { Isobutene Rate } \\
(\mathrm{gmole} / \mathrm{kg}-\mathrm{hr})\end{array}$ & Isobutene & Linear Butenes & Diisobutyl Ether \\
\hline $13033-14$ & pure isobutanol & 95.5 & 13.1 & 0.919 & 0.079 & 0.000 \\
\hline $13033-18$ & $\begin{array}{c}3 \text { moles isobutanol/ } \\
1 \text { mole water }\end{array}$ & 86.3 & 11.5 & 0.926 & 0.067 & 0.004 \\
\hline $13033-20$ & $\begin{array}{c}3 \text { moles isobutanol// } \\
\text { 2 moles water }\end{array}$ & 77.7 & 11.1 & 0.923 & 0.062 & 0.009 \\
\hline
\end{tabular}


Appendix I: Literature.Survey 
Memorandum

To: $\quad$ T.H. Hsiung

Dept./Loc.: $\quad$ PG\&E Research/Iron Run

From: B. E. Latshaw

Dept./Ext.: $\quad$ PG\&E Research/3995

Date: 24 March 1992

Subject: Literature Report and Related Information - Dehydration of Isobutanol to Isobutylene

cc:
D. M. Brown
R.P. Underwood
T. W. Copeman
F. J. Waller
D. M. Herron

\section{SUMMARY:}

A thorough literature search was performed to obtain information on the dehydration of isobutanol to isobutylene. Because of the limited information available on this particular reaction, the search strategy was broadened to the dehydration of alcohols to alkenes with special interest in obtaining information on the catalyst, reactor type, and reaction conditions used in the work. Work on the dehydration of ethanol was not included because of the lack of correlation between the mechanisms followed for the dehydration of ethanol and isobutanol, i.e. isomerization is an important factor for isobutanol.

A number of catalysts have been used in the literature to study the dehydration of alcohols to alkenes. These catalysts can be divided into four groups: aluminas and modified aluminas, zeolites, metal phosphates and sulfates, and oxides. Alumina has been the most widely used dehydration catalyst and has been implemented into at least two pilot plant operations for the dehydration of isoamyl alcohol. From this information, it appears that the catalysts best suited for the dehydration of isobutanol would be a treated alumina or possibly just a less pure gamma-alumina, a phosphate or sulfate modified zirconia, or a calcium phosphate. These catalysts were specified because of their inactivity for producing the butanol isomers during the course of the reaction. The reaction conditions obtained from the literature indicate temperatures ranging from about 300 to $400 \mathrm{C}$ and pressures around atmospheric. The thermodynamic calculations for the dehydration of isobutanol show that the reaction is endothermic and therefore, requires the higher temperatures in order to obtain a reasonable conversion. According to the literature, the majority of the work has been performed in packed bed reactors; however, a limited amount of literature has been found which describes a process for the dehydration of tertiary-butyl alcohol utilizing a slurry phase reactor.

Attempts are being made to obtain more information on this matter. It was difficult to make any reasonable conclusions in regard to the catalyst life expectancy. It appears that the occurrence of side reactions which lead to carbon formation on the catalyst surface should be inhibited by the absence of strong acid sites. 


\section{INTRODUCTION:}

The dehydration of isobutyl alcohol to isobutene is an important reaction because of the use of isobutene as a feed stock for the production of methyl tertiary butyl ether (MTBE). Since it has been shown that isobutyl alcohol can be successfully produced from coal derived syngas, the next step to the production of MTBE is to develop the dehydration process of isobutanol. A literature review of the dehydration of isobutyl alcohol has been conducted; however, there does not appear to be a large amount of information on this specific reaction. In regard to this fact, an expanded view of the literature was undertaken to obtain any available information on the dehydration of alcohols with a similar carbon structure, i.e. 2methyl-1-alkanols. The desired product of the dehydration reaction is isobutene (2-methyl-1olefin), but it is quite possible to obtain all of the butene isomers. Thus, a catalyst and reaction conditions need to be determined which will give isobutene as the primary product and inhibit to a large extent any isomerization from occurring.

\section{DEHYDRATION REACTION:}

Since the dehydration mechanism is undoubtedly a function of both the structure of the catalyst as well as the structure of the alcohol, a single reaction mechanism cannot be established. According to the literature though, alumina appears to have been the most widely used dehydration catalyst and therefore, the most widely studied. In order to obtain some insight into the reaction mechanism, information will be presented on the dehydration of alcohols over alumina with specific reference to isobutanol when applicable.

In general, dehydration of alcohols occurs over an acid catalyst. On alumina, two different acid sites are present, namely Lewis and Bronsted. The Bronsted acid sites result from the surface hydroxyl groups and are considered on average to be weakly acidic. ${ }^{1}$ The Lewis acid sites result from the incomplete coordination of surface aluminum atoms by surrounding oxygen atoms. ${ }^{2}$ These incompletely coordinated aluminum atoms arise due to removal of the surface hydroxyl groups through condensation with adjacent hydroxyl groups and evolution of water. This removal of surface water also creates Lewis base sites which are oxygen ions. ${ }^{2}$

The adsorption of the alcohol to the surface occurs through hydrogen bonds between the alcohol hydroxyl group and the surface hydroxyl group and oxide ion. ${ }^{3}$ At this point it is believed that the reaction scheme is slightly different depending on the structure of the alcohol. ${ }^{3}$ The schemes proposed are based on the fact that the alumina contains only weak to moderate acidic sites and thus the reaction can be compared to dehydration in dilute aqueous acids. Taft et al. ${ }^{4}$ found that tertiary alcohols abstract the hydrogen from the acid forming a carbonium ion basically free of covalently bonded water. Less stable secondary carbonium ions were found to be stabilized by specific interaction with two water molecules indicating a more concerted mechanistic character. ${ }^{5}$ Dostrovsky and Klein 6 determined that oxygen exchange with primary alcohols in dilute acid solution occurred through a concerted mechanism and not by way of a carbonium ion.

The mechanism of dehydration for a primary alcohol such as isobutanol occurs through abstraction of the $\beta$-hydrogen of the alcohol by the surface oxide ion with subsequent cleavage of the alcohol hydroxyl group forming water and a surface oxide ion. ${ }^{7}$ This 
mechanism has been concluded through a number of experimental observations. Knozinger 8 found that if aluminum hydroxide (which exposes solely hydroxyl groups at the surface) is used as the catalyst, there is complete inactivity for the dehydration of tertiary butanol. However, if the catalyst is heated such that the trihydroxide losses water to form the monohydroxide resulting as well in the formation of oxygen and aluminum ions, the dehydration reaction is observed. This indicates that other surface sites must take part in the formation of olefins. It has also been shown that selective poisoning of the Lewis acid sites by pyridine does not significantly alter the dehydration of alcohols. ${ }^{8}$ Roca et al. ${ }^{9}$ on the other hand have verified the participation of basic sites by poisoning experiments with tetracyanoethylene.

The rate limiting step during the dehydration reaction has been studied by Knozinger and Scheglila. 10 By examining primary kinetic isotope effects for the dehydration of tertiary, secondary, and iso-butanol in the gas phase, they determined that deuteration of the hydroxyl group does not cause an isotope effect and thus excludes the hydroxyl proton from any rate determining participation. This result also excludes the desorption of water as being rate determining at least in the case where the water is adsorbed by hydrogen bonds to hydroxyl or deuteroxyl surface groups. The kinetic isotope effect for $\beta$-carbon deuteration was greatest for the primary isobutanol and least for tertiary butanol. At temperatures below $200 \mathrm{C}$, they believe that all three alcohols exhibit $\mathrm{E}$ 2-like behavior, but as the temperature is raised the mechanism for tertiary alcohol shifts to E 1-like. An E2 reaction mechanism involves a single transition state in which the base pulls a proton away from the carbon while the hydroxide ion simultaneously departs allowing the double bond to form. The E1 reaction mechanism however, involves two steps whereby the alcohol undergoes cleavage of the hydroxyl ion with formation of a carbonium ion. This carbonium ion then loses a proton to the base to form the alkene. The results presented by Knozinger and Scheglila 10 reaffirm the mechanisms postulated earlier by Pines and Manassen ${ }^{3}$ for the dehydration of tertiary, secondary, and primary alcohols on weak acid sites.

The mechanism for dehydration is not the same for all alcohols. Arai et al. ${ }^{11}$ found while studying the dehydration of ethanol that at low temperatures $(\mathrm{T}<135 \mathrm{C})$ the major product desorbed from the alumina catalyst was diethyl ether. At higher temperatures they found a decrease in ether formation and an increase in ethylene formation. They postulated that the ether was formed by reaction of two nearby surface ethoxides. The presence of the surface ethoxides was verfied through IR studies. Knozinger and Kohne 12 however, found ethylene to be produced only above $250 \mathrm{C}$ during ethanol dehydration. They believed that the ethylene was formed directly from dehydration as well as through decomposition of the ether. As the temperature was increased, the ether composition decreased significantly. The difference between the two findings is most likely a result of slight variations in the catalyst as well as the fact that Knozinger and Kohne performed continuous operation while Arai et al. performed batch experiments. Knozinger and Kohne proposed that the ether formed by reaction of an adsorbed alcohol with a surface ethoxide. They found a similar behavior for straight-chained alcohols up to n-hexanol; however, the temperature range in which ether could be isolated as the only product decreased with increasing chain length. They were also unable to detect any ether as a dehydration product of the branched butanols. This appears to be due to the instability of the alkoxide of the branched butanols. Surface alkoxides were 
detected by IR spectroscopy for the ether-forming alcohols whereas no surface alkoxide could be detected for the olefin-forming alcohols. ${ }^{2}$ Thus it appears that the dehydration of isobutanol over alumina occurs through the concerted mechanism proposed by Pines and Haag. ${ }^{7}$

The E 2-like mechanism for dehydration of primary and secondary alcohols has been fairly well accepted. It is the transition state during the dehydration of the alcohol which appears to still be in question. Pillai and Pines ${ }^{13}$ as well as Kibby et al. ${ }^{14}$ had determined that alcohol dehydration on $\gamma$-alumina occurs as the trans-elimination of the elements of water. It has also been found that when formation of the cis- and trans-isomers is possible, the cis-olefin forms preferentially. $2,3,7$ From the results of selectivity studies, Schwab and Schwab-Agallidis 15 proposed that the dehydration proceeded in pores and crevices of the catalyst. This view was also taken by Pines and Manassen ${ }^{3}$ and Pines and Pillai ${ }^{16}$ on the assumption that acidic and basic sites would be located on opposite sides of the pore. This scheme would indicate a reaction controlled by diffusion which has never been observed for alumina. Knozinger et al. 17 proposed that the alcohol molecule adsorbed onto the surface exercises as a whole vibrational motions, such that the $\mathrm{O}-\mathrm{C}_{\alpha}-\mathrm{C}_{\beta}-\mathrm{H}$ plane inclines to the surface. This would lead to the sterically more favorable conformation where bulky substituents are farthest away from the surface leading to preferential cis formation. Sedlacek and Kraus 18 have determined from quantum chemical modelling using the adsorbed state proposed by Knozinger et al. 17 that anti-elimination is the more energetically favorable path on the alumina surface. Sedlacek ${ }^{19}$ was also able to explain the significant preference for cis-olefin formation by taking into account geometric and electronic factors.

It appears that an E2 reaction mechanism is followed for the dehydration of isobutanol on alumina. According to Pines and $\mathrm{Haag}^{7}$ as well as Knozinger and Scheglila 10 , it appears that pure $\beta$-H elimination occurs to form the primary dehydration product. This olefin product may then readsorb onto the strong acid sites where it may undergo isomerization. It is also assumed that oligermization occurs on these strong acid sites when the olefin is readsorbed. This most likely can be avoided by either running at lower conversions so as to avoid the olefin concentration from building up to a point where the probability of readsorption becomes high or by selectively poisoning the strong acid sites. Running at lower conversions was proposed due to the observed increase in isomer composition with increased contact time. It is also possible that at higher temperatures $(\mathrm{T}>300 \mathrm{C}) \gamma-\mathrm{H}$ elimination may occur with sebsequent migration of the hydrogen or methyl group forming a number of isomers. 20

\section{DEHYDRATION CATALYSTS AND REACTION CONDITIONS:}

The information presented in this section has been divided into subsections according to the type of catalyst used for the dehydration reaction, namely: aluminas, zeolites, metal phosphates and sulfates, and oxides. According to the literature, alumina is a widely used catalyst for the dehydration of alcohols. Because of this, the information regarding alumina has been organized according to the structure of the alcohol (mixed alcohols, 2-methyl-1alkanols, and isoamyl alcohol) used in the reaction so as to provide only that information which is most relavent in regard to the dehydration of isobutanol. The type of reactor and reaction conditions used by the various authors is also discussed as well as any pertinent information with respect to catalyst fouling and competitive side reactions. 


\section{A. ALUMINA:}

The surface of alumina contains both acidic and basic sites. These acidic sites range in strength from strong to weak. Pines and Pillai 21 found that by modifying alumina with ammonia it was possible to produce relatively pure primary $\beta-\mathrm{H}$ dehydration products from a number of alcohols such as 3,3-dimethyl-1-butanol without significant quantities of their isomers. Pines and Haag ${ }^{7}$ found that by incorporating small amounts of sodium $(0.001 \%$ $1.5 \%$ weight) into the alumina, the activity.for dehydration decreased as the sodium content increased, however the more significant finding was that the activity for isomerization decreased substantially. According to the findings of Pines and Haag, 22 aluminas without alkali contain a substantial number of strong acid sites; aluminas prepared from alkali aluminates contain a large number of weak acid sites; and aluminas impregnated with alkalibase contain a reduced number of acidic sites without an appreciable change in the strength distribution. When the alumina is impregnated with alkali base, it is quite possible that if the base concentration is low and the solute is nonselectively adsorbed, the solution may be depleted of solute before the pores are filled. This would lead to the nonpreferential decrease in acid sites. The fact that both isomerization and dehydration decrease on impregnation of an alkali-base could result from adsorption of the base on the aluminum ions as well as sodium exchange with the surface hydroxyl protons.

\section{MIXED ALCOHOLS:}

Several patents have been issued which describe the use of an alumina catalyst for dehydration of alcohols. Hofstadt et al. ${ }^{23}$ suggested using an alumina catalyst impregnated with $\mathrm{LiOH}, \mathrm{KOH}$, or $\mathrm{NaOH}$ with alkali metal concentrations of 0.1 to $1.5 \mathrm{wt} . \%$. for the dehydration of $\mathrm{C}_{4}-\mathrm{C}_{6}$ alcohols produced from a synthesis gas. An undisclosed alumina catalyst was proposed by Reichl 24 for the dehydration of a mixed alcohol stream produced from synthesis gas. Reichle 25 used a high-purity (alkoxide derived) $\gamma$-alumina with low impurity levels impregnated with metal nitrates for the dehydration of normal alcohols to high-purity $\alpha$-olefins. The metal ion consisted of $\mathrm{Ba}, \mathrm{K}, \mathrm{Rb}$, or $\mathrm{Cs}$ with a concentration on the doped catalyst of $0.05-2.0 \mathrm{wt}$.\%. Reichle suggests.a low impurity alumina most likely so that the poisoning can be controlled solely through impregnation with the metal nitrates. Alvila et al. ${ }^{26}$ proposed the use of a commercially available (Harshaw) aluminum oxide catalyst for the dehydration of a stream of mixed butanols. The proportion of straightchained: branched alcohols was 1.3:1. The preparation of $\alpha$-olefins in high selectivity from fatty alcohols was described by Voeste and Buchold. 27 In their process, they used a $\gamma$ alumina doped with $\mathrm{NH}_{3}$ to dehydrate the alcohols while inhibiting any isomerization. Min'ko and Timofeev 28 described a pilot facility which uses an aluminum oxide catalyst treated with $0.25 \% \mathrm{KOH}$ for the dehydration of several normal alcohols and isoamyl alcohol. They found that using this catalyst they could produce 1-hexene with $90-95 \%$ selectivity.

The above mentioned dehydration reactions were carried out in packed bed reactors. The reaction conditions used were temperatures ranging from $300-500 \mathrm{C}$ and pressures ranging from 0.5 to 1 atmosphere. The LHSV (liquid hourly space velocity) were on the order of 1-4 liters of alcohol feed per liter of catalyst per hour. These conditions were utilized to obtain a product stream which consisted of a high selectivity for the primary olefin. 


\section{ISOBUTANOL OR 2-METHYL-1-ALKANOLS:}

The dehydration of isobutanol was performed by Kim et al. ${ }^{29}$ using an aluminum oxide catalyst doped with $1.5-2 \% \mathrm{Ca}\left(\mathrm{H}_{2} \mathrm{PO}_{4}\right)_{2}$ to inhibit skeletal isomerization. The reaction was carried out at temperatures of 300-400 C and GHSV of 300-2500.providing contact times of 5 seconds or less. They found that the yield of isobutylene could be raised from $80 \%$ to $96 \%$ by modifying the alumina catalyst. It was determined by Kim et al. 30 that by carrying out the reaction in a fluidized bed reactor they were able to obtain results which were similar to those obtained in a fixed bed reactor.

Several patents were issued on the use of modified alumina as a dehydration catalyst for 2 methyl-1-alkanols whereby the modified alumina produces a higher yield of the 2-methyl-1olefin. Specific increases in the product selectivity or yield were not always stated.

Shioyama ${ }^{31}$ proposed using a zinc aluminate catalyst which is prepared by mixing equimolar portions of $\gamma$-alumina and.zinc oxide in a ball mixer and then processed to produce the final physical form. Results were obtained which were similar to those using a sodium modified alumina, but the zinc aluminate had a wider temperature range over which the maximum olefin yield was produced. He also determined that the zinc aluminate was more effective than simple mixtures of zinc oxide and alumina. Resofszki et al. 32 studied the dehydration reaction using a solid solution of iron oxide and aluminum oxide prepared by spraydecomposing the aqueous solution of the nitrates at $500 \mathrm{C}$. They found that the addition of 110 mole\% of iron oxide caused a sharp decrease in the acidity of the catalyst as well as total inactivity for skeletal isomerization. A zinc aluminate catalyst was also suggested by John 33 . However, John used a $\gamma$-alumina which was impregnated with an aqueous zinc salt solution producing an alumina carrier with zinc aluminate on its surface. With this zinc aluminate he was able to obtain 1-pentene with better than $90 \%$ selectivity. Drake ${ }^{34}$ proposed the use of an alumina treated by soaking it in a solution of an organic carboxylic acid and a diluent to produce 2-methyl-1-butene with a selectivity of $85-95 \%$. The amount of carboxylic acid used in the treatment of the silica can range from about $0.01-0.1 \mathrm{~g}$ per gram of alumina. An alumina catalyst which was modified simply by heat treatment was utilized by Drake ${ }^{35}$ for the dehydration of branched alcohols. According to his process, a mixed boehmite (aluminum oxide-hydroxide)/chi-alumina catalyst is heated to about $550 \mathrm{C}$ for several hours under a stream of nitrogen. The result is a relatively pure chi-alumina which shows high selectivities for the primary dehydration products without subsequent isomerization.

The above discussed catalysts were utilized for the dehydration reaction of branched alcohols to their corresponding olefins. The reactions were carried out in fixed bed reactors over a temperature range of 250-450 $\mathrm{C}$ and pressures of 1-7 atmospheres. The alcohol was introduced to the reactor at a.WHSV ranging from 0.1 to 20 grams of alcohol feed per gram of catalyst per hour along with an inert carrier gas flow of 40-50 liters per hour.

\section{ISOAMYL ALCOHOL:}

Two studies have been performed on the dehydration of 3-methyl-1-butanol to provide information for optimal pilot plant operation. The studies were concerned with determination of a catalyst and reaction conditions which would produce a product stream with a high yield of 3-methyl-1-butene and low concentrations of product isomers. Drake et al. ${ }^{36}$ of the Phillips Petroleum Co. found that a base treated gamma alumina inhibited the formation of 
product isomers. The pilot plant utilized a packed bed reactor operating at about $300 \mathrm{C}$ core temperature and a pressure of approximately 3 atmospheres. The alcohol feed was varied from 1.0-1.5 LHSV resulting in a product yield of greater than $85 \% 3$-methyl-1-butene. It should be noted that the product yield dropped to about $70-75 \%$ when the unit was run on a lower purity feed. Nitrogen was used as a carrier gas for the alcohol feed. Early tests on the catalyst life revealed that approximately 1000 pounds of 3-methyl-1-butene were produced per pound of catalyst. The second pilot plant operation was described by Timofeev et al. 37 Their process relied on a $\gamma$-alumina impregnated with $0.25 \mathrm{wt} . \% \mathrm{KOH}$. The dehydration was carried out at approximately $380 \mathrm{C}$ with an alcohol feed of 4 liters per liter of catalyst per hour. Under these conditions, they were able to obtain a product selectivity of about $70 \%$.

\section{B. ZEOLITES AND AMORPHOUS ALUMINOSILICA:}

Several experimental studies have been carried out in which silica-alumina catalysts of various compositions have been used for the dehydration of isobutyl alcohol. Weisz and coworkers 38 looked at the molecular shape selective dehydration of the isomeric butanols on Ca-zeolites 5A and 10X. They found that approximately $100 \%$ conversion of the isobutanol could be obtained at $300 \mathrm{C}$ on the $10 \mathrm{X}$ catalyst, but that negligible conversion occurred for the dehydration on the 5A. This implies that the isobutanol is excluded from the crystal interior of the zeolite 5A. Normal butanol was dehydrated to about the same extent on both. No analysis of the butene products was presented. Amorphous aluminosilica gels and zeolites having chemical compositions corresponding to that of type $X$ zeolite were used for the dehydration of isobutanol by Levchuk and Dzis'ko. 39 Running the reaction at $310 \mathrm{C}$ they determined that the conversion could be increased by lowering the space velocity; however, they also found a corresponding increase in the concentration of polymeric products. Over the range of space velocities used, normal butene isomers constituted approximately 20-30\% of the product stream. Samples with low sodium content were found to decrease in activity quite rapidly with time. This could result from oligomer formation within the pores and their inability to diffuse out. Their results showed that at low conversions the rate of dehydration as well as isomerization were independent of the alcohol conversion, but both became dependent with increasing conversion. They also found a linear decay of both rates with increasing sodium content.

Makarova et al.40,41 performed limited experiments on the dehydration of isobutanol on $\mathrm{H}$ ZSM-5. Their reaction conditions were $100-150 \mathrm{C}, 1$ atmosphere pressure, and low conversions $(<10 \%)$ such that the reaction was zero order with respect to isobutanol. They did not provide an analysis of the product stream butene isomer composition. IR studies were performed to determine a possible reaction scheme. They believe that the reaction occurs through formation of a surface alkoxide which reacts with the alcohol to form a hydrogen bonded ether. This ether, restricted from diffusing out of the channel intersection, decomposes to form a butene and an alcohol molecule. Under conditions of higher conversion or interupted alcohol flow, they found a significant increase in oligomer formation. They postulate this to arise from interaction of the butene with the highly reactive alkoxide as the butene is diffusing through the pore. 


\section{METAL PHOSPHATES AND SULFATES:}

Hofstadt et al. ${ }^{23}$ suggested using either an aluminum phosphate or a calcium phosphate as the dehydration catalyst for a mixed alcohol stream. However, they stated that they preferred using an aluminum oxide or calcium phosphate, $\mathrm{Ca}_{3}\left(\mathrm{PO}_{4}\right)_{2}$, as the dehydration catalyst so that secondary reactions (condensation and polymerization) could be suppressed. A phosphorous rich hydroxyapatite catalyst $\mathrm{Ca} 9\left(\mathrm{HPO}_{4}\right)\left(\mathrm{PO}_{4}\right)_{5} \mathrm{OH}$ was investigated by Kibby et al. 14,42 for the dehydration reaction of several alcohols. They found that upon dehydration of isobutanol they were able to obtain about $90 \%$ isobutene with $10 \%$ normal butenes. The reaction was carried out at 300-400 C and low conversions such that the reaction was zero. order with respect to the alcohol concentration. The calcium rich form of this catalyst, $\mathrm{Ca}{ }_{10}\left(\mathrm{PO}_{4}\right)_{6}(\mathrm{OH})_{2}$ makes it a suitable catalyst for alcohol dehydrogenation. Brett et al. 43 states that the dehydration reaction is catalyzed by the acidic phosphate hydrogen. Clearfield and Thakur ${ }^{44}$ studied the dehydration of cyclohexanol using a zirconium phosphate catalyst. They found the catalyst to be very selective toward the dehydration reaction with little activity for isomerization or dehydrogenation. The reaction was performed over a temperature range of 300-400 C and they determined that the dehydration data fit a first order rate equation. Clearfield and Thakur also proposed that the primary active sites are the monohydrogen phosphate protons with a possible secondary active site being of the Lewis acid type.

A sulfate modified zirconia catalyst was proposed by Klier et al. 45 as a possible catalyst for the dehydration of isobutanol. They found that when a mixture of isobutanol and methanol were charged to the reactor, the catalyst proved to be efficient and highly selective for the production of isobutene with methanol dehydration suppressed. However, no work has been done to study solely the dehydration reaction of isobutanol with this catalyst. Thorton and Gates 46 studied the dehydration of isobutyl alcohol using a poly(styrene-divinylbenzene) matrix containing sulfate groups as the catalyst. The reaction was performed at approximately $100 \mathrm{C}$ giving a mixture of butene isomers and isobutane formation at low substrate partial pressures. The reaction was accompanied by about a $20 \%$ decrease in rate over tens of hours of operation resulting from a catalyst which became covered in a dark, sticky tar. The catalyst deactivation was not observed with either isopropyl or sec-butyl alcohols. According to Knozinger, 20 it is believed that the dehydration of alcohols on ion exchange resins occurs through oxonium or carbonium ion intermediates.

\section{OXIDE CATALYSTS:}

Schwab and Schwab-Agallidis ${ }^{15}$ studied the dehydration of ethanol to ethylene on a number of oxide catalysts $\left(\mathrm{ZnO}, \mathrm{TiO}_{2}, \mathrm{Cr}_{2} \mathrm{O}_{3}, \gamma-\mathrm{Al}_{2} \mathrm{O}_{3}, \mathrm{CeO}_{3}\right.$, and $\left.\mathrm{ThO}_{2}\right)$ and found that the product stream from the alumina and thoria catalysts consisted of better than $90 \%$ ethylene. Canesson and Blanchard 47 found that on dehydration of secondary alcohols over thoria a high selectivity was shown for the formation of the 1-alkene. They proposed that the reaction proceeds as a syn-elimination occurring by an $\mathrm{E} 1 \mathrm{cB}$ pathway. A reaction occurring by an $\mathrm{E} 1 \mathrm{cB}$ mechanism involves the loss of a proton from the alcohol to the base with formation of a negatively charged carbanion which then losses the hydroxide ion in a separate step to yield the alkene. Studying the possibility of $\gamma-\mathrm{H}$ eliminations from certain alcohols during the course of dehydration at 300-350 C, Siddhan and Narayanan 48 found that thoria showed very little propensity for $\gamma$-eliminations whereas the products obtained from alumina doped 
with sodium exhibited a significant contribution from $\gamma$-eliminations. It should also be noted that alumina exhibited a much higher activity for the dehydration of alcohols such as 3methyl-1-pentanol than did thoria.

The dehydration of isobutanol was observed by Kotsarenko and Malysheva 49 using binary compounds of the type $a \mathrm{M}_{\mathrm{m}} \mathrm{O}_{\mathrm{n}}(1-a) \mathrm{SiO}_{2}$, where $\mathrm{M}=\mathrm{Al}, \mathrm{Ga}, \mathrm{Zr}, \mathrm{Be}$, and $\mathrm{Y}$ as catalysts. The reactions were carried out over the temperature range of $275-350 \mathrm{C}$ using a circulation-flow method with a circulation rate of 800 liters per hour. They found that with increasing alcohol concentration, the order of the reaction changed from first to zero on all of the catalysts. The results of their experiments showed that isobutylene made up about $60-70 \mathrm{~mole} \%$ of all the butylenes formed for all of the binary compounds. They also found that a gamma-alumina sample produced about $95 \%$ isobutylene. No indication as to the chemical composition of the alumina was given. Results for the isomerization of an isobutylene feed showed that alumina and the binary compounds of $\mathrm{Be}$ and $\mathrm{Y}$ were inactive for this reaction. From their results they concluded that the dehydration reaction of isobutanol on the binary oxides occurs through a carbonium ion mechanism leading to a high rate of normal olefins. Davis ${ }^{50}$ looked at the dehydration of branched secondary and tertiary alcohols over aluminum and molybdenum oxide at temperatures of 180-275 C. For certain alcohols (i.e. 2,2-dimethyl-3pentanol) it was found that molybdena produced a significant quantity of products which resulted from skeletal isomerization whereas the alumina did not. Davis postulated that the skeletal isomerization resulted from the dehydration step and not from a secondary reaction. The acidity and basicity of a number of metal oxides were investigated by Gervasini and Auroux. 51 The catalysts were tested for the decomposition of isopropanol to propene and acetone. While it is difficult to make any conclusions about the use of these catalysts for the dehydration of isobutanol, there are a few points that should be mentioned. They found that the oxides of Mo and $\mathrm{W}$ gave propene in the temperature range of $400-430 \mathrm{~K}$ while those of $\mathrm{Al}, \mathrm{Nb}, \mathrm{Ta}, \mathrm{Ti}$, and $\mathrm{Zr}$ were active in the temperature range of $430-490 \mathrm{~K}$. This would indicate that $\mathrm{MOO}_{3}$ and $\mathrm{WO}_{3}$ possess stronger acid sites than the other oxides. However, it should be noted that $\mathrm{MoO}_{3}$ and $\mathrm{WO}_{3}$ also gave acetone, an undesired product in the dehydration reaction, at lower temperatures.

\section{DEHYDRATION IN A SLURRY REACTOR:}

Some work has been undertaken in the use of liquid phase reaction technology for the dehydration of tertiary butyl alcohol (TBA). A patent issued to Dockner and Krug 52 describes a process in which a feed of TBA and nitrogen are passed into a packed quartz tube filled with vacuum gas oil (boiling point $400 \mathrm{C}$ ) containing about $5 \%$ resin catalyst. The reaction is carried out at $205 \mathrm{C}$ giving $97 \%$ yield isobutene. Abraham and Prescott ${ }^{53}$ discuss the processes utilized by several companies for the dehydration of tertiary butanol to isobutene. According to the authors, Cities Service dissolves the TBA and a p-toluene sulfonic acid catalyst in a reaction medium of xylene. The isobutylene is removed as a gas and the water separates out and is removed continuously. Nippon, Asashi, and Maruzen use powdered resin catalysts in a stirred reactor for their processes. It must be noted that the patents referenced by Abraham and Prescott could not be located as cited in their article. 


\section{THERMODYNAMICS:}

Calculations were made to determine the heat of reaction as well as the change in the Gibbs free energy upon dehydration of isobutanol to form isobutene and water. The heat of reaction at $298 \mathrm{C}$ and 1 atmosphere is $8.16 \mathrm{kcal} / \mathrm{mole}$ and the Gibbs free energy change is -0.64 $\mathrm{kcal} / \mathrm{mole}$. The entropy change was determined to be $24.1 \mathrm{cal} / \mathrm{mole} \mathrm{K}$. The heat of reaction was also calculated at $300 \mathrm{C}$ with its value being $8.75 \mathrm{kcal} / \mathrm{mole}$. Thus, the reaction is endothermic and will require the process to be run at elevated temperatures in order to obtain good conversions. Klotz ${ }^{54}$ performed some equilibrium calculations for the dehydration reaction and found that the equilibrium favors almost $100 \%$ conversion in the temperature range of $100-300 \mathrm{C}$ and that it was only slightly shifted toward isobutanol at elevated pressures up to 52 atmospheres. The adiabatic temperature drop for the reaction was also determined by $\mathrm{Klotz}^{55}$. He found that at inlet conditions of 1 atmosphere and $200 \mathrm{C}$ the temperature dropped to $77 \mathrm{C}$ for $100 \%$ conversion while for an inlet temperature of $300 \mathrm{C}$ the temperature dropped to $130 \mathrm{C}$. The temperature drop for the low inlet condition is controlled by the condensation of water in the reactor.

\section{CONCLUSIONS:}

From the information that has been gathered on the dehydration of alcohols, and in particular 2-methyl-1-alkanols, it appears that the catalysts best suited for the dehydration of isobutanol would be a treated alumina or possibly just a less pure gamma-alumina, a phosphate or sulfate modified zirconia, or a calcium phosphate. The literature indicates that the reaction should be run at temperatures ranging from about 300 to $400 \mathrm{C}$ and at pressures around atmospheric. From the thermodynamics it is seen that the reaction is endothermic and requires the higher temperatures in order to obtain reasonable conversion of the isobutanol. According to the literature, the majority of the work has been performed in packed bed reactors; however, some of the TBA dehydration processes indicate that a slurry phase reactor should provide the proper conditions for an efficient and economic isobutanol dehydration process. It was difficult to make any reasonable conclusions in regard to the catalyst life expectancy. It appears that a catalyst which does not possess strong acid sites such that isomerizations do not occur should also inhibit other side reactions from occurring which lead to carbon formation on the catalyst surface.

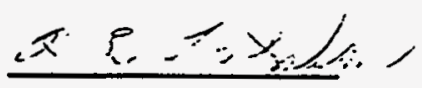

B. E. Latshaw

\section{REFERENCES:}

1. E. P. Parry, J. Catal., 2 2371 (1963).

2. H. Knozinger, Angew. Chem. Intern. Ed., I, 791 (1968).

3. H. Pines and J. Manassen, Advan. Catal., 16, 49 (1966).

4. R. W. Taft Jr., E. L. Purles, P. Riesz, and C. A. De Fazio, J. Am. Chem. Soc., 77, 1584 (1955).

5. Manassen, J., and F. S. Klien, Chem. Soc. (London) Spec. Publ., 14 4203 (1960).

6. I. Dostrovsky and F. S. Klien, J. Chem. Soc., 4401 (1955).

7. H. Pines and W. O. Haag, J. Am. Chem. Soc., $\underline{83}, 2847$ (1961). 
8. H. Knozinger; Angew. Chem., 80, 778 (1968).

9. F: Fiqueras Roca, L. de Mourges, and Y. Tranbouze, J. Catal., 14, 107 (1969).

10. H. Knozinger and A. Scheglila, J. Catal., 17, 252 (1970).

11. H. Arai, J. Take, Y. Saito, and Y Yoneda, J. Catal., 9, 146 (1967).

12. H. Knozinger and R. Kohne, J. Catal., 5, 264 (1966).

13. C. N. Pillai and H. Pines, J. Am. Chem. Soc., 83 ; 3274 (1961).

14. C. Kibby, S. Lande, and W. Hall, J. Am. Chem. Soc., 94, 214 (1972).

15. G. Schwab and E. Schwab-Agallidis, J. Am. Chem. Soc., 71, 1806.(1949).

16. H. Pines and C. N. Pillai, J. Am. Chem. Soc., 83, 3270 (1961).

17. H. KInozinger, H. Buhl, and K. Kochloefl, J. Catal., 24, 57 (1972).

18. J. Sedlacek and M. Kraus, React. Kinet. Catal. Lett., 2, 57 (1975).

19. J. Sedlacek, J. Catal., 57, 208 (1979).

20. H. Knozinger, "The Dehydration of Alcohols" in "The Chemistry of the Hydroxyl

Group," S. Patai, ed., Interscience Publishers, 1971.

21. H. Pines and C. Pillai, J. Am. Chem. Soc., $\underline{82}$ 2401 (1960).

22. H. Pines and W. Haag, J. Am. Chem. Soc., 82,2471 (1960).

23. C. E. Hofstadt, M. Schneider, and K. Kochloefl, U.S. Pat. 4,398,050 (1983).

24. E. Reichl, U.S. Pat. 4,534,772 (1985).

25. W. Reichle, Res. Discl., 283, 717, Union Carbide Corp. (1987).

26. L. Alvila, T. Pakkanen, O. Krause, and M. Joutsimo, U.S. Pat. 4,777,320 (1988).

27. T. Voeste and H. Buchold, DE Pat. 3,915,493 (1990).

28. T. Min'ko and A. Timofeev, Khim. Prom-st. (Moscow), (10), 595 (1986).

29. S. Kim, H. Chang, J. Che, and J. Rim, Choson Minjujuui Inmin Konghwaguk Kwahagwon Tongbo, 26 (6), 303 (1978).

30. S. Kim, H. Chang, J. Je, C. Lin, Choson Minjujuui Inmin Konghwaguk Kwahagwon Tongbo, (6), 47 (1979).

31. T. Shioyama, U.S. Pat. 4,260, 845 (1981).

32. G. Resofszki, J. Juhasz, T. Kovacs, and B. Jover, Geterog. Katal., 5th, Pt.1, 273 (1983).

33. C. S. John, GB Pat. 2,181,070 (1987).

34. C. Drake, U.S. Pat. 4,602,119 (1986).

35. C. Drake, U.S. Pat. 4,529,827 (1985).

36. C. Drake, M. Martinovich, and S. Marwil, Chem. Eng. Prog., 81, 52 (1985).

37. A. Timofeev, L. Romanchenko, I. Pis'man, and T. Min'ko, Prom-st. Kauch., (6), 6 (1982).

38. P. B. Weisz, V. J. Frillette, R. W. Maatman, and E. B. Mower, J. Catal., 1, 307 (1962).

39. V. S. Levchuk and V. A. Dzis'ko, Kinet. Katal., 10 (6), 1289 (1969).

40. M. Makarova, C. Williams, V. Romannikov, K. I. Zamaraev, and J. M. Thomas, J. Chem. Soc. Faraday Trans., $\underline{86}$ (3), 581 (1990).

41. C. Williams, M. Makarova, L. Malysheva, E. Paukshtis, K. Zamaraev, and J. M. Thomas, J. Chem. Soc. Faraday trans., 86 (20), 3473 (1990).

42. C. L. Kibby and W. K. Hall, J. Catal., 29, 144 (1973).

43. J. A. S. Brett, L. G. Christner, and W. K. Hall, J. Am. Chem. Soc., 89, 5535 (1967).

44. A. Clearfield and D. S. Thakur, J. Catal., 65, 185 (1980).

45. K. Klier, R. G. Herman, M. A. Johansson, and O. C. Feeley, Div. Fuel Chem., ACS Spring Meeting, April, 1992.

46. P. Thornton and B. C. Gates, J. Catal., 34, 275 (1974).

47. P. Canesson and M. Blanchard, J. Catal. 42, 205 (1976). 
48. S. Siddhan and K. Marayanan, J. Catal., 59, 405 (1979).

49. N. S. Kotsarenko and L. V. Malysheva, Kinet. Katal., 24, 877 (1983).

50. B. H. Davis, J. Catal., 79, 58 (1983).

51. A. Gervasini and A. Auroux, J. Catal., 131, 190 (1991).

52. T. Docker and H. Krug, DE Pat. 3,317,165 (1983).

53. O. C. Abraham and G. F. Prescott, Hydrocarbon Proc., Feb., 51 (1992).

54. H. Klotz, APCI memo, "Equilibrium Conversions for Isobutylene/Alcohol Reactions," 6 November (1991).

55. H. Klotz, APCI memo, "Isobutanol Heats of Reaction," 30 January (1992). 
Appendix II: Thermodynamic Calculations 
To:

T. H. Hsiung

Dept./LoC PSG RES/Iron Run

From: H. C. Klotz

Dept./Ext. MIS-RES/4638

Date: 6 November 1991

Subject: Equilibrium Calculations for Isobutylene/Alcohol Reactions

As you requested, I have estimated equilibrium compositions for two reactions involving conversion of isobutanol (IBOH) or tert-butanol (TBOH) to isobutylene (IBUE) and water. These calculations are based on ideal gas properties obtained from the JANF thermodynamic system. The calculations indicate that the . isobutanol reaction essentially goes to completion, whereas the tert-butanol reaction goes to a lesser extent. If you have any questions, please contact me.

$\mathrm{Rxn} 1: \mathrm{IBOH}=\mathrm{IBUE}+\mathrm{H} 2 \mathrm{O}$

Condition

$\mathrm{T}=100 \mathrm{C}, \mathrm{P}=1 \mathrm{~atm}$

$\mathrm{T}=200 \mathrm{C}, \mathrm{P}=1 \mathrm{~atm}$

$T=300 \mathrm{C}, P=1 \mathrm{~atm}$

$\mathrm{T}=100 \mathrm{C}, \mathrm{P}=52 \mathrm{~atm}$

$\mathrm{T}=200 \mathrm{C}, \mathrm{P}=52 \mathrm{~atm}$

$\mathrm{T}=300 \mathrm{C}, \mathrm{P}=52 \mathrm{~atm}$

$\begin{array}{lrr}\text { Mol\% } & \because & \text { Mól\% } \\ \text { IBOH } & \text { IBUE } & \cdot \text { Mol\% } \\ \text { H2O } & \end{array}$

.0026

.0004

.0001

.135

.022

.003
50.00

50.00

50.00

49.93

49.99

50.00
50.00

50.00

50.00

49.93

49.99

50.00

\section{$\mathrm{Rxn} 2: \mathrm{TBOH}=\mathrm{IBUE}+\mathrm{H2O}$}

\begin{tabular}{lrrr}
\multicolumn{1}{c}{ Condition } & $\begin{array}{c}\text { Mol\% } \\
\text { TBOH }\end{array}$ & $\begin{array}{c}\text { Mol\% } \\
\text { IBUE }\end{array}$ & \multicolumn{1}{c}{ Mol\% } \\
T2Q & & & \\
$\mathrm{T}=100 \mathrm{C}, \mathrm{P}=1 \mathrm{~atm}$ & 54.84 & 22.58 & 22.58 \\
$\mathrm{~T}=300 \mathrm{C}, \mathrm{P}=1 \mathrm{~atm}$ & 2.62 & 48.69 & 48.69 \\
$\mathrm{~T}=100 \mathrm{C}, \mathrm{P}=1 \mathrm{~atm}$ & 0.14 & 49.93 & 49.93 \\
$\mathrm{~T}=200 \mathrm{~atm}$ & 91.90 & 4.05 & 4.05 \\
$\mathrm{~T}=300 \mathrm{C}, \mathrm{P}=52 \mathrm{~atm}$ & 44.48 & 27.76 & 27.76 \\
& 6.50 & 46.75 & 46.75
\end{tabular}

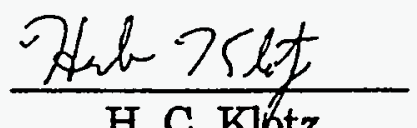


To: $\quad$ B. E. Latshaw

From: H. C. Klotz

Date: $\quad 30$ January 1992

Subject: Isobutanol Dehydration Heats of Reaction
Dept./Loc PG\&E Res/Iron Run

Dept./Ext. MIS-RES/4638
cc: T. H. Hsiung
P. M. Mathias

As you requested, heats of reaction and adiabatic temperature drops for the isobutanol dehydration reaction have been estimated for a variety of conditions. The calculations are based on the LC Peng-Robinson model (ITHRMO=17) in the CAPP thermodynamic system. The heat of reaction to form isobutylene and water from isobutanol is $6.4 \mathrm{kcal} / \mathrm{gmol}$ in the gas phase over the range of conditions you specified.

I've also calculated the temperature decrease in an adiabatic reactor as a function of isobutanol conversion from two initial conditions ( $\mathrm{T}=200 \mathrm{C}, \mathrm{P}=1$ atm; $\mathrm{T}=300 \mathrm{C}$, $\mathrm{P}=1 \mathrm{~atm}$ ) which are summarized below:

\begin{tabular}{|c|c|c|c|c|c|}
\hline \multirow{2}{*}{$\begin{array}{c}\text { \%IBOH } \\
\text { Conversion }\end{array}$} & \multicolumn{2}{|c|}{$\begin{array}{l}\text { Initial Condition } 1 \\
\mathrm{~T}=200 \mathrm{C}, \mathrm{P}=1 \mathrm{~atm} \\
\mathrm{x}(\mathrm{IBOH})=1.0\end{array}$} & & \multicolumn{2}{|c|}{$\begin{array}{l}\text { Initial Condition } 2 \\
T=300 \mathrm{C}, \mathrm{P}=1 \mathrm{~atm} \\
\quad \mathrm{x}(\mathrm{IBOH})=1.0\end{array}$} \\
\hline & Final T(C) & Liq Phase? & & Final T (C) & Liq Phase? \\
\hline 0 & 200 & $N$ & & 300 & $N$ \\
\hline 10 & 182 & $N$ & & 284 & $\mathrm{~N}$ \\
\hline 20 & 164 & $\mathbf{N}$ & & 269 & $\mathrm{~N}$ \\
\hline 30 & 145 & $\mathbf{N}$ & & 252 & $\mathrm{~N}$ \\
\hline 40 & 126 & $\mathrm{~N}$ & & 236 & $\mathbf{N}$ \\
\hline 50 & 107 & $\mathrm{~N}$ & , & 219 & $\mathbf{N}$ \\
\hline 60 & 87 & $\mathbf{N}$ & & 202 & $\mathrm{~N}$ \\
\hline 70 & 77 & $Y$ & & 185 & $N$ \\
\hline 80 & 77 & $Y$ & & 167 & $N$ \\
\hline 90 & 77 & $Y$ & & 149 & $N$ \\
\hline 100 & 77 & $\mathrm{Y}$ & & 130 & $N$ \\
\hline
\end{tabular}

As you know, equilibrium calculations indicate that this reaction should essentially go to completion at both conditions (1). Since the reaction is endothermic, there is the potential for a liquid phase to form as the reaction proceeds. As illustrated above, a liquid phase forms at the $T=200 \mathrm{C}$ initial condition between 60 and $70 \%$ $\mathrm{IBOH}$ conversion, but no liquid phase forms for $\mathrm{T}=300 \mathrm{C}$ case. 
A series of calculations were also made for the $\mathrm{T}=300 \mathrm{C}$ case at various pressures to determine the maximum reactor pressure which avoids forming a liquid phase during the reaction. The maximum pressure based on this criteria is $5.4 \mathrm{~atm}$, and the temperature profile as a function of conversion is essentially identical to that shown for the $\mathrm{T}=300 \mathrm{C}$ and $\mathrm{P}=1 \mathrm{~atm}$ case.

If you have any questions, please contact me.

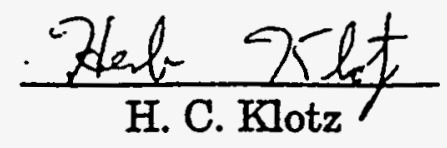

\section{References}

1. APCI memo, H. C. Klotz to T. H. Hsiung, "Equilibrium Calculations for Isobutylene/Alcohol Reactions", 6 November 1991 
Appendix III: Analytical System 


\section{Unit 1 GC Conditions}

Higher Alcohols and Isomers Analysis

Temperatures

GC Oven Program

$30^{\circ} \mathrm{C}(3 \mathrm{~min})-15^{\circ} \mathrm{C} / \mathrm{min}-180^{\circ} \mathrm{C}(0 \mathrm{~min})$

Injector A (Packed V2) $\quad 180^{\circ} \mathrm{C}$

Injector B (Packed V3) $200^{\circ} \mathrm{C}$

Detector A (FID V2) $\quad 250^{\circ}$

Dectector B (FID V3) $\quad 200^{\circ}$

Aux Oven (Valve Oven A) $\quad 120^{\circ} \mathrm{C}$

Valco Temp. Controller (Valve Oven B) $120^{\circ}$

Valve 2 (10 port) Higher Alcohols

Column

Head Pressure

Flow Rate

Excess Flow

Sample Loop
$15 \mathrm{~m} \times 0.53 \mathrm{~mm} \mathrm{ID} \times 5 \mu \mathrm{m}$ film, AT-1 (Alltech) Capillary

5 psig Helium

$6 \mathrm{ml} / \mathrm{min}$

$20 \mathrm{ml} / \mathrm{min}$

$25 \mu \mathrm{l}$

Valve 3 (10 Port) Isomers

Column

$25 \mathrm{~m} \times 0.53 \mathrm{~mm} \mathrm{Al} \mathrm{O}_{3}$ Capillary PLOT

Pre-Column

Backflush Flow

$10 \mathrm{~m} \times 0.53 \mathrm{~mm}$ CP-WAX 52 Capillary

Head Pressure

Flow Rate

$10 \mathrm{ml} / \mathrm{min}$

$2 \mathrm{psig}$

$3 \mathrm{ml} / \mathrm{min}$

Sample Loop

$8 \mu \mathrm{l}$

Valve Times (Valves 1 and 2 controlled by HP GC, Valve 3 controlled by Turbochrom)

Valve 1 ON

Valve 2 and 3 ON

$0.01 \mathrm{~min}$ Vent to atmosphere

Valve $3 \mathrm{OFF}$

Valve $1 \mathrm{OFF}$

Valve $2 \mathrm{OFF}$

$0.09 \mathrm{~min}$ Inject Valves 2 and 3

$0.4 \mathrm{~min}$ Return Valve 3 and backflush pre-column

$0.5 \mathrm{~min}$ Return atmospheric vent valve

$1.1 \mathrm{~min}$ Return valve 2

Signal Output ( $0-1$ volt)

Signal A Range (Turbochrom chanel 0, V2) 6

Signal B Range (Turbochrom chanel 1, V3) 3

Misc
Equilibration Time
$1 \mathrm{~min}$
Run Time
$13 \min$
Max. Column Oven Temp.
$200^{\circ} \mathrm{C}$ 


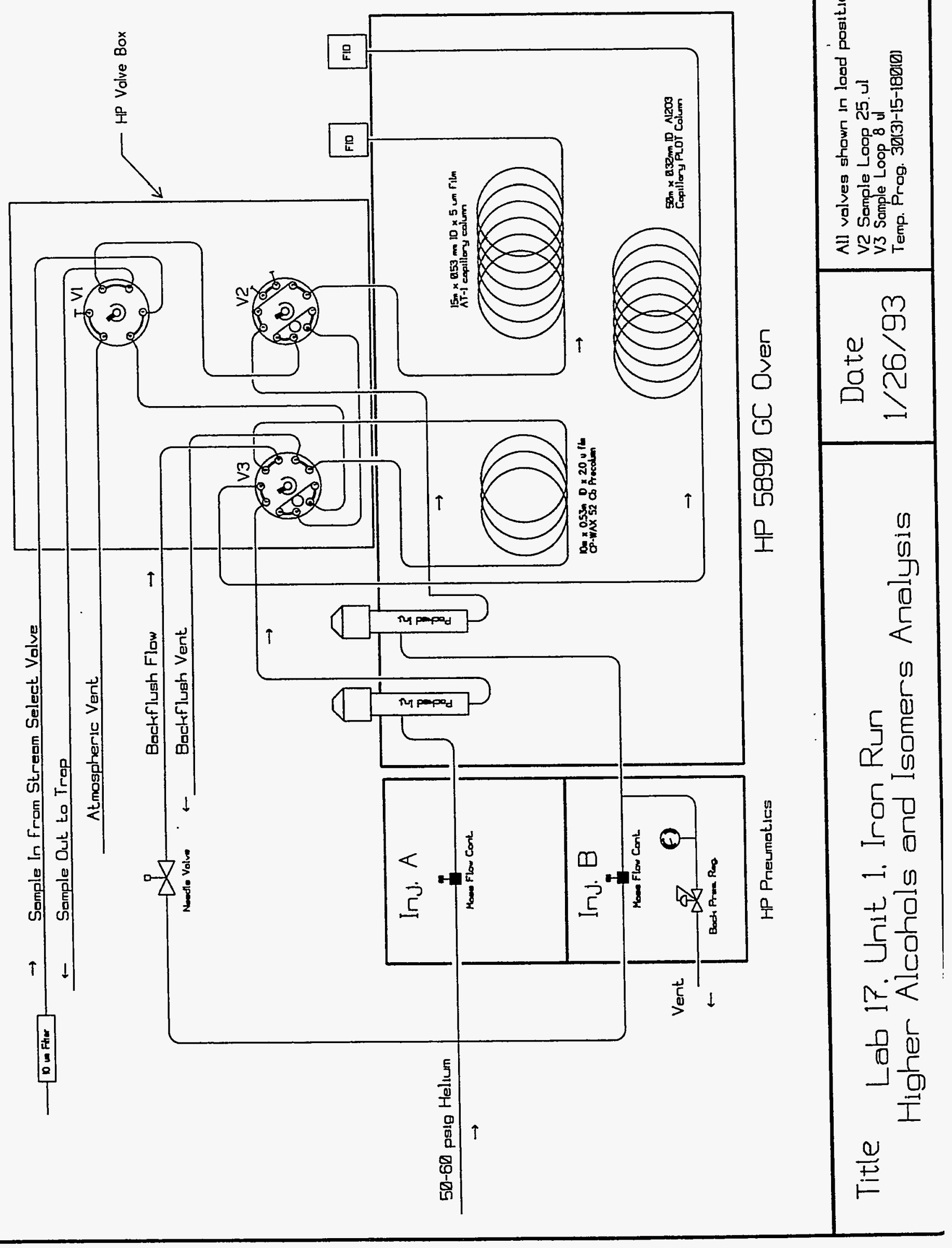


Appendix IV: Experimental Data 


\section{TABLE 1}

Measured Performance of Catapal B Gamma Alumina Catalyst Isobutanol Injected into Vaporizer Unit

\begin{tabular}{|c|c|c|c|c|c|c|c|c|c|c|c|}
\hline $\begin{array}{c}\text { Run \# } \\
11782- \\
\end{array}$ & $\begin{array}{c}\text { Temp } \\
\left({ }^{\circ} \mathrm{C}\right) \\
\end{array}$ & $\begin{array}{c}\text { Pressure } \\
\text { (psig) }\end{array}$ & $\begin{array}{c}\text { Isobutanol } \\
\text { Feed } \\
(\mathrm{g} / \mathrm{kg}-\mathrm{hr})\end{array}$ & $\begin{array}{c}\text { Inlet } \\
\text { GHSV } \\
\text { (sl/kg-hr) }\end{array}$ & $\begin{array}{c}\text { Isobutanol } \\
\text { Conversion } \\
\%\end{array}$ & $\begin{array}{c}\text { Isobutene } \\
\text { Rate } \\
(\mathrm{g} / \mathrm{kg}-\mathrm{hr})\end{array}$ & $\begin{array}{c}\text { Linear C4 } \\
\text { Rate } \\
(\mathrm{g} / \mathrm{kg}-\mathrm{hr})\end{array}$ & $\begin{array}{c}\text { Ether } \\
\text { Rate } \\
\text { (g/kg-hr) }\end{array}$ & $\begin{array}{c}\text { Water } \\
\text { Rate } \\
\text { (g/kg-hr) }\end{array}$ & $\begin{array}{c}\text { Isobutene } \\
\text { Selectivity } \\
(w t \%)\end{array}$ & $\begin{array}{c}\text { Carbon } \\
\text { Recovery } \\
\%\end{array}$ \\
\hline $78 \mathrm{~A}$ & 250 & 150 & 416.0 & 2580 & 33.5 & 81.9 & 2.9 & 18.0 & 30.9 & 78.5 & 101 \\
\hline $78 \mathrm{~B}$ & 250 & 500 & 416.0 & 2367 & 20.7 & 45.7 & 1.1 & 15.6 & 18.2 & 71.3 & 101 \\
\hline $78 \mathrm{C}$ & 250 & 500 & 1040.0 & 6372 & 14.1 & 76.9 & 1.9 & 26.2 & 30.7 & 71.1 & 101 \\
\hline $78 \mathrm{D}$ & 250 & 150 & 1040.0 & 6352 & 21.2 & 121.2 & 3.0 & 22.5 & 44.2 & 80.9 & 99 \\
\hline $78 A-2$ & 250 & 150 & 416.0 & 2407 & 35.7 & 74.0 & 2.4 & 13.9 & 27.4 & 80.9 & 95 \\
\hline $78 \mathrm{E}$ & 330 & 158 & 416.0 & 2453 & 98.3 & 300.8 & 26.9 & 0.0 & 105.3 & 91.5 & 106 \\
\hline $78 \mathrm{~F}$ & 330 & 501 & 416.0 & 2357 & 98.1 & 302.8 & 23.7 & 0.0 & 105.1 & 92.4 & 106 \\
\hline $78 \mathrm{G}$ & 330 & 503 & 1040.0 & 6158 & 94.8 & 751.4 & 55.7 & 0.5 & 259.7 & 92.7 & 108 \\
\hline $78 \mathrm{H}$ & 330 & 149 & 1040.0 & 6433 & 86.4 & 687.3 & 57.8 & 0.0 & 239.4 & 92.0 & 109 \\
\hline $78 \mathrm{E}-2$ & 330 & 149 & 416.0 & 2480 & 97.8 & 301.6 & 26.1 & 0.0 & 105.3 & 91.8 & 107 \\
\hline
\end{tabular}

$5 \%$ isobutanol, $95 \%$ nitrogen; slurry: $30.07 \mathrm{~g}$ catalyst, $120.86 \mathrm{~g}$ Drakeol 10 oil inlet GHSV based on nitrogen and isobutanol

linear C4 = 1-butene, cis-2-butene, and trans-2-butene; ether = diisobutyl ether

water rate was calculated based on rates of butenes, ether, and traces of propene, butane, and isobutane

isobutene selectivity based on water free product distribution 
TABLE 2

Measured Performance of Catapal B Gamma Alumina Catalyst Isobutanol Injected Directly into Reactor

\begin{tabular}{|c|c|c|c|c|c|c|c|c|c|c|c|}
\hline $\begin{array}{l}\text { Run \# } \\
11782-\end{array}$ & $\begin{array}{c}\text { Temp } \\
\left({ }^{\circ} \mathrm{C}\right)\end{array}$ & $\begin{array}{c}\text { Pressure } \\
\text { (psig) }\end{array}$ & $\begin{array}{c}\text { Isobutanol } \\
\text { Feed } \\
(\mathrm{g} / \mathrm{kg}-\mathrm{hr})\end{array}$ & $\begin{array}{c}\text { Inlet } \\
\text { GHSV } \\
\text { (sl/kg-hr) }\end{array}$ & \begin{tabular}{|c|}
$\begin{array}{c}\text { Isobutanol } \\
\text { Conversion } \\
\%\end{array}$ \\
\end{tabular} & $\begin{array}{c}\text { Isobutene } \\
\text { Rate } \\
\text { (g/kg-hr) }\end{array}$ & $\begin{array}{c}\text { Linear C4 } \\
\text { Rate } \\
(\mathrm{g} / \mathrm{kg}-\mathrm{hr})\end{array}$ & $\begin{array}{c}\text { Ether } \\
\text { Rate } \\
\text { (g/kg-hr) }\end{array}$ & $\begin{array}{c}\text { Water } \\
\text { Rate } \\
\text { (g/kg-hr) }\end{array}$ & $\begin{array}{c}\text { Isobutene } \\
\text { Selectivity } \\
\text { (wt\%) }\end{array}$ & $\begin{array}{c}\text { Carbon } \\
\text { Recovery } \\
\%\end{array}$ \\
\hline $88 \mathrm{~A}$ & 250 & 151 & 410.6 & 2645 & 31.9 & 122.5 & 3.1 & 16.0 & 43.6 & 86.1 & 115 \\
\hline $88 B$ & 250 & 499 & 410.6 & 2614 & 19.7 & 66.3 & 1.3 & 16.4 & 25.1 & 77.8 & 109 \\
\hline $88 \mathrm{D}$ & 250 & 500 & 1026.6 & 6281 & 15.6 & 167.3 & 3.7 & 27.9 & 60.6 & 83.2 & 111 \\
\hline 881 & 290 & 149 & 410.6 & 2550 & 89.3 & 317.6 & 17.5 & 1.0 & 107.9 & 94.2 & 119 \\
\hline $88 \mathrm{~J}$ & 290 & 500 & 410.6 & 2479 & 70.6 & 273.3 & 10.8 & 7.2 & 92.9 & 93.3 & 124 \\
\hline $88 \mathrm{~K}$ & 290 & 150 & 1026.6 & 6278 & 71.5 & 647.1 & 31.0 & 11.6 & 220.3 & 93.4 & 106 \\
\hline $88 \mathrm{E}$ & 332 & 152 & 410.6 & 2570 & 99.6 & 322.6 & 30.1 & 0.0 & 113.3 & 91.3 & 114 \\
\hline $88 N^{*}$ & 332 & 152 & 895.0 & 2717 & 97.4 & 635.1 & 52.0 & 0.5 & 221.0 & 91.9 & 105 \\
\hline $88 \mathrm{M}^{* *}$ & 332 & 152 & 1316.2 & 2844 & 95.0 & 1036.9 & 80.1 & 0.5 & 359.4 & 92.3 & 118 \\
\hline $88 \mathrm{H}$ & 329 & 156 & 1026.6 & 6198 & 97.4 & 727.5 & 60.2 & 0.0 & 253.2 & 92.0 & 104 \\
\hline $88 G$ & 329 & 500 & 1026.6 & 6268 & 94.8 & 716.3 & 52.3 & 0.5 & 247.3 & 92.6 & 105 \\
\hline 880 & 329 & 750 & 1026.6 & 6177 & 92.1 & 702.8 & 47.2 & 1.2 & 241.6 & 92.9 & 105 \\
\hline
\end{tabular}

$5 \%$ isobutanol, $95 \%$ nitrogen; *10\% isobutanol, $90 \%$ nitrogen; ** $15 \%$ isobutanol, $85 \%$ nitrogen; slurry: $30.46 \mathrm{~g}$ catalyst, $120.68 \mathrm{~g} \mathrm{Drakeol} 10$ oil inlet GHSV based on nitrogen and isobutanol, linear C4 = 1-butene, cis-2-butene, and trans-2-butene; ether = diisobutyl ether water rate was calculated based on rates of butenes, ether, and traces of propene, butane, and isobutane

isobutene selectivity based on water free product distribution 


\section{TABLE 3}

Measured Performance of Versal B Eta Alumina Catalyst Isobutanol Injected Directly into Reactor

\begin{tabular}{|c|c|c|c|c|c|c|c|c|c|c|c|}
\hline $\begin{array}{c}\text { Run \# } \\
11782-\end{array}$ & $\begin{array}{c}\text { Temp } \\
\left({ }^{\circ} \mathrm{C}\right)\end{array}$ & $\begin{array}{l}\text { Pressure } \\
\text { (psig) }\end{array}$ & $\begin{array}{c}\text { Isobutanol } \\
\text { Feed } \\
(\mathrm{g} / \mathrm{kg}-\mathrm{hr})\end{array}$ & $\begin{array}{c}\text { Inlet } \\
\text { GHSV } \\
\text { (sl/kg-hr) }\end{array}$ & $\begin{array}{c}\text { Isobutanol } \\
\text { Conversion } \\
\%\end{array}$ & $\begin{array}{c}\text { Isobutene } \\
\text { Rate } \\
(\mathrm{g} / \mathrm{kg}-\mathrm{hr})\end{array}$ & \begin{tabular}{|c|} 
Linear C4 \\
Rate \\
(g/kg-hr)
\end{tabular} & $\begin{array}{c}\text { Ether } \\
\text { Rate } \\
\text { (g/kg-hr) }\end{array}$ & $\begin{array}{c}\text { Water } \\
\text { Rate } \\
\text { (g/kg-hr) } \\
\end{array}$ & \begin{tabular}{|c|}
$\begin{array}{c}\text { Isobutene } \\
\text { Selectivity } \\
(w t \%)\end{array}$ \\
\end{tabular} & $\begin{array}{c}\text { Carbon } \\
\text { Recovery } \\
\% \\
\end{array}$ \\
\hline $92 \mathrm{~A}$ & 271 & 154 & 404.1 & 2582 & 48.2 & 139.9 & 6.5 & 14.8 & 50.1 & 86.2 & 106 \\
\hline $92 B$ & 269 & 158 & 1010.3 & 6275 & 27.3 & 262.0 & 8.4 & 35.4 & 94.1 & 84.9 & 114 \\
\hline $92 \mathrm{C}$ & 329 & 156 & 404.1 & 2582 & 98.6 & 312.4 & 25.2 & 0.2 & 108.6 & 92.3 & 112 \\
\hline $92 \mathrm{D}$ & 330 & 158 & 1010.3 & 6076 & 96.1 & 758.3 & 58.3 & 0.3 & 262.5 & 92.5 & 111 \\
\hline $92 \mathrm{E}$ & 329 & 157 & 388.6 & 2548 & 98.9 & 290.8 & 24.6 & 0.1 & 101.4 & 92.0 & 109 \\
\hline 92F* & 331 & 158 & 906.7 & 2705 & 95.1 & 660.8 & 51.1 & 0.4 & 229.0 & 92.3 & 109 \\
\hline $92 \mathrm{G}^{*}$ & 329 & 501 & 906.7 & 2639 & 81.5 & 582.1 & 37.6 & 5.2 & 200.4 & 92.4 & 110 \\
\hline $92 \mathrm{H}^{*}$ & 329 & 99 & 906.7 & 2781 & 93.1 & 647.2 & 48.0 & 0.8 & 223.6 & 92.6 & 109 \\
\hline 92I & 329 & 150 & 388.6 & 2552 & 97.7 & 295.7 & 24.8 & 0.0 & 103.0 & 91.9 & 112 \\
\hline $92 J$ & 270 & 150 & 388.6 & 2552 & 44.5 & 135.7 & 5.2 & 10.5 & 47.4 & 89.2 & 108 \\
\hline
\end{tabular}

$5 \%$ isobutanol, $95 \%$ nitrogen; * $10 \%$ isobutanol, $90 \%$ nitrogen; slurry: $30.95 \mathrm{~g}$ catalyst, $122.05 \mathrm{~g}$ Drakeol $10 \mathrm{oil}$ inlet GHSV based on nitrogen and isobutanol

linear C4 = 1-butene, cis-2-butene, and trans-2-butene; ether = diisobutyl ether

water rate was calculated based on rates of butenes, ether, and traces of propene, butane, and isobutane

isobutene selectivity based on water free product distribution

runs A-D performed using Isco 314 syringe pump, runs E-J performed using Isco LC-5000 syring pump 
TABLE 4

Measured Performance of Catapal B Gamma Alumina Catalyst Doped with 0.2 wt.\% Potassium

\begin{tabular}{|c|c|c|c|c|c|c|c|c|c|c|c|}
\hline $\begin{array}{l}\text { Run \# } \\
11782-\end{array}$ & $\begin{array}{l}\text { Temp } \\
\left({ }^{\circ} \mathrm{C}\right)\end{array}$ & $\begin{array}{c}\text { Pressure } \\
\text { (psig) }\end{array}$ & \begin{tabular}{|c|} 
Isobutanol \\
Feed \\
$(\mathrm{g} / \mathrm{kg}-\mathrm{hr})$
\end{tabular} & $\begin{array}{c}\text { Inlet } \\
\text { GHSV } \\
\text { (sl/kg-hr) }\end{array}$ & $\begin{array}{c}\text { Isobutanol } \\
\text { Conversion } \\
\%\end{array}$ & $\begin{array}{c}\text { Isobutene } \\
\text { Rate } \\
(\mathrm{g} / \mathrm{kg}-\mathrm{hr})\end{array}$ & $\begin{array}{c}\text { Linear C4 } \\
\text { Rate } \\
(\mathrm{g} / \mathrm{kg}-\mathrm{hr})\end{array}$ & $\begin{array}{c}\text { Ether } \\
\text { Rate } \\
\text { (g/kg-hr) }\end{array}$ & $\begin{array}{c}\text { Water } \\
\text { Rate } \\
\text { (g/kg-hr) }\end{array}$ & $\begin{array}{c}\text { Isobutene } \\
\text { Selectivity } \\
\text { (wt\%) }\end{array}$ & $\begin{array}{c}\text { Carbon } \\
\text { Recovery } \\
\%\end{array}$ \\
\hline $98 \mathrm{~A}$ & 269 & 154 & 400.8 & 2526 & 19.6 & 59.5 & 1.6 & 17.7 & 23.2 & 75.0 & 108 \\
\hline $98 \mathrm{~B} *$ & 267 & 500 & 400.8 & 2478 & 42.8 & 35.5 & 0.3 & 11.9 & 13.9 & 73.3 & 74 \\
\hline $98 \mathrm{C}$ & 273 & 151 & 1068.7 & 6474 & 12.7 & 127.3 & 2.7 & 34.6 & 2.7 & 76.2 & 109 \\
\hline $98 D$ & 328 & 151 & 400.8 & 2605 & 94.1 & 297.6 & 18.6 & 0.6 & 101.7 & $\overline{93.6}$ & 111 \\
\hline $98 \mathrm{E}$ & 329 & 501 & 400.8 & 2510 & 89.3 & 283.4 & 15.9 & 1.2 & 5.4 & 93.9 & 110 \\
\hline $98 \mathrm{~F}$ & 330 & 148 & 1068.7 & 6378 & 84.3 & 712.4 & 40.0 & 4.7 & 242.7 & 93.7 & 110 \\
\hline
\end{tabular}

5\% isobutanol, $95 \%$ nitrogen; slurry: $30.01 \mathrm{~g}$ catalyst, $120.01 \mathrm{~g}$ Drakeol 10 oil inlet GHSV based on nitrogen and isobutanol

linear C4 =1-butene, cis-2-butene, and trans-2-butene; ether $=$ diisobutyl ether

water rate was calculated based on rates of butenes, ether, and traces of propene, butane, and isobutane isobutene selectivity based on water free product distribution

* low concentration of isobutanol measured in the outlet flow, reason for this is unknown 
TABLE 5

Measured Performance of Catapal B Gamma Alumina Catalyst Doped with 0.5 wt.\% Potassium

\begin{tabular}{|c|c|c|c|c|c|c|c|c|c|c|c|}
\hline $\begin{array}{l}\text { Run \# } \\
11782-\end{array}$ & $\begin{array}{l}\text { Temp } \\
\left({ }^{\circ} \mathrm{C}\right)\end{array}$ & $\begin{array}{c}\text { Pressure } \\
\text { (psig) }\end{array}$ & $\begin{array}{c}\text { Isobutanol } \\
\text { Feed } \\
(\mathrm{g} / \mathrm{kg}-\mathrm{hr})\end{array}$ & $\begin{array}{c}\text { Inlet } \\
\text { GHSV } \\
\text { (sl/kg-hr) }\end{array}$ & \begin{tabular}{|c|} 
Isobutanol \\
Conversion \\
$\%$
\end{tabular} & $\begin{array}{c}\text { Isobutene } \\
\text { Rate } \\
\text { (g/kg-hr) }\end{array}$ & $\begin{array}{c}\text { Linear C4 } \\
\text { Rate } \\
\text { (g/kg-hr) }\end{array}$ & $\begin{array}{c}\text { Ether } \\
\text { Rate } \\
\text { (g/kg-hr) }\end{array}$ & $\begin{array}{c}\text { Water } \\
\text { Rate } \\
\text { (g/kg-hr) }\end{array}$ & $\begin{array}{c}\text { Isobutene } \\
\text { Selectivity } \\
\text { (wt\%) }\end{array}$ & $\begin{array}{c}\text { Carbon } \\
\text { Recovery } \\
\%\end{array}$ \\
\hline $01 \mathrm{~A}$ & 269 & 149 & 400.9 & 2553 & 13.1 & 37.4 & 0.7 & 15.0 & 15.3 & 69.4 & 106 \\
\hline 01B & 269 & 151 & 1069.1 & 6310 & 11.1 & 48.8 & 0.6 & 21.3 & 1.1 & 67.7 & 99 \\
\hline$\overline{01 C}$ & 328 & 149 & 400.9 & 2568 & 84.9 & 266.6 & 11.4 & 2.0 & 89.7 & 94.8 & 108 \\
\hline $01 D$ & 329 & 152 & 1069.1 & 6279 & 67.6 & 551.9 & 23.2 & 18.3 & 188.5 & 92.5 & 107 \\
\hline $01 \mathrm{E}$ & 331 & 147 & 280.6 & 1672 & 89.5 & 195.5 & 9.3 & 0.7 & 66.0 & 94.7 & 108 \\
\hline
\end{tabular}

$5 \%$ isobutanol, $95 \%$ nitrogen; slurry: $30.00 \mathrm{~g}$ catalyst, $120.00 \mathrm{~g}$ Drakeol $10 \mathrm{oil}$ inlet GHSV based on nitrogen and isobutanol

linear C4 = 1-butene, cis-2-butene, and trans-2-butene; ether = diisobutyl ether

water rate was calculated based on rates of butenes, ether, and traces of propene, butane, and isobutane

isobutene selectivity based on water free product distribution 
TABLE 6

Measured Performance of Catapal B Gamma Alumina Catalyst

Doped with 0.8 wt.\% Potassium

\begin{tabular}{|c|c|c|c|c|c|c|c|c|c|c|c|}
\hline $\begin{array}{l}\text { Run \# } \\
13033-\end{array}$ & $\begin{array}{c}\text { Temp } \\
\left({ }^{\circ} \mathrm{C}\right)\end{array}$ & $\begin{array}{c}\text { Pressure } \\
\text { (psig) }\end{array}$ & $\begin{array}{c}\text { Isobutanol } \\
\text { Feed } \\
\text { (g/kg-hr) }\end{array}$ & $\begin{array}{c}\text { Inlet } \\
\text { GHSV } \\
\text { (sl/kg-hr) }\end{array}$ & $\begin{array}{c}\text { Isobutanol } \\
\text { Conversion } \\
\%\end{array}$ & $\begin{array}{c}\text { Isobutene } \\
\text { Rate } \\
\text { (g/kg-hr) }\end{array}$ & $\begin{array}{c}\text { Linear C4 } \\
\text { Rate } \\
(\mathrm{g} / \mathrm{kg}-\mathrm{hr})\end{array}$ & $\begin{array}{c}\text { Ether } \\
\text { Rate } \\
\text { (g/kg-hr) }\end{array}$ & $\begin{array}{c}\text { Water } \\
\text { Rate } \\
\text { (g/kg-hr) }\end{array}$ & $\begin{array}{c}\text { Isobutene } \\
\text { Selectivity } \\
\text { (wt\%) }\end{array}$ & $\begin{array}{c}\text { Carbon } \\
\text { Recovery } \\
\%\end{array}$ \\
\hline $1 A^{*}$ & 270 & 151 & 400.8 & 2527 & -5.9 & 17.5 & 0.2 & 14.1 & 5.7 & 53.5 & 116 \\
\hline 1B & 270 & 161 & 1068.7 & 6399 & 3.4 & 21.3 & 0.2 & 17.7 & 9.3 & 53.3 & 101 \\
\hline $1 \mathrm{C}$ & 329 & 156 & 400.8 & 2572 & 67.7 & 212.3 & 8.2 & 12.5 & 72.5 & 90.5 & 109 \\
\hline ID & 330 & 159 & 1068.7 & 6338 & 45.6 & 369.3 & 13.4 & 53.6 & 130.3 & 83.5 & 108 \\
\hline $1 \mathrm{E}$ & 331 & 150 & 179.0 & 1184 & 84.5 & 115.1 & 4.8 & 1.5 & 38.7 & 94.2 & 105 \\
\hline $1 F^{* *}$ & 329 & 153 & 1258.4 & 982 & 70.1 & 299.7 & 9.0 & 53.1 & 106.5 & 81.1 & 68 \\
\hline
\end{tabular}

$5 \%$ isobutanol, $95 \%$ nitrogen; slurry: $30.01 \mathrm{~g}$ catalyst, $120.11 \mathrm{~g}$ Drakeol 10 oil inlet GHSV based on nitrogen and isobutanol

linear $\mathbf{C 4}=1$-butene, cis-2-butene, and trans-2-butene; ether = diisobutyl ether

water rate was calculated based on rates of butenes, ether, and traces of propene, butane, and isobutane

isobutene selectivity based on water free product distribution

* high concentration of isobutanol measured in the outlet flow, reason for this is unknown

** 39\% isobutanol, $61 \%$ nitrogen; low carbon recovery due to concensation of isobutanol in the line between the reactor and GC 
TABLE 7

Measured Performance of Catapal B Gamma Alumina Catalyst Doped with $0.5 \mathrm{wt}$.\% Potassium, Dried at $120 \mathrm{C}$ before Calcination

\begin{tabular}{|c|c|c|c|c|c|c|c|c|c|c|c|}
\hline $\begin{array}{l}\text { Run \# } \\
\text { 13033- }\end{array}$ & $\begin{array}{c}\text { Temp } \\
\left({ }^{\circ} \mathrm{C}\right)\end{array}$ & $\begin{array}{c}\text { Pressure } \\
\text { (psig) }\end{array}$ & $\begin{array}{c}\text { Isobutanol } \\
\text { Feed } \\
(\mathrm{g} / \mathrm{kg}-\mathrm{hr})\end{array}$ & $\begin{array}{c}\text { Inlet } \\
\text { GHSV } \\
(\mathrm{sl} / \mathrm{kg}-\mathrm{hr})\end{array}$ & $\begin{array}{c}\text { Isobutanol } \\
\text { Conversion } \\
\%\end{array}$ & $\begin{array}{c}\text { Isobutene } \\
\text { Rate } \\
(\mathrm{g} / \mathrm{kg}-\mathrm{hr})\end{array}$ & $\begin{array}{c}\text { Linear C4 } \\
\text { Rate } \\
(\mathrm{g} / \mathrm{kg}-\mathrm{hr})\end{array}$ & $\begin{array}{c}\text { Ether } \\
\text { Rate } \\
\text { (g/kg-hr) }\end{array}$ & $\begin{array}{c}\text { Water } \\
\text { Rate } \\
\text { (g/kg-hr) }\end{array}$ & $\begin{array}{c}\text { Isobutene } \\
\text { Selectivity } \\
\text { (wt\%) }\end{array}$ & $\begin{array}{c}\text { Carbon } \\
\text { Recovery } \\
\%\end{array}$ \\
\hline $7 \mathrm{~A}$ & 271 & 149 & 400.9 & 2513 & 17.3 & 33.8 & 0.7 & 21.1 & 13.9 & 59.0 & 101 \\
\hline $7 \mathrm{~B}$ & 329 & 154 & 1069.1 & 6239 & 69.9 & 529.3 & 22.3 & 30.5 & 181.8 & 90.3 & 102 \\
\hline$\overline{7 C}$ & 330 & 145 & 400.9 & 2582 & 86.2 & 254.1 & 12.0 & 3.1 & 86.4 & 93.8 & 103 \\
\hline $7 D$ & 329 & 33 & 280.6 & 1669 & 92.2 & 186.1 & 9.7 & 0.5 & 62.9 & 94.3 & 101 \\
\hline $7 \mathrm{E}^{*}$ & 331 & 33 & 230.3 & 1689 & 92.1 & 151.5 & 7.5 & 0.3 & 61.1 & 78.9 & 103 \\
\hline
\end{tabular}

$5 \%$ isobutanol, $95 \%$ nitrogen; slurry: $30.00 \mathrm{~g}$ catalyst, $120.10 \mathrm{~g}$ Drakeol 10 oil inlet GHSV based on nitrogen and isobutanol

linear C4 = 1-butene, cis-2-butene, and trans-2-butene; ether = diisobutyl ether

water rate was calculated based on rates of butenes, ether, and traces of propene, butane, and isobutane isobutene selectivity based on water free product distribution, theoretical isobutene selectivity $=86.2 \%$

* feed consisted of 2 moles isobutanol / 1 mole methanol, GHSV measured based on total feed 
TABLE 8

Measured Performance of Versal B Eta Alumina Catalyst Doped with $0.2 \mathrm{wt} . \%$ Potassium

\begin{tabular}{|c|c|c|c|c|c|c|c|c|c|c|c|}
\hline $\begin{array}{l}\text { Run \# } \\
13033-\end{array}$ & $\begin{array}{l}\text { Temp } \\
\left({ }^{\circ} \mathrm{C}\right)\end{array}$ & $\begin{array}{c}\text { Pressure } \\
\text { (psig) }\end{array}$ & $\begin{array}{l}\text { Isobutanol } \\
\text { Feed } \\
\text { (g/kg-hr) }\end{array}$ & $\begin{array}{c}\text { Inlet } \\
\text { GHSV } \\
\text { (sl/kg-hr) }\end{array}$ & \begin{tabular}{|c|} 
Isobutanol \\
Conversion \\
$\%$
\end{tabular} & $\begin{array}{c}\text { Isobutene } \\
\text { Rate } \\
\text { (g/kg-hr) }\end{array}$ & $\begin{array}{c}\text { Linear C4 } \\
\text { Rate } \\
(\mathrm{g} / \mathrm{kg}-\mathrm{hr})\end{array}$ & $\begin{array}{c}\text { Ether } \\
\text { Rate } \\
\text { (g/kg-hr) }\end{array}$ & $\begin{array}{c}\text { Water } \\
\text { Rate } \\
\text { (g/kg-hr) }\end{array}$ & $\begin{array}{l}\text { Isobutene } \\
\text { Selectivity } \\
\text { (wt\%) }\end{array}$ & $\begin{array}{c}\text { Carbon. } \\
\text { Recovery. } \\
\%\end{array}$ \\
\hline $9 \mathrm{~A}$ & 249 & 155 & 400.5 & 2473 & 16.6 & 41.6 & 0.7 & 19.3 & 16.2 & 66.9 & . 103 \\
\hline $9 \mathrm{~B}$ & 269 & 154 & 400.5 & 2473 & 50.9 & 127.5 & 3.5 & 24.5 & 45.5 & 81.3 & 100 \\
\hline $9 \mathrm{C}$ & 290 & 156 & 400.5 & 2484 & 78.2 & 225.1 & 8.4 & 8.6 & 76.2 & 92.8 & 101 \\
\hline $9 \mathrm{D}$ & 310 & 155 & 400.5 & 2484 & 93.1 & 273.5 & 12.5 & 1.0 & 92.1 & 94.9 & 102 \\
\hline $9 \mathrm{E}$ & 329 & 157 & 400.5 & 2508 & 98.0 & 278.8 & 17.7 & 0.0 & 95.3 & 93.9 & 100 \\
\hline $9 \mathrm{~F}$ & 330 & 156 & 1068.0 & 6078 & 93.7 & 713.9 & 43.4 & 1.4 & 243.5 & 93.7 & 101 \\
\hline
\end{tabular}

$5 \%$ isobutanol, $95 \%$ nitrogen; slurry: $30.03 \mathrm{~g}$ catalyst, $120.88 \mathrm{~g}$ Drakeol 10 oil inlet GHSV based on nitrogen and isobutanol

linear C4 = 1-butene, cis-2-butene, and trans-2-butene; ether = diisobutyl ether

water rate was calculated based on rates of butenes, ether, and traces of propene, butane, and isobutane

isobutene selectivity based on water free product distribution 
TABLE 9

Measured Performance of Versal GH Gamma Alumina Catalyst Isobutanol Injected Directly into Reactor

\begin{tabular}{|c|c|c|c|c|c|c|c|c|c|c|c|}
\hline $\begin{array}{l}\text { Run \# } \\
13033-\end{array}$ & $\begin{array}{l}\text { Temp } \\
\left({ }^{\circ} \mathrm{C}\right)\end{array}$ & $\begin{array}{c}\text { Pressure } \\
\text { (psig) }\end{array}$ & $\begin{array}{c}\text { Isobutanol } \\
\text { Feed } \\
(\mathrm{g} / \mathrm{kg}-\mathrm{hr})\end{array}$ & $\begin{array}{c}\text { Inlet } \\
\text { GHSV } \\
\text { (sl/kg-hr) }\end{array}$ & $\begin{array}{c}\text { Isobutanol } \\
\text { Conversion } \\
\%\end{array}$ & $\begin{array}{c}\text { Isobutene } \\
\text { Rate } \\
(\mathrm{g} / \mathrm{kg}-\mathrm{hr})\end{array}$ & $\begin{array}{c}\text { Linear C4 } \\
\text { Rate } \\
(\mathrm{g} / \mathrm{kg}-\mathrm{hr})\end{array}$ & $\begin{array}{c}\text { Ether } \\
\text { Rate } \\
(\mathrm{g} / \mathrm{kg}-\mathrm{hr})\end{array}$ & $\begin{array}{c}\text { Water } \\
\text { Rate } \\
\text { (g/kg-hr) }\end{array}$ & $\begin{array}{c}\text { Isobutene } \\
\text { Selectivity } \\
\text { (wt\%) }\end{array}$ & $\begin{array}{c}\text { Carbon } \\
\text { Recovery } \\
\%\end{array}$ \\
\hline $12 A$ & 290 & 161 & 396.4 & 2380 & 80.5 & 240.0 & 13.3 & 4.5 & 82.0 & 92.9 & 105 \\
\hline $12 \mathrm{~B}$ & 290 & 157 & 1057.1 & 6118 & 58.3 & 455.8 & 20.6 & 32.8 & 157.6 & 89.2 & 105 \\
\hline $12 \mathrm{C}$ & 290 & 150 & 185.0 & 1169 & 90.9 & 125.5 & 7.5 & 0.5 & $\overline{42.8}$ & 93.8 & 105 \\
\hline $12 D$ & 310 & 156 & 396.4 & 2489 & 95.1 & 278.1 & 20.4 & 0.2 & 96.0 & 92.8 & 105 \\
\hline $12 E$ & 310 & 150 & 1057.1 & 6144 & 85.0 & 662.4 & 40.3 & 5.8 & 226.7 & 93.0 & 104 \\
\hline $12 \mathrm{~F}$ & 310 & 150 & 185.0 & 1070 & 97.8 & 131.1 & 10.1 & 0.0 & 45.4 & 92.7 & 103 \\
\hline $12 G$ & 330 & 154 & 396.4 & 2430 & 98.7 & 284.5 & 25.1 & 0.0 & 99.5 & 91.6 & 105 \\
\hline $12 \mathrm{H}$ & 330 & 159 & 1057.1 & 6120 & 95.6 & 733.2 & 60.9 & 0.4 & 255.3 & 91.9 & 104 \\
\hline $121^{*}$ & 330 & 150 & 185.0 & 1187 & 99.1 & 149.3 & 13.5 & 0.0 & 52.3 & 91.5 & 117 \\
\hline
\end{tabular}

$5 \%$ isobutanol, $95 \%$ nitrogen; slurry: $30.34 \mathrm{~g}$ catalyst, $120.08 \mathrm{~g}$ Drakeol 10 oil inlet GHSV based on nitrogen and isobutanol

linear C4 = 1-butene, cis-2-butene, and trans-2-butene; ether = diisobutyl ether

water rate was calculated based on rates of butenes, ether, and traces of propene, butane, and isobutane

isobutene selectivity based on water free product distribution

* three separate runs were performed with each having a carbon recovery of $117-118 \%$, believed to be a pump malfunction when set to this pump rate 
TABLE 10

Measured Performance of Engelhard Gamma Alumina Catalyst Isobutanol Injected Direclty into Reactor

\begin{tabular}{|c|c|c|c|c|c|c|c|c|c|c|c|}
\hline $\begin{array}{l}\text { Run \# } \\
13033-\end{array}$ & $\begin{array}{c}\text { Temp } \\
\left({ }^{\circ} \mathrm{C}\right)\end{array}$ & $\begin{array}{c}\text { Pressure } \\
\text { (psig) }\end{array}$ & $\begin{array}{c}\text { Isobutanol } \\
\text { Feed } \\
\text { (g/kg-hr) }\end{array}$ & $\begin{array}{c}\text { Inlet } \\
\text { GHSV } \\
\text { (sl/kg-hr) }\end{array}$ & $\begin{array}{c}\text { Isobutanol } \\
\text { Conversion } \\
\%\end{array}$ & $\begin{array}{c}\text { Isobutene } \\
\text { Rate } \\
(\mathrm{g} / \mathrm{kg}-\mathrm{hr})\end{array}$ & $\begin{array}{c}\text { Linear C4 } \\
\text { Rate } \\
(\mathrm{g} / \mathrm{kg}-\mathrm{hr})\end{array}$ & $\begin{array}{c}\text { Ether } \\
\text { Rate } \\
\text { (g/kg-hr) }\end{array}$ & $\begin{array}{c}\text { Water } \\
\text { Rate } \\
\text { (g/kg-hr) }\end{array}$ & $\begin{array}{c}\text { Isobutene } \\
\text { Selectivity } \\
\text { (wt\%) }\end{array}$ & $\begin{array}{c}\text { Carbon } \\
\text { Recovery } \\
\%\end{array}$ \\
\hline $14 \mathrm{~A}$ & 290 & 151 & 397.3 & 2336 & 93.6 & 270.9 & 20.0 & 0.0 & 93.6 & 92.9 & 103 \\
\hline 14B & 290 & 151 & 1059.5 & 6093 & 79.9 & 633.6 & 40.4 & 9.9 & 218.1 & 92.1 & 106 \\
\hline $14 \mathrm{C}$ & 291 & 150 & 185.4 & 1101 & 97.1 & 132.3 & 10.1 & 0.3 & 45.8 & 92.3 & 105 \\
\hline $14 D$ & 310 & 152 & 397.3 & 2425 & 98.7 & 285.1 & 25.9 & 0.0 & 100.0 & 91.4 & 105 \\
\hline $14 \mathrm{E}$ & 310 & 154 & 1059.5 & 6017 & 95.5 & 735.2 & 62.8 & 0.4 & 256.6 & 91.9 & 104 \\
\hline $14 \mathrm{~F}$ & 310 & 152 & 185.4 & 1134 & 99.4 & 132.3 & 12.5 & 0.0 & 46.5 & 91.1 & 104 \\
\hline $14 \mathrm{G}$ & 330 & 147 & 397.3 & 2445 & 99.7 & 285.6 & 28.1 & 0.0 & 100.9 & 90.8 & 105 \\
\hline $14 \mathrm{H}$ & 330 & 147 & 1059.5 & 6190 & 99.3 & 750.0 & 77.8 & 0.0 & 266.1 & 90.4 & 104 \\
\hline $14 \mathrm{I}$ & 330 & 142 & 185.4 & 1136 & 99.9 & 132.0 & 14.4 & 0.0 & 47.0 & 90.0 & 105 \\
\hline $14 \mathrm{~J}$ & 290 & 505 & 397.3 & 2396 & 80.7 & 235.2 & 13.9 & 5.0 & 80.9 & 91.9 & 104 \\
\hline $14 K$ & 287 & 509 & 1059.5 & 5934 & 59.2 & 451.9 & 21.1 & 39.4 & 157.6 & 87.0 & 105 \\
\hline $14 \mathrm{~L}$ & 290 & 499 & 185.4 & 1134 & 89.6 & 119.4 & 6.9 & 1.9 & 40.9 & 92.3 & 102 \\
\hline $14 \mathrm{~A}-2$ & 291 & 135 & 397.3 & 2523 & 91.9 & 275.5 & 18.7 & 0.7 & 94.7 & 92.9 & 107 \\
\hline $14 \mathrm{M}$ & 308 & 498 & 397.3 & 2376 & 93.8 & 275.0 & 20.2 & 0.5 & 95.1 & 92.5 & 105 \\
\hline $14 \mathrm{~N}$ & 310 & 500 & 1059.5 & 5910 & 84.5 & 652.2 & 57.8 & 7.3 & 225.2 & 91.9 & 104 \\
\hline 140 & 312 & 492 & 185.4 & 1069 & 97.1 & 128.8 & 9.8 & 0.1 & 44.6 & 92.2 & 102 \\
\hline
\end{tabular}

5\% isobutanol, $95 \%$ nitrogen; slurry: $30.27 \mathrm{~g}$ catalyst, $119.95 \mathrm{~g}$ Drakeol 10 oil

inlet GHSV based on nitrogen and isobutanol, isobutene selectivity based on water free product distribution linear C4 = 1-butene, cis-2-butene, and trans-2-butene; ether = diisobutyl ether

water rate was calculated based on rates of butenes, ether, and traces of propene, butane, and isobutane 
TABLE 11

Measured Performance of Engelhard Gamma Alumina Catalyst Effect of Stirrer Speed on Mass Transfer

\begin{tabular}{|c|c|c|c|c|c|c|c|c|c|c|c|}
\hline $\begin{array}{c}\text { Run \# } \\
13033-\end{array}$ & $\begin{array}{c}\text { Temp } \\
\left({ }^{\circ} \mathrm{C}\right)\end{array}$ & $\begin{array}{c}\text { Pressure } \\
(\mathrm{psig})\end{array}$ & $\begin{array}{c}\text { Stirrer } \\
\text { Speed } \\
(\mathrm{RPM})\end{array}$ & $\begin{array}{c}\text { Inlet } \\
\mathrm{GHSV} \\
(\mathrm{s} / \mathrm{kg}-\mathrm{hr})\end{array}$ & $\begin{array}{c}\text { Isobutanol } \\
\text { Conversion } \\
\%\end{array}$ & $\begin{array}{c}\text { Isobutene } \\
\text { Rate } \\
(\mathrm{g} / \mathrm{kg}-\mathrm{hr})\end{array}$ & $\begin{array}{c}\text { Linear C4 } \\
\text { Rate } \\
(\mathrm{g} / \mathrm{kg}-\mathrm{hr})\end{array}$ & $\begin{array}{c}\text { Ether } \\
\text { Rate } \\
(\mathrm{g} / \mathrm{kg}-\mathrm{hr})\end{array}$ & $\begin{array}{c}\text { Water } \\
\text { Rate } \\
(\mathrm{g} / \mathrm{kg}-\mathrm{hr})\end{array}$ & $\begin{array}{c}\text { Isobutene } \\
\text { Selectivity } \\
(\mathrm{wt} \%)\end{array}$ & $\begin{array}{c}\text { Carbon } \\
\text { Recovery } \\
\%\end{array}$ \\
\hline $14 \mathrm{~S}$ & 310 & 505 & 1200 & 11428 & 74.3 & 1166.5 & 74.6 & 32.3 & 403.6 & 90.8 & 105 \\
\hline $14 \mathrm{~T}$ & 310 & 510 & 600 & 11495 & 67.2 & 1035.7 & 59.7 & 45.5 & 358.7 & 89.9 & 104 \\
\hline $14 \mathrm{U}$ & 310 & 509 & 2000 & 11495 & 73.3 & 1153.5 & 72.2 & 35.0 & 399.5 & 90.4 & 106 \\
\hline $14 \mathrm{~V}$ & 310 & 507 & 800 & 11495 & 70.6 & 1116.7 & 67.1 & 40.1 & 386.3 & 90.2 & 106 \\
\hline $14 \mathrm{~W}$ & 310 & 493 & 300 & 11517 & 58.6 & 977.9 & 55.5 & 75.0 & 342.8 & 87.5 & 110 \\
\hline
\end{tabular}

$5 \%$ isobutanol, $95 \%$ nitrogen; isobutanol feed: $2119.1 \mathrm{~g} / \mathrm{kg}-\mathrm{hr}$ slurry: $30.27 \mathrm{~g}$ catalyst, $119.95 \mathrm{~g}$ Drakeol 10 oil inlet GHSV based on nitrogen and isobutanol

linear C4 = 1-butene, cis-2-butene, and trans-2-butene; ether = diisobutyl ether

water rate was calculated based on rates of butenes, ether, and traces of propene, butane, and isobutane

isobutene selectivity based on water free product distribution 
TABLE 12

Measured Performance of Engelhard Gamma Alumina Catalyst

Effect of Water Cofeed on Dehydration Rate, 3 moles isobutanol/ 1 mole water at $310^{\circ} \mathrm{C}$

\begin{tabular}{|c|c|c|c|c|c|c|c|c|c|c|c|}
\hline $\begin{array}{l}\text { Run \# } \\
13033-\end{array}$ & $\begin{array}{l}\text { Temp } \\
\left({ }^{\circ} \mathrm{C}\right)\end{array}$ & $\begin{array}{c}\text { Pressure } \\
\text { (psig) }\end{array}$ & $\begin{array}{c}\text { Isobutanol } \\
\text { Feed } \\
(\mathrm{g} / \mathrm{kg}-\mathrm{hr})\end{array}$ & $\begin{array}{c}\text { Inlet } \\
\text { GHSV } \\
\text { (sl/kg-hr) }\end{array}$ & $\begin{array}{c}\text { Isobutanol } \\
\text { Conversion } \\
\%\end{array}$ & $\begin{array}{c}\text { Isobutene } \\
\text { Rate } \\
\text { (g/kg-hr) }\end{array}$ & $\mid \begin{array}{c}\text { Linear C4 } \\
\text { Rate } \\
(\mathrm{g} / \mathrm{kg}-\mathrm{hr})\end{array}$ & $\begin{array}{c}\text { Ether } \\
\text { Rate } \\
\text { (g/kg-hr) }\end{array}$ & $\begin{array}{c}\text { Water } \\
\text { Rate } \\
\text { (g/kg-hr) }\end{array}$ & $\begin{array}{c}\text { Isobutene } \\
\text { Selectivity } \\
\text { (wt\%) }\end{array}$ & $\begin{array}{c}\text { Carbon } \\
\text { Recovery } \\
\%\end{array}$ \\
\hline $18 \mathrm{~A}$ & 310 & 165 & 373.1 & 2347 & 94.1 & 268.9 & 21.7 & 1.3 & 127.9 & 91.8 & 109 \\
\hline $18 \mathrm{~B}$ & 310 & 182 & 995.0 & 6209 & 86.3 & 643.9 & 46.5 & 3.1 & 307.5 & 92.5 & 106 \\
\hline $18 \mathrm{C}$ & 311 & 158 & 174.1 & 1192 & 97.9 & 123.2 & 10.4 & 0.0 & 58.1 & 91.9 & 104 \\
\hline $18 D$ & 310 & 354 & 373.1 & 2495 & 93.3 & 243.4 & 19.4 & 0.4 & 114.1 & 91.9 & 100 \\
\hline $18 \mathrm{E}$ & 309 & 359 & 995.0 & 6268 & 80.8 & 594.5 & 41.4 & 7.3 & 301.7 & 91.8 & 105 \\
\hline $18 \mathrm{~F}$ & 310 & 344 & 174.1 & 1164 & 96.8 & 116.7 & 9.6 & 1.3 & 52.8 & 91.0 & 100 \\
\hline $18 G$ & 309 & 499 & 373.1 & 2436 & 89.4 & 241.1 & 17.2 & 1.1 & 113.7 & 92.5 & 103 \\
\hline $18 \mathrm{H}$ & 310 & 509 & 995.0 & 6086 & 75.4 & 546.2 & 33.9 & 12.5 & 271.3 & 91.4 & 104 \\
\hline $18 \mathrm{I}$ & 309 & 496 & 174.1 & 1154 & 95.3 & 113.0 & 8.4 & 92.4 & 53.1 & 92.4 & 98 \\
\hline
\end{tabular}

liquid injection: 3 moles isobutanol/ 1 mole water

$4.5 \%$ isobutanol, $1.5 \%$ water, $94 \%$ nitrogen; slurry: 30.27 g catalyst, $119.95 \mathrm{~g}$ Drakeol 10 oil

inlet GHSV based on nitrogen and isobutanol

linear C4 = 1-butene, cis-2-butene, and trans-2-butene; ether = diisobutyl ether

isobutene selectivity based on water free product distribution

*water rate was determined by $\mathbf{G C}$ 


\section{TABLE 13}

Measured Performance of Engelhard Gamma Alumina Catalyst

Effect of Water Cofeed on Dehydration Rate, 3 moles isobutanol/ 1 mole water at $290^{\circ} \mathrm{C}$

\begin{tabular}{|c|c|c|c|c|c|c|c|c|c|c|c|}
\hline $\begin{array}{c}\text { Run \# } \\
13033-\end{array}$ & $\begin{array}{c}\text { Temp } \\
\left({ }^{\circ} \mathrm{C}\right)\end{array}$ & $\begin{array}{c}\text { Pressure } \\
(\mathrm{psig})\end{array}$ & $\begin{array}{c}\text { Isobutanol } \\
\text { Feed } \\
(\mathrm{g} / \mathrm{kg}-\mathrm{hr})\end{array}$ & $\begin{array}{c}\text { Inlet } \\
\text { GHSV } \\
(\mathrm{s} / \mathrm{kg}-\mathrm{hr})\end{array}$ & $\begin{array}{c}\text { Isobutanol } \\
\text { Conversion } \\
\%\end{array}$ & $\begin{array}{c}\text { Isobutene } \\
\text { Rate } \\
(\mathrm{g} / \mathrm{kg}-\mathrm{hr})\end{array}$ & $\begin{array}{c}\text { Linear C4 } \\
\text { Rate } \\
(\mathrm{g} / \mathrm{kg}-\mathrm{hr})\end{array}$ & $\begin{array}{c}\text { Ether } \\
\text { Rate } \\
(\mathrm{g} / \mathrm{kg}-\mathrm{hr})\end{array}$ & $\begin{array}{c}\text { Water } \\
\text { Rate } \\
(\mathrm{g} / \mathrm{kg}-\mathrm{hr})\end{array}$ & $\begin{array}{c}\text { Isobutene } \\
\text { Selectivity } \\
(\mathrm{wt} \%)\end{array}$ & $\begin{array}{c}\text { Carbon } \\
\text { Recovery } \\
\%\end{array}$ \\
\hline $20 \mathrm{~A}$ & 290 & 148 & 375.6 & 2472 & 87.9 & 242.5 & 16.3 & 1.2 & 114.3 & 92.9 & 104 \\
\hline $20 \mathrm{~B}$ & 291 & 159 & 1001.5 & 6450 & 72.1 & 524.7 & 31.2 & 10.8 & 264.0 & 92.2 & 103 \\
\hline $20 \mathrm{C}$ & 290 & 137 & 175.3 & 1210 & 95.1 & 119.7 & 8.8 & 0.2 & 55.9 & 92.8 & 102 \\
\hline $20 \mathrm{D}$ & 289 & 502 & 375.6 & 2406 & 68.7 & 172.6 & 8.1 & 8.1 & 89.1 & 90.9 & 98 \\
\hline $20 \mathrm{E}$ & 290 & 510 & 1001.5 & 6110 & 50.5 & 332.6 & 15.0 & 37.2 & 198.3. & 85.8 & 100 \\
\hline $20 \mathrm{~F}$ & 290 & 505 & 175.3 & 1170 & 85.8 & 101.9 & 5.6 & 1.2 & 48.5 & 93.3 & 96 \\
\hline
\end{tabular}

liquid injection: 3 moles isobutanol/ 1 mole water

$5 \%$ isobutanol, $95 \%$ nitrogen; slurry: $30.07 \mathrm{~g}$ catalyst, $120.15 \mathrm{~g}$ Drakeol 10 oil inlet GHSV based on nitrogen and. isobutanol .

linear C4 = 1-butene, cis-2-butene, and trans-2-butene; ether = diisobutyl ether isobutene selectivity based on water free product distribution

water rate was determined by $\mathbf{G C}$ 


\section{TABLE 14}

Measured Performance of Engelhard Gamma Alumina Catalyst

Effect of Water Cofeed on Dehydration Rate, 3 moles isobutanol/ 2 moles water at $290^{\circ} \mathrm{C}$

\begin{tabular}{|c|c|c|c|c|c|c|c|c|c|c|c|}
\hline $\begin{array}{l}\text { Run \# } \\
13033-\end{array}$ & $\begin{array}{l}\text { Temp } \\
\left({ }^{\circ} \mathrm{C}\right)\end{array}$ & $\begin{array}{c}\text { Pressure } \\
\text { (psig) }\end{array}$ & $\begin{array}{l}\text { Isobutanol } \\
\text { Feed } \\
(\mathrm{g} / \mathrm{kg}-\mathrm{hr})\end{array}$ & $\begin{array}{c}\text { Inlet } \\
\text { GHSV } \\
(\mathrm{s} / \mathrm{kg}-\mathrm{hr})\end{array}$ & $\begin{array}{c}\text { Isobutanol } \\
\text { Conversion } \\
\%\end{array}$ & $\begin{array}{c}\text { Isobutene } \\
\text { Rate } \\
\text { (g/kg-hr) }\end{array}$ & $\begin{array}{c}\text { Linear C4 } \\
\text { Rate } \\
(\mathrm{g} / \mathrm{kg}-\mathrm{hr})\end{array}$ & $\begin{array}{c}\text { Ether } \\
\text { Rate } \\
\text { (g/kg-hr) }\end{array}$ & $\begin{array}{c}\text { Water } \\
\text { Rate } \\
\text { (g/kg-hr) }\end{array}$ & $\begin{array}{c}\text { Isobutene } \\
\text { Selectivity } \\
\text { (wt\%) }\end{array}$ & $\begin{array}{c}\text { Carbon } \\
\text { Recovery } \\
\%\end{array}$ \\
\hline $20 \mathrm{H}$ & 288 & 158 & 424.8 & 2507 & 73.5 & 235.4 & 13.3 & 4.6 & 153.7 & 92.5 & 105 \\
\hline 201 & 290 & 166 & 1085.5 & 6335 & 55.1 & 424.5 & 22.1 & 24.0 & $326: 7$ & 89.5 & 102 \\
\hline $20 \mathrm{~J}$ & 290 & 148 & 188.8 & 1237 & 89.6 & 123.6 & 8.4 & 0.4 & 74.1 & 92.9 & 103 \\
\hline $20 \mathrm{~K}$ & 288 & 510 & 424.8 & 2513 & 58.8 & 154.5 & 6.9 & 14.7 & 1.19 .2 & 87.3 & 96 \\
\hline $20 \mathrm{~L}$ & 293 & 520 & 943.9 & 6228 & 42.0 & 254.4 & 10.9 & 31.5 & 241.3 & 84.8 & 99. \\
\hline $20 \mathrm{M}$ & 290 & 510 & 188.8 & 1101 & 65.1 & 92.7 & 4.6 & 4.5 & 64.4 & 90.5 & 106 \\
\hline $20 \mathrm{~N}$ & 286 & 543 & 2171.0 & 11867 & 51.2 & 255.9 & 7.3 & 47.0 & 586.4 & 81.9 & 67.4 \\
\hline
\end{tabular}

liquid injection: 3 moles isobutanol/ 2 moles water

$5 \%$ isobutanol, $95 \%$ nitrogen; slurry: $30.07 \mathrm{~g}$ catalyst, $120.15 \mathrm{~g}$ Drakeol 10 oil inlet GHSV based on nitrogen and isobutanol

linear C4 = 1-butene, cis-2-butene, and trans-2-butene; ether = diisobutyl ether

isobutene selectivity based on water free product distribution

water rate was determined by GC 
TABLE 15

Measured Performance of Engelhard Gamma Alumina Catalyst

Effect of Water Cofeed on Dehydration Rate, 3 moles isobutanol 2 moles water at $310^{\circ} \mathrm{C}$

\begin{tabular}{|c|c|c|c|c|c|c|c|c|c|c|c|}
\hline $\begin{array}{l}\text { Run \# } \\
\text { 13033- }\end{array}$ & $\begin{array}{c}\text { Temp } \\
\left({ }^{\circ} \mathrm{C}\right)\end{array}$ & $\begin{array}{l}\text { Pressure } \\
\text { (psig) }\end{array}$ & $\begin{array}{c}\text { Isobutanol } \\
\text { Feed } \\
(\mathrm{g} / \mathrm{kg}-\mathrm{hr})\end{array}$ & $\begin{array}{c}\text { Inlet } \\
\text { GHSV } \\
\text { (sl/kg-hr) }\end{array}$ & \begin{tabular}{|c|} 
Isobutanol \\
Conversion \\
$\%$
\end{tabular} & $\begin{array}{c}\text { Isobutene } \\
\text { Rate } \\
\text { (g/kg-hr) }\end{array}$ & $\begin{array}{c}\text { Linear C4 } \\
\text { Rate } \\
(\mathrm{g} / \mathrm{kg}-\mathrm{hr})\end{array}$ & $\begin{array}{c}\text { Ether } \\
\text { Rate } \\
\text { (g/kg-hr) }\end{array}$ & $\begin{array}{c}\text { Water } \\
\text { Rate } \\
\text { (g/kg-hr) }\end{array}$ & \begin{tabular}{|c|} 
Isobutene \\
Selectivity \\
(wt\%)
\end{tabular} & $\begin{array}{c}\text { Carbon } \\
\text { Recovery } \\
\%\end{array}$ \\
\hline 200 & 310 & 158 & 424.8 & 2525 & 89.2 & 285.7 & 22.0 & 0.9 & 172.8 & 92.2 & 107 \\
\hline $20 \mathrm{P}$ & 310 & 160 & 1085.5 & 6202 & 77.7 & 621.0 & 41.9 & 6.9 & 395.5 & 92.1 & 104 \\
\hline $20 Q$ & 310 & 130 & 188.8 & 1193 & 96.2 & 134.8 & 11.1 & 0.2 & 79.3 & 91.9 & 106 \\
\hline $20 R$ & 309 & 519 & 424.8 & 2485 & 74.6 & 241.9 & 15.2 & 4.9 & 156.3 & 91.7 & 107 \\
\hline $20 S$ & 310 & 527 & 1085.5 & 6236 & 60.1 & 481.7 & 27.2 & 23.2 & 350.3 & 89.6 & 105 \\
\hline $20 \mathrm{~T}$ & 310 & 513 & 188.8 & 1071 & 88.0 & 126.4 & 8.2 & 0.8 & 76.1 & 92.7 & 107 \\
\hline $20 U$ & 309 & 506 & 2171.0 & 11875 & 47.7 & 723.7 & 40.4 & 56.1 & 611.9 & 87.6 & 102 \\
\hline
\end{tabular}

liquid injection: 3 moles isobutanol/ 2 moles water

$5 \%$ isobutanol, $95 \%$ nitrogen; slurry: $30.07 \mathrm{~g}$ catalyst, $120.15 \mathrm{~g}$ Drakeol 10 oil inlet GHSV based on nitrogen and isobutanol

linear $\mathbf{C 4}=1$-butene, cis-2-butene, and trans-2-butene; ether = diisobutyl ether

isobutene selectivity based on water free product distribution

water rate was determined by $\mathbf{G C}$ 